[Aus der Augenklinik u. dem pharmakologischen Institut der Univ. Greifswald.]

\title{
Experimentelle Beiträge zum pathologischen Flüssigkeitswechsel des Anges.
}

\author{
Von \\ Prof. Dr. Martin Kochmann and Prof. Dr. Paul Römer, \\ Privatdozent der Pharmakologie Direktor der Augenklinik.
}

Mit 32 Figuren und 2 Kurven im Text.

Im folgenden berichten wir über eine grössere Reihe von experimentellen Untersuchungen, die für die Augenheilkunde und Pharmakologie vielleicht einiges Interesse erwecken werden.

Dieselben nehmen ihren Ausgang von der von Römer gemachten Entdeckung, nach der es gelingt, durch intravenöse Injektion von wenigen Kubikzentimetern eines Serums, das dem Kranken während des Coma diabeticum entnommen wird, beim Kaninchen eine ganz auffallende und ziemlich lang anhaltende Hypotonie der Augen zu erzeugen.

Bekanntlich verdanken wir Heine und Krause die wichtige klinische Feststellung, dass während des Coma diabeticum die Augen eine starke Hypotonie aufweisen können.

Römer machte nun zuerst den erfolgreichen Versuch, durch intravenöse Darreichung des im Coma entnommenen Serums diese Hypotonie auf normale Tiere zu übertragen. Da sich sogleich mit diesen ersten Versuchen zeigte, dass diese Fähigkeit dem normalen menschlichen Serum nicht zukommt, so stand die Augenheilkunde schon allein im Hinblick auf das Glaukom - vor einem interessanten Problem.

Dazu kam, dass unabhängig von uns, nachdem wir in der Zwischenzeit unsere gemeinsamen Versuche begonnen hatten, Hertel ${ }^{1}$ ) allerdings von einem andern Gesichtspunkt aus, sich ebenfalls mit der Hypotonie im Coma diabeticum beschäftigt hatte.

Nach Hertels Ansicht, die sich auf experimentelle Untersuchungen stützt, handelt es sich bei der Hypotonie im Coma diabe-

1) IIertel, E., Münch. med. Wochenschr. Bd. LX. S. 1191. 1913. 
Experim. Beiträge zum pathologischen Flüssigkeitswechsel des Auges. 529

ticum nicht um einen spezifischen Vorgang im Auge, sondern um eine Anderung der osmotischen Verhältnisse und Wechselwirkungen zwischen Ange und Blutflissigkeit; diese Druckrerminderung sei mit der in Parallele zu setzen, die sich auch bei Tieren durch Exhöhung der molekularen Konzentration des Blutes infolge Injektion hypertonischer lösungen von Salzen, Harnstoff, Zucker usw. hervorrufen lässt.

$\mathrm{Ob}$ derartige Vorgänge tatsächlich für das Zustandekommen der diabetischen Hypotonie in Frage kommen, lässt sich zurzeit wohl nicht mit Sicherheit entscheiden. Anderseits darf diese Erklärung keineswegs von vornherein abgelehnt werden, so dass die Möglichkeit besteht, dass der von Hertel angenommene Mechanismus bei der Entstehung der Augendruckverminderung im Coma eine gewisse Rolle spielen könnte.

Wenn sich aber bei unsern Kaninchen durch das isotonische Blutserum von Comakranken die Hypotonie auch auf gesunde Tiere übertragen lässt, so versteht es sich von selbst, dass dieser Druckherabsetzung eine andere Genese zugrunde liegen muss.

Römer war sich sofort darüber klar, dass hier ausser rein ophthalmologischen Fragen wichtige pharmakologische and chemische Probleme zu lösen waren, die ein Zusammenarbeiten des Pharmakologen and Ophthalmologen wïnschenswert erscheinen liessen.

\section{T. Teil.}

Wirkung des Comaserums auf den Augendruck und die durch den subconjunctivalen Kochsalzreiz bedingte intraokulare Drucksteigerung.

Infolge der gütigen Unterstützung von seiten der Herren Geheimrat Krehl-Heidelberg, Prof. Brauer-Hamburg, Prof. RostoskiDresden und mehrerer anderer Kollegen waren wir in der Lage, nach und nach eine grössere Reihe von Serumproben von Fällen mit Coma diabeticum zu untersuchen. Wir sprechen auch an dieser Stelle hiermit allen diesen Herren unseren herzlichsten Dank aus.

Die Wirkung dieser Serumproben auf den intraokularen Druck des Kaninchenauges bei intravenöser Darreichung ist naturgemäss keine ganz gleichmässige. Manche Serumproben sind bei gleicher Menge wirksamer als andere, manche sind anscheinend fast ganz unwirksam.

Inwieweit etwa dieser verschiedenen Intensitat der Wirkung beim Kaninchen der Grad der Hypotonie bei den einzelnen Comafällen selbst entsprechen mag, entzieht sich unserer Kenntnis, ist auch für die folgenden Versuche ohne Belang. 
Will man sich über die hypotonisierende Wirkung des Comaserums orientieren, so genügt zunächst die tonometrische Kontrolle des Auges mittels des Schiötzschen Tonometers, wie folgende Versuche demonstrieren mögen.

\section{Protokolle.}

A. Wirkung des Comaserums beim Kaninchen nach intravenöser Injektion von $5 \mathrm{cem}$.

\begin{tabular}{|c|c|c|c|c|c|c|c|c|}
\hline \multirow{3}{*}{$\begin{array}{l}\text { Zeit in Min. } \\
\text { nach der In- } \\
\text { jektion }\end{array}$} & \multicolumn{8}{|c|}{ Intraokularer Druck in $\mathrm{mm} H g$} \\
\hline & & & & & & & & $\mathrm{V}$ \\
\hline & Links & Rechts & Links & Rechts & Links & Rechts & Linles & Rechts \\
\hline 0 & 27 & 25 & 23 & 25 & 27 & 25 & 23 & 25 \\
\hline 5 & 17 & 17 & 18 & 15 & 17 & 17 & 18 & 15 \\
\hline 10 & - & - & 12 & 12 & 15 & 15 & 12 & 12 \\
\hline 15 & - & - & 12 & 12 & 15 & 15 & 12 & 12 \\
\hline 30 & - & - & 10 & 10 & 15 & 15 & 10 & 10 \\
\hline 45 & 18 & 18 & - & - & 18 & 18 & 10 & 10 \\
\hline 60 & 18 & 15 & 10 & 10 & 18 & 18 & 10 & 10 \\
\hline $20-29$ Std. & 21 & 21 & 18 & 18 & - & - & - & - \\
\hline 2 Tage. & 25 & 25 & - & - & - & - & - & - \\
\hline
\end{tabular}

Kaninchen Nr. 35. $2070 \mathrm{~g}$.

\begin{tabular}{|c|c|c|c|}
\hline Zeit & Links & Rechts & \\
\hline $10^{20}$ & 21 & 21 & \\
\hline $10^{25}$ & $10 \mathrm{cem}$ & Comaserum & \\
\hline $10^{30}$ & 21 & 21 & \\
\hline $10^{28}$ & & -13 & \\
\hline $10^{4.5}$ & - & 13 & \\
\hline $10^{50}$ & 12 & - & \\
\hline $11^{35}$ & 8 & 8 & 1. $1015 \mathrm{~mm}$ Ha Plutdmole \\
\hline $12^{03}$ & 8 & 8 & bei $121,5 \mathrm{~mm}$ Hg Blutaruck \\
\hline $12^{0 \pi}$ & 8 & 8 & $" 118,5, \quad " \quad \Rightarrow$ \\
\hline $12^{10}$ & 8 & 8 & $" 132,0 \quad " \quad "$ \\
\hline
\end{tabular}

B. Wirkung des normalen Serums beim Kaninehen, 5 cem intravenös.

\begin{tabular}{|c|c|c|c|c|c|c|c|c|c|c|}
\hline \multirow{3}{*}{$\begin{array}{l}\text { Zeit in Min. } \\
\text { nach der } \\
\text { Injektion }\end{array}$} & \multicolumn{10}{|c|}{ Intraokularer Druck in mm $\mathrm{Hg}$} \\
\hline & \multicolumn{2}{|c|}{ I } & \multicolumn{2}{|c|}{ II } & \multicolumn{2}{|c|}{ III } & \multicolumn{2}{|c|}{ IV } & \multicolumn{2}{|c|}{$\mathrm{V}$} \\
\hline & $\frac{\sqrt[3]{3}}{3}$ & 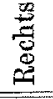 & 造 & 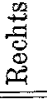 & $\frac{2}{3}$ & 告 & 尊 & 急 & 僁 & 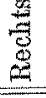 \\
\hline 0 & 21 & 20 & 25 & 25 & 21 & 2. & 25 & 2 & 21 & 21 \\
\hline $\mathbf{b}$ & 21 & 2 & 25 & 2 & 28 & 2 & 2 & & 2 & 21 \\
\hline 10 & 2. & 2 & 25 & 24 & 21 & 2 & 2 & 2 & 21 & \\
\hline 15 & 20 & 21 & 25 & 25 & 23 & 2 & 2 & 0 & 2 & 21 \\
\hline 30 & 18 & 20 & 27 & 25 & 23 & 2 & 24 & 2 & & 90 \\
\hline 45 & - & - & 27 & 25 & 23 & 2 & 25 & 2 & 2 & 21 \\
\hline & 20 & 21 & 25 & 25 & 21 & 21 & 25 & 25 & 21 & 20 \\
\hline $20 \mathrm{Std}$ & 21 & 20 & -18 & - & 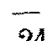 & , & 4 & $\mathrm{hhr}$ & & \\
\hline Alter de & & & 18 & & & & & & & \\
\hline
\end{tabular}


Experim. Beiträge zum pathologischen Flüssigkeitswechsel des Anges. 531

Die folgenden Versuche zeigen, dass bei dieser durch wirksame Comasera erzeugten intraokularen Druckherabsetzung der Eiweissge-

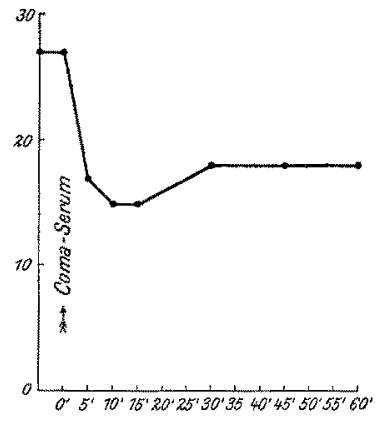

Fig. 1.

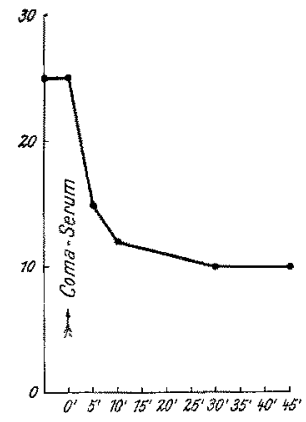

Fig. 2.

Sinken des intraokulären Drucks nach $5 \mathrm{ccm}$ Comaserum intravenös. (Vergleiche Versuch A. III und IV.)

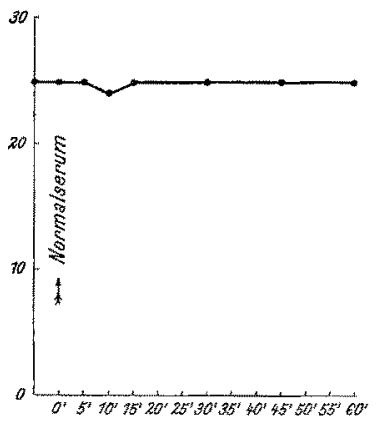

Fig. 3.

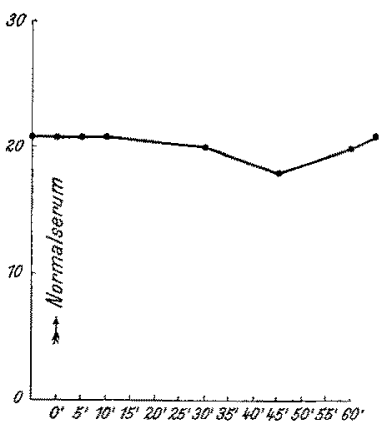

Fig. 4.

Gleichbleiben des Augendruckes nach Injektion von $5 \mathrm{ccm}$ normalem menschlichen Serum. (Vergleiche Versuch B. II and V.)

halt des Kammerwassers nicht verändert wird. Dieser Eiweissgehalt wurde noch durch den Zusatz von gleichen Mengen Esbachschen Reagens zu den gewonnenen Kammerwassermengen an der Hand von ebenso behandelten Serumverdünnungen geschätzt. Später wandten wir, wie sich zeigen wird, eine andere Methode zur Bestimmung des Eiweissgehaltes im Kammerwasser an.

Bei dieser eigentïmlichen Wirkung des Comaserums auf den intraokularen Druck erhebt sich naturgemäss als erste Frage:

Ist diese Hypotonie vielleicht nur durch ein Sinken des arteriellen Blutdrucks bedingt, dem sich nach der bisher herrschenden Lehre dann ein Sinken auch des intraokularen Drucks anschliesst?

Diese Frage ist um so mehr berechtigt, als wir ja wissen, dass heterogenes Serum für einen andern Organismus unter Umstän- 
Eiweissgehalt des Kammerwassers bei der durch intravenöse Injektion von Comaserum erzeugten Hypotonie.

\begin{tabular}{|c|c|c|c|c|c|}
\hline \multicolumn{6}{|c|}{$10 \mathrm{ccm}$ Comaserum vom Menschen } \\
\hline \multicolumn{3}{|c|}{ Vor der Seruminjektion } & \multicolumn{3}{|c|}{$10^{\prime}$ nach der Seruminjektion } \\
\hline \multirow{2}{*}{$\begin{array}{c}\text { Intraokular. } \\
\text { Druek in } \\
\text { mm } \mathrm{Hg}\end{array}$} & \multicolumn{2}{|c|}{$\begin{array}{l}\text { Eiweissgehalt des } \\
\text { Kammerwassers }\end{array}$} & \multirow{2}{*}{$\begin{array}{l}\text { Intraokular. } \\
\text { Druck in } \\
\text { mm } H g\end{array}$} & \multicolumn{2}{|c|}{$\begin{array}{c}\text { Eiweissgehalt des } \\
\text { Kammerwassers }\end{array}$} \\
\hline & $\begin{array}{l}\text { Serum- } \\
\text { verdünnung }\end{array}$ & $\begin{array}{c}\text { ungefährer } \\
\text { Eiweissgeh. } \%\end{array}$ & & $\begin{array}{l}\text { Serum- } \\
\text { verdünnung }\end{array}$ & $\begin{array}{c}\text { ungefährer } \\
\text { Eiweissgeh. } \%\end{array}$ \\
\hline 21 & $1: 200$ & 0,04 & 11 & $1: 200$ & 0,04 \\
\hline 21 & $1: 100$ & 0,08 & 8 & $1: 100$ & 0,08 \\
\hline 21 & $1: 200$ & 0,04 & 12 & $1: 200$ & 0,04 \\
\hline 21 & $1: 200$ & 0,04 & 13 & $1: 200$ & 0,04 \\
\hline \multicolumn{6}{|c|}{$10 \mathrm{ccm}$ Normalserum vom Menschen } \\
\hline 19 & $1: 200$ & 0,04 & 19 & $1: 200$ & 0,04 \\
\hline 23 & $1: 200$ & 0,04 & 21 & 1:200 & 0,04 \\
\hline 21 & $1: 200$ & 0,04 & 19 & $1: 200$ & 0,04 \\
\hline 21 & $1: 200$ & 0,04 & 21 & $1: 200$ & 0,04 \\
\hline
\end{tabular}

den toxisch wirken, und bei hochgradiger Vergiftung naturgemäss auch der allgemeine Blutdruck sinken kann. Allein schon der Vergleich mit dem normalen Serum, dem diese hypotonisierende Wirkung nicht zukommt, machte es wenig wahrscheinlich, dass die Hypotonie durch eine toxische Senkung des Blutdrucks erklärt werden könne. Es müsste dann schon die Annahme gemacht werden, dass das Comaserum eben viel toxischer sein würde als das normale menschliche Serum.

Zur sicheren Entscheidung aber musste naturgemäss der Blutdruck bei einem mit Comaserum behandelten Tier genauer bestimmt werden. Dies geschah zunächst in einem Versuch, in dem der Blutdruck mit dem Quecksilbermanometer in der Carotis gemessen, mit wenigen geringen Schwankungen die gleiche Höhe behielt, während der intraokulare Druck nach $5 \mathrm{ccm}$ Comaserum intravenös einen Abfall um 9-10 $\mathrm{mm} \mathrm{Hg}$ zeigte. (Messung mit dem Schiötz schen Tonometer am nicht narkotisierten Tier.)

Nachdem ein solcher Versuch gezeigt hatte, dass die Hypotonie nach der intravenösen Injektion von Comaserum unabhängig vom Blutdruck zustande kommt, sind wir dann dazu übergegangen, die Verhältnisse genauer zu, untersuchen, indem wir den Augendruck mit dem Wesselyschen Registriermanometer und gleichzeitig den Blutdruck mittels des Gadschen Blutwellenschreibers aufschrieben. Sämtliche Versuche wurden am Kaninchen angestellt.

Wir haben zwar bereits auf der Naturforscherversammlung in 
Experim. Beiträge zum pathologischen Flüssigkeitswechsel des Auges. 533

Wien das Modell eines Instrumentes demonstriert, welches vor dem Wesselyschen Manometer den Vorzug hat, dass der Augendruck sofort in absoluten Werten aufgeschrieben wird und nicht erst aus der nachträglichen Eichung berechuet zu werden braucht. Der Apparat bedarf jedoch noch weiterer Verbesserung und ist deshalb bisher der Praxis noch nicht übergeben worden. Aus diesem Grunde und damit gegen unsere Versuche nicht der Einwand erhoben werden kann, dass das Resultat vielleicht zum Teil durch die Anwendung eines neuen, noch nicht ganz vollkommenen Instrumentes erzielt worden sei, haben wir, wie ausdrücklich betont werden muss, sämtliche dieser Arbeit zugrunde liegenden Versuche mit dem Wesselyschen Registriermanometer ausgeführt.

Wir betonen weiter, dass wir sämtliche einschlägigen Versuche so oft wiederholt haben, bis das Resultat einwandfrei foststand. Wir können aber, damit der Umfang der Arbeit nicht gar zu sehr anschwillt, nicht alle Versuchsprotokolle veröffentlichen.

Das erste wichtigste Resultat, das wir sehr bald feststellen konnten, besteht in der Tatsache, dass das Comaserum intravenös verabreicht nicht nur eine Hypotonie der Augen bewirken kann, sondern auch imstande ist, die sonst nach subconjunctivaler Injektion von stark hypertonischer Kochsalzlösung auftretende erhebliche intrakulare Dracksteigerung zu verhüten.

$\mathrm{Da}$ diese intraokulare Drucksteigerung in den folgenden Versuchen eine grosse Rolle spielt, so geben wir hier aus unsern Vorversuchen zunächst den typischen Verlauf eines solchen Kochsalzreizes wieder, wie er von $\mathrm{Wessely}^{1}$ ) zuerst genauer registriert worden ist, und wie auch wir ihn jedesmal wieder antrafen.

Protokoll.

Kaninchen Nr. 9. 2300 g. Curaresiert. Künstliche Atmung.

\begin{tabular}{c|c|c|c}
\hline \hline Zeit & $\begin{array}{c}\text { Mittl. Blutdr. } \\
\text { in } \mathrm{mm} H g\end{array}$ & $\begin{array}{c}\text { Augendruck } \\
\text { in } \mathrm{mm} H g\end{array}$ & Bemerkungen \\
\hline \hline $10^{52}$ & - & - & $\begin{array}{c}2 \mathrm{ccm} 1 \% \text { Curare subcutan, } 11^{15}, 0,5 \mathrm{~cm} \\
\text { intravenös }\end{array}$ \\
$11^{24}$ & 95 & 22,3 & \\
$11^{26}$ & 95 & 21,0 & \\
$11^{27}$ & 100 & 22,3 & $0,5 \mathrm{ccm} 10^{\circ} / \mathrm{NaCl}$ subconjunctival \\
$11^{28}$ & 122,5 & 31,2 &
\end{tabular}

I) Wessely, K., Arch. f. Augenheilk. Bd. LX. S. 1 u. 97. 1908. 


\begin{tabular}{|c|c|c|c|}
\hline Zeit & $\begin{array}{l}\text { Mittl. Blutdr. } \\
\text { in mm } H g\end{array}$ & $\begin{array}{l}\text { Augendruck } \\
\text { in } \mathrm{mm} H g\end{array}$ & Bemerkungen \\
\hline $11291_{i 2}^{3}$ & 110 & 41,3 & \\
\hline $11301 / 2$ & 107,0 & 42,6 & \\
\hline$\left.1131\right|_{2} ^{1}$ & 100 & 45,2 & \\
\hline$\left.11^{321}\right|_{2}$ & 97,5 & 46,1 & \\
\hline 1134 & 95,6 & 46,1 & \\
\hline 1135 & 85 & 45,2 & \\
\hline 1137 & 87,5 & 42,6 & \\
\hline 1138 & 87,5 & 41,7 & \\
\hline 1140 & 90 & 40,0 & \\
\hline$\left.1.1411\right|_{2}$ & 87,5 & 38,1 & \\
\hline 1143 & 85 & 38,1 & \\
\hline 1144 & 87,5 & 36,5 & \\
\hline $11^{46}$ & 87,5 & 33,5 & \\
\hline 1147 & 87,5 & 31,9 & \\
\hline$\left.11^{4} 8^{1}\right|_{2}$ & 87,5 & 30,4 & \\
\hline 1200 & 90 & 28,3 & \\
\hline $12^{01}$ & 125 & 29,0 & \\
\hline
\end{tabular}

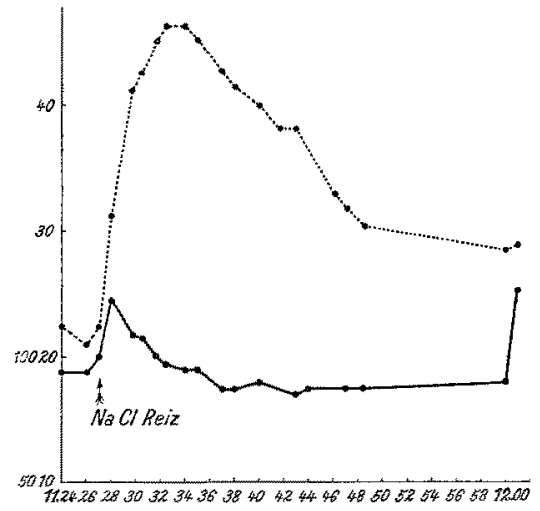

Fig. 5. Verlauf des intraokulären Druckanstieges nach subconjunetivaler Injektion von $0,5 \mathrm{ccm} 10 \%$ Kochsalzlösung (,normaler Kochsalzreiz"). 1/4 der Orig.-Grösse.

Die folgenden Versuche demonstrieren nun den Einfluss des menschlichen Comaserums auf den intraokularen Druck des Kaninchenauges und beweisen weiter die Tatsache, dass der durch die subconjunctivale Kochsalzinjektion bedingte intraokulare Druckanstieg durch das Comaserum mehr oder weniger verhütet werden kann.

Kaninchen Nr. 33. 2875 g. Curaresiert. Künstliche Atmung. (Fig. 6.)

\begin{tabular}{c|c|c|c}
\hline Zeit & $\begin{array}{c}\text { Blutdruck in } \\
\text { mm } H g\end{array}$ & $\begin{array}{c}\text { Augendruck } \\
\text { in mm } H g\end{array}$ & Bemerkungen \\
\hline $5^{05}$ & - & - & 1 ccm Curare 170 subcutan \\
$5^{18}$ & - & - & desgl. \\
$5^{25}$ & - & - & desgl. \\
$5^{39}$ & 110,0 & - & \\
$5^{50}$ & 100,0 & 16,2 & \\
$5^{59}$ & 97,5 & 16,0 & \\
$5^{54}$ & 97,5 & 15,6 &
\end{tabular}


Experim. Beiträge zum pathologischen Flüssigkeitswechsel des Auges. 535

\begin{tabular}{|c|c|c|c|}
\hline Zeit & $\begin{array}{c}\text { Blutdruck in } \\
\text { mm } H g\end{array}$ & $\begin{array}{l}\text { Augendruck } \\
\text { in } \mathrm{mm} \mathrm{Hg}\end{array}$ & Bemerkungen \\
\hline $555-56$ & - & - & $5 \mathrm{ccm}$ Comaserum intravenös \\
\hline 556 & 110,0 & 15,3 & \\
\hline $5^{58}$ & 116,0 & 12,9 & \\
\hline 600 & 106,5 & 12,4 & \\
\hline $6^{02}$ & 102,5 & 12,2 & \\
\hline 604 & 100,0 & 10,6 & $0,5 \mathrm{ccm} 10 \%$ Kochsalzlösung subeonj. \\
\hline 606 & 100,0 & 10,7 & \\
\hline $6^{08}$ & 102,5 & 10,9 & \\
\hline $6^{10}$ & 100,0 & 11,2 & \\
\hline 612 & 102,5 & 11,8 & \\
\hline 614 & 102,5 & 13,5 & \\
\hline 616 & 100,0 & 14,7 & \\
\hline 618 & 100,0 & 16,5 & \\
\hline 620 & $100,0-130,0$ & $16,5-24,8$ & \\
\hline 622 & 107,5 & 24,0 & $4 \mathrm{ccm}$ Serum \\
\hline 624 & 100,0 & 24,8 & \\
\hline 626 & 90,0 & 21,6 & \\
\hline 628 & 87,5 & 19,6 & \\
\hline 629 & 87,5 & 19,1 & \\
\hline $6^{34}$ & 87,5 & 16,5 & \\
\hline $6^{37}$ & 87,5 & 15,3 & \\
\hline $6^{42}$ & 87,5 & 14,7 & \\
\hline 647 & 87,5 & 13,8 & \\
\hline 653 & 87.5 & 13,8 & \\
\hline 659 & 105,0 & 13,8 & \\
\hline 703 & 105,0 & 12,9 & \\
\hline
\end{tabular}

Fig. 6. Vgl. Kaninchen Nr.33, Abfall des intraokulären Druckes und unbedeutender Anstieg nach Kochsalzreiz als Folge der intravenösen Injektion von Comaserum. $1 / 4$ natürl. Grösse.

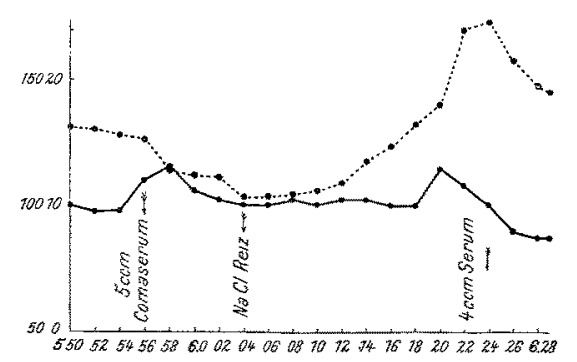

Kaninchen Nr. 32. 2600 g. Curaresiert. Künstliche Atmung. (Fig. 7.)

\begin{tabular}{|c|c|c|c|}
\hline Zeit & $\begin{array}{l}\text { Blutdruck in } \\
\mathrm{mm} \mathrm{Hg}\end{array}$ & $\begin{array}{l}\text { Augendruck } \\
\text { in } \mathrm{mm} \mathrm{Hg}\end{array}$ & Bemerkungen \\
\hline $2^{30}$ & - & - & $1 \mathrm{ccm}$ Curare $1 \%$ subcutan \\
\hline 235 & $\ldots$ & - & $21 \mathrm{~mm} \mathrm{Hg}$ Augendruck tonometrisch \\
\hline 245 & - & - & $1,5 \mathrm{ccm}$ Curare subcutan \\
\hline 305 & 86,5 & 20,7 & \\
\hline 307 & 95,0 & 20,3 & \\
\hline 309 & 90,0 & 20,0 & \\
\hline 311 & 96,5 & 19,3 & \\
\hline 312 & 105,0 & 19,7 & \\
\hline 313 & 110,0 & 19,0 & \\
\hline 314 & 172,0 & - & $\begin{array}{l}5 \mathrm{ccm} \text { Comaserum, gleichzeitig } 0,5 \mathrm{ccm} \\
\mathrm{NaCl} 10 \% \text { subconjunctival }\end{array}$ \\
\hline
\end{tabular}




\begin{tabular}{l|c|c|c}
\hline \hline Zeit & $\begin{array}{c}\text { Blutdruck in } \\
\text { mm } H g\end{array}$ & $\begin{array}{c}\text { Augendruck } \\
\text { in mm } H g\end{array}$ & Bemerkungen \\
\hline 316 & 145,0 & 19,0 & \\
$3^{18}$ & 112,5 & 18,6 & \\
$3^{20}$ & 122,5 & 18,6 & \\
322 & 120,5 & 19,0 & \\
$3^{24}$ & 112,5 & 19,3 & \\
$3^{28}$ & 115,0 & 19,7 & \\
$3^{30}$ & 120,0 & 20,0 & \\
$3^{332}$ & 120,0 & 20,0 & \\
$3^{34}$ & 120,0 & 20,3 & \\
$3^{35}$ & 122,5 & 20,3 & \\
$3^{36}$ & 122,5 & $\overline{3}$ & \\
$3^{37}$ & 120,0 & 19,0 & \\
& 120,0 & 19,0 &
\end{tabular}

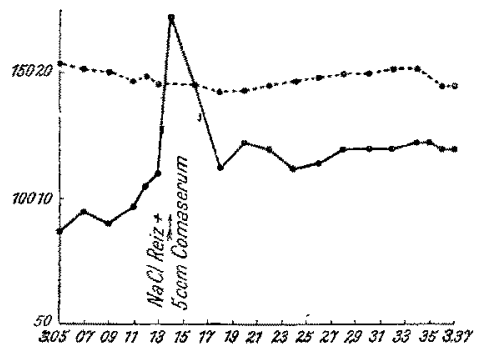

Fig.7. Vgl. Kaninchen Nr.32. Comaserum, intravenös verabreicht, unterdrückt den gleichzeitig applizierten Kochsalzreiz. $1 / 4$ natürliche Grösse.

Kaninehen Nr. 35. $2570 \mathrm{~g}$. Athernarkose.

\begin{tabular}{|c|c|c|c|}
\hline 385 & - & - & Narkosebeginn \\
\hline 356 & 89,0 & - & \\
\hline 357 & 97,5 & - & \\
\hline 402 & 107,5 & 24,7 & \\
\hline 408 & 106,0 & 24,7 & \\
\hline 405 & 97,5 & 28,3 & Vollkommene Narkose \\
\hline 406 & 102,0 & 22,7 & \\
\hline 407 & 100,0 & 22,0 & $10 \mathrm{ccm}$ Comaserum intravenos \\
\hline 408 & 117,5 & 22,7 & \\
\hline 409 & 111,0 & 23,3 & \\
\hline 411 & 100,0 & 22,7 & \\
\hline $4^{\left.12^{1}\right|_{2}}$ & 75,0 & 19,0 & \\
\hline 414 & 73,0 & 16,0 & \\
\hline 415 & 71,0 & 15,0 & \\
\hline $4^{\left.16^{1}\right|_{2}}$ & 82,5 & 14,5 & \\
\hline 419 & 95,0 & 15,0 & \\
\hline 480 & 95,5 & 15,0 & \\
\hline 421 & 96,0 & 15,0 & \\
\hline 498 & 96,0 & 15,0 & $0,5 \mathrm{ccm} 10^{\circ} / 0$ ige Kochsalzlös. subconj \\
\hline $424^{1}{ }_{2}$ & 105,0 & 15,5 & \\
\hline 426 & 107,0 & $\mathbf{1 6 , 0}$ & \\
\hline 427 & 102,0 & 16,5 & \\
\hline 428 & 105,0 & 17,0 & \\
\hline 429 & 105,0 & 17,5 & \\
\hline 430 & 105,0 & 18,0 & \\
\hline 431 & 105,0 & 19,0 & \\
\hline$\left.4^{33} 1^{1}\right|_{2}$ & 107,5 & 19,5 & \\
\hline
\end{tabular}


Experim. Beiträge znm pathologischen Flüssigkeitswechsel des Auges. 537

Kaninchen Nr. 36. 2175 g. Curaresiert. Künstliche Atmung. (Fig. 8.)

\begin{tabular}{|c|c|c|c|}
\hline Zeit & $\mid \begin{array}{c}\text { Blutdruck in } \\
\text { mm } \mathrm{Hg}\end{array}$ & $\begin{array}{l}\text { Angendruck } \\
\text { in } \mathrm{mm} H g\end{array}$ & Bemerkungen \\
\hline 1020 & - & - & $3 \operatorname{ccm} 1 \%$ Curare subcutan \\
\hline 1055 & 117,5 & - & \\
\hline 1102 & 115,0 & 28,9 & \\
\hline 1104 & 112,5 & 32,2 & \\
\hline $11^{06}$ & 115,0 & 37,3 & \\
\hline 1108 & 117,5 & 37,3 & \\
\hline $11^{10}$ & 112,0 & 37,3 & \\
\hline $11^{12}$ & 117,5 & 36,5 & $3 \mathrm{ccm}$ Comaserum in die $V$. jugularis \\
\hline 1114 & 117,5 & 35,5 & \\
\hline $11^{16}$ & 117,5 & 26,8 & \\
\hline 1118 & 112,5 & 21,6 & \\
\hline $11^{20}$ & 110,0 & 19,6 & \\
\hline $11^{22}$ & 117,5 & 18,9 & \\
\hline $11^{24}$ & 110,0 & 21,1 & $0,5 \mathrm{ccm} 10 \%$ ige $\mathrm{NaCl}$-Lösung subconj. \\
\hline $11^{26}$ & 110,0 & 22,6 & \\
\hline 1128 & 115,0 & 28,9 & \\
\hline $11^{30}$ & 120,0 & 34,4 & \\
\hline 1132 & 120,0 & 34,4 & \\
\hline $11^{34}$ & 120,0 & 35,5 & \\
\hline 1136 & 120,0 & 35,5 & \\
\hline 1138 & 120,0 & 35,5 & \\
\hline $11^{40}$ & 112,5 & 35,5 & \\
\hline $11^{122}$ & 120,0 & 34,2 & \\
\hline 1114 & 120,0 & 34,2 & \\
\hline $11^{46}$ & 120,0 & 32,2 & \\
\hline $11^{48}$ & 120,0 & 31,1 & \\
\hline \multicolumn{4}{|c|}{$\begin{array}{l}\text { Fig. 8. Kaninchen Nr. } 36 . \\
\text { Der pathologisch gesteigerte } \\
\text { Augendruck wird durch das } \\
\text { Comaserum steil erniedrigt. } \\
\text { Der Kochsalzreiz lässt den } \\
\text { Druck noch nicht auf den } \\
\quad \text { Anfangswert steigen. }\end{array}$} \\
\hline
\end{tabular}

Noch deutlicher zeigt sich die Wirkung des Serums bei der Verhütung des Kochsalzreizes in folgendem Versuch.

Kaninchen Nr. 67. 2510 g. Curaresiert. Künstliche Atmung. (Fig. 9.)

\begin{tabular}{c|c|c|c}
\hline \hline Zeit & $\begin{array}{c}\text { Blutdruck in } \\
\text { mm } H g\end{array}$ & $\begin{array}{c}\text { Augendruck } \\
\text { in mm } H g\end{array}$ & Bemerkungen \\
\hline 405 & 99,0 & 21,3 & \\
407 & 100,0 & 20,0 & 5 ccm menschl. Comaserum intravenös \\
408 & $\overline{-}$ & $\overline{19,7}$ & \\
409 & 116,5 & 19,7 & \\
411 & 116,5 & 19,3 &
\end{tabular}




\begin{tabular}{c|c|c|c}
\hline Zeit & $\begin{array}{c}\text { Blutdruok in } \\
\mathrm{mm} H g\end{array}$ & $\begin{array}{c}\text { Augendruck } \\
\text { in mm } H g\end{array}$ & Bemerkungen \\
\hline \hline 413 & 115,0 & 19,3 & $0,5 \mathrm{~cm} 10 \%$ ige Kochsalzlös. subconj. \\
$4^{16}$ & 152,5 & 18,0 & \\
$4^{18}$ & 123,0 & 18,0 & \\
$4^{21}$ & 119,0 & 18,0 & \\
$4^{23}$ & 118,0 & 17,3 & \\
$4^{24}$ & 119,0 & 17,3 & \\
& & &
\end{tabular}

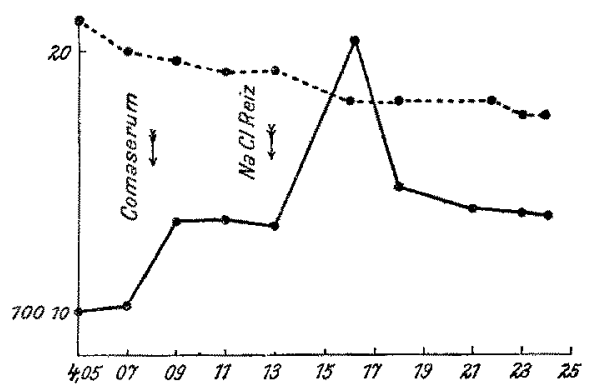

Fig. 9. Kaninchen Nr. 67. Das Comaserum vermag sogar bei steigendem Blutdruek die Wirkung des Kochsalzreizes aufzuheben. 1/2 natürliche Grösse.

Dass sich das Comaserum in dieser Beziehung wesentlich vom normalen Serum unterscheidet, wird aus den folgenden Versuchen hervorgehen. Wir haben selbstverständlich eine grosse Anzahl von allen möglichen Serumarten untersucht.

Kaninchen Nr. 42. 2320 g. Curaresiert. Künstliche Atmung. (Fig. 10.)

\begin{tabular}{|c|c|c|c|}
\hline Zeit & $\begin{array}{c}\text { Blutdruck in } \\
\mathrm{mm} \mathrm{Hg}\end{array}$ & $\begin{array}{l}\text { Augendruck } \\
\text { in } \mathrm{mm} H g\end{array}$ & Bemerkungen \\
\hline 1005 & - & - & $12 \mathrm{ccm}$ Curare $1 \%$ subcutan \\
\hline 1032 & - & - & $\{0,5 \mathrm{ccm}$ intravenös \\
\hline 1040 & 190,0 & 20,8 & \\
\hline 1042 & 187,5 & 18,2 & \\
\hline 1044 & 187,5 & 17,0 & \\
\hline $10^{46}$ & 205,0 & 16,0 & $\begin{array}{l}0,5 \mathrm{~cm} 10 \% \text { ige } \mathrm{NaCl} \text {-Lös. subconjunct, } \\
5 \mathrm{ccm} \text { normales menschliches Serum } \\
\text { intravenös }\end{array}$ \\
\hline 1048 & 180,0 & 18,1 & \\
\hline 1050 & 230,0 & 23,5 & \\
\hline $10^{52}$ & 200,0 & 26,8 & \\
\hline $10^{54}$ & 205,0 & 32,0 & \\
\hline 1056 & 205,0 & 40,0 & \\
\hline $10^{\circ}$ & 190,0 & 49,4 & \\
\hline 1100 & 190,0 & 56,9 & \\
\hline 1101 & 192,5 & 54,4 & \\
\hline 1107 & 197,5 & 45,9 & \\
\hline 1109 & 197,5 & 42,9 & \\
\hline $11^{11}$ & 197,5 & 41,2 & \\
\hline 1115 & 197,5 & 38,0 & \\
\hline 1117 & 197,5 & 34,0 & \\
\hline 1120 & 197,5 & 31,0 & \\
\hline
\end{tabular}


Experim. Beiträge zum pathologischen Flüssigkeitswechsel des Auges. 539

Fig. 10. Normales menschliches Serum hebt den Kochsalzreiz nicht auf. $1 / \star$ natürliche Grösse.

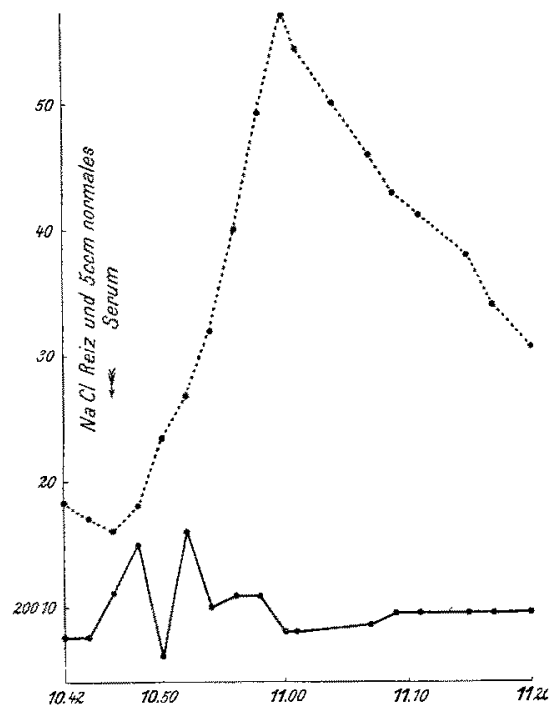

Kaninchen Nr. 31. 2850 g. Curaresiert. Künstliche Atmung.

\begin{tabular}{c|c|c|c}
\hline Zeit & $\begin{array}{c}\text { Blutdruck in } \\
\mathrm{mm} H g\end{array}$ & $\begin{array}{c}\text { Augendruck } \\
\text { in mm } H g\end{array}$ & Bemerzungen \\
\hline \hline 544 & 140,0 & 14,4 & \\
546 & 135,0 & 13,9 & $\begin{array}{l}\text { 5 ccm normales menschliches Serum } \\
\text { intravenös }\end{array}$ \\
548 & 152,5 & 12,9 & \\
550 & 150,0 & 12,2 & \\
552 & 140,0 & 11,9 & \\
$5^{54}$ & 145,0 & 12,8 & 0,5 cem $10 \%$ ige $N a C l$-Lösung subconj. \\
556 & 145,0 & 14,4 & \\
604 & 135,0 & 47,5 & \\
635 & 137,5 & 15,0 &
\end{tabular}

Kaninchen Nr. 41. 2440 g. Curaresiert. Künstliche Atmung.

\begin{tabular}{c|c|c|c}
\hline Zeit & $\begin{array}{c}\text { Blutdruck in } \\
\mathrm{mm} H g\end{array}$ & $\begin{array}{c}\text { Augendruck } \\
\text { in mm } H g\end{array}$ & Bernerkungen \\
\hline 337 & 135 & 16,9 & \\
349 & 135 & 16,2 & 0,5ccm $10 \%$ ige Kochsalzlösung subconj. \\
350 & $\overline{3}$ & $\overline{-}$ & \\
351 & 165 & 17,2 & 5 cem normales Hundeserum intravenös \\
353 & 147 & 19,3 & \\
355 & 130 & 25,0 & \\
357 & 120 & 25,8 & \\
404 & 105 & 41,2 & \\
424 & 130 & 22,5 &
\end{tabular}


Kaninchen Nr. 40. 2640 g. Curaresiert. Künstliche Atmung. (Fig. 11.)

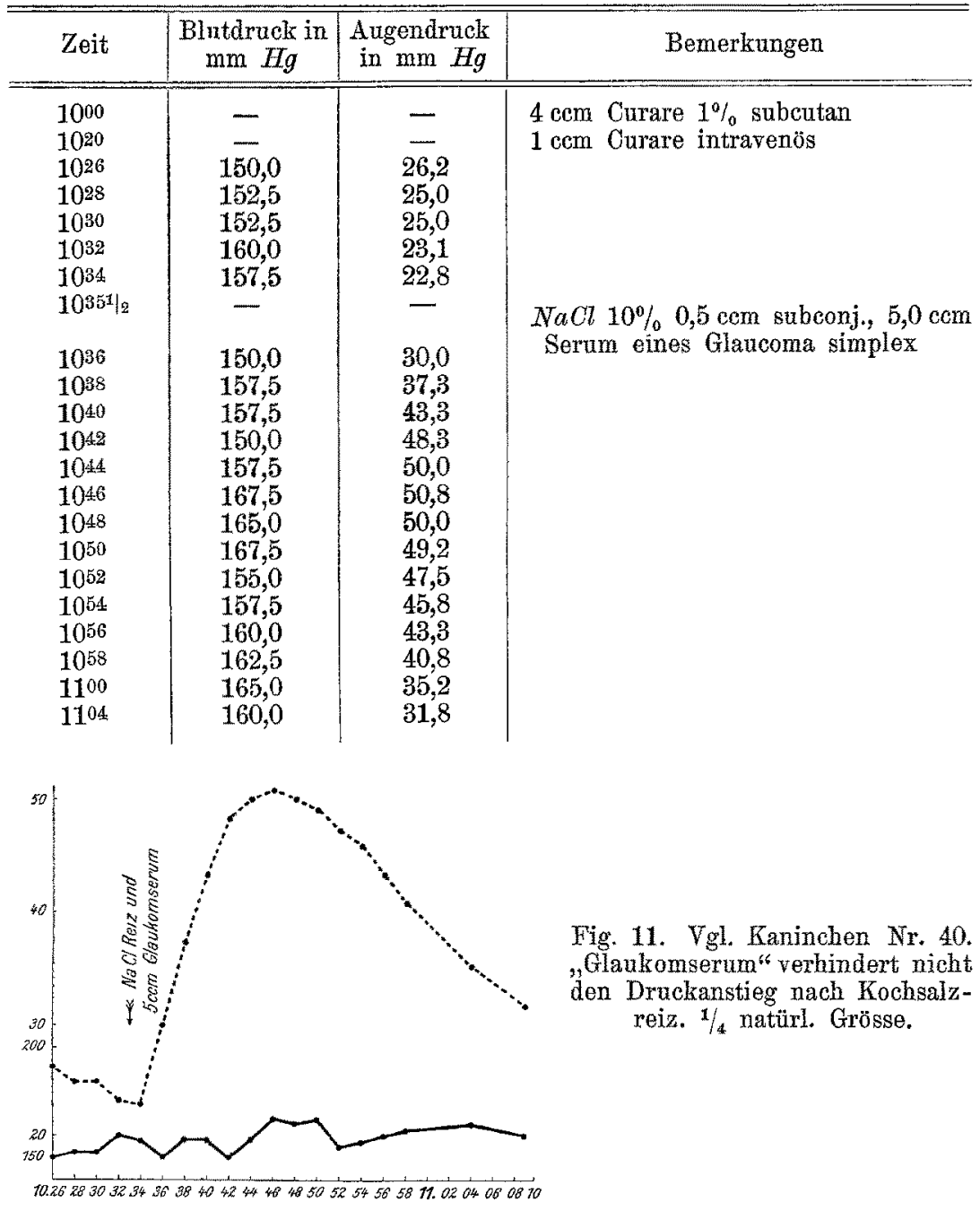

Kaninchen Nr. 19. 2310 g. Curare. Künstliche Atmung. (Fig. 12.)

\begin{tabular}{|c|c|c|c|}
\hline Zeit & $\begin{array}{l}\text { Blutdruck in } \\
\text { nam } \mathrm{Hg}\end{array}$ & $\begin{array}{l}\text { Angendruck } \\
\text { in } \mathrm{mm} H g\end{array}$ & Bemerkungen \\
\hline 515 & - & - & $3 \mathrm{ccm}$ Curare $1 \%$ snbcutan \\
\hline $5^{40}$ & 139 & 20,0 & \\
\hline $5^{46}$ & 196 & 21,0 & \\
\hline $5^{48}$ & 150 & 21,0 & \\
\hline $5^{40}$ & - & - & $\begin{array}{l}5 \mathrm{ccm} \text { eines menschlichen Eklampsie- } \\
\text { serums }\end{array}$ \\
\hline
\end{tabular}


Experim. Beiträge zum pathologischen Flüssigkeitswechsel des Auges. 541

\begin{tabular}{l|c|c|c}
\hline Zeit & $\begin{array}{c}\text { Blutdruck in } \\
\text { mm } H g\end{array}$ & $\begin{array}{c}\text { Augendruck } \\
\text { in mm } H g\end{array}$ & Bemerkungen \\
\hline $5^{51}$ & 196 & 21,0 & \\
$5^{53}$ & 149 & 20,0 & \\
$5^{56}$ & 138 & 20,0 & Aortenkompression \\
$5^{57}$ & 200 & 22,5 &
\end{tabular}

Fig. 12. $5 \mathrm{~cm}$ Eklampsieserum lässt den Augendruck nicht sinken. 1/2 natürliche Grösse.

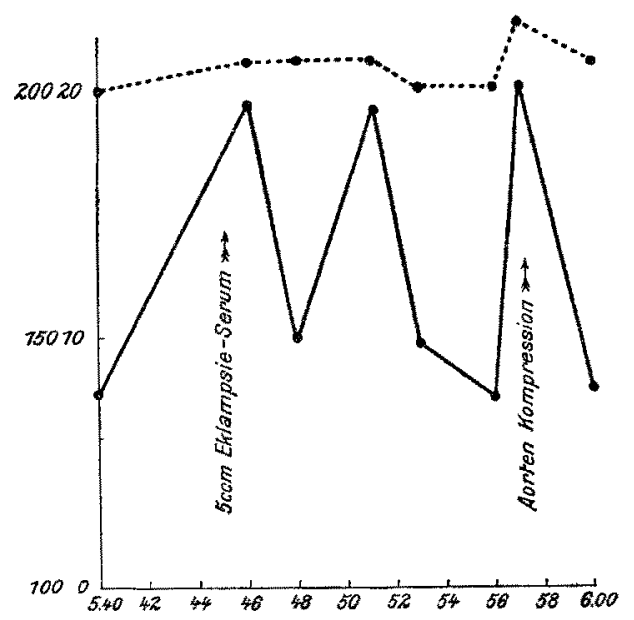

Kaninchen Nr. 43. 2440 g. Curaresiert. Künstliche Atmang. (Fig. 13.)

\begin{tabular}{l|c|c|c}
\hline Zeit & $\begin{array}{c}\text { Blutdruck in } \\
\text { mm } H g\end{array}$ & $\begin{array}{c}\text { Augendruck } \\
\text { in mm } H g\end{array}$ & Bemerkungen \\
\hline 347 & 135 & 16,9 & \\
349 & 135 & 16,3 & 0,5 ccm 10\% Kochsalzlösung subconj. \\
350 & - & - & 5 ccm norm. Hundeserum intravenös \\
& & & \\
351 & 165 & 17,2 & \\
353 & 147 & 19,3 & \\
355 & 130 & 25,0 & \\
357 & 120 & 25,8 & \\
359 & 110 & 29,2 & \\
401 & 110 & 36,3 & \\
403 & 105 & 40,0 & \\
404 & 105 & 41,2 & \\
405 & 105 & 39,1 & \\
407 & 112 & 38,2 & \\
409 & 105 & 36,3 & \\
411 & 105 & 34,5 & \\
413 & 105 & 32,7 & \\
416 & 107 & 29,2 & \\
419 & 107 & 27,5 & \\
421 & 130 & 25,0 & \\
494 & 130 & 22,5 &
\end{tabular}




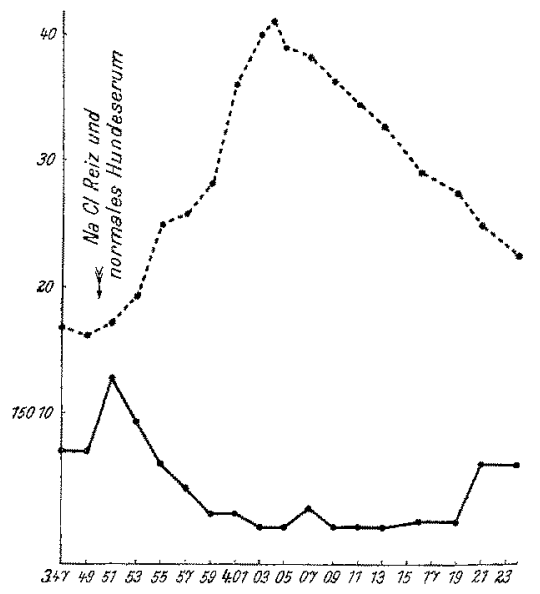

Fig. 13. Kaninchen Nr. 43. Normales Hundeserum vermag den Druckanstieg nach Kochsalzreiz nicht aufzuheben. $1 / 4$ natürliche Grösse.

Kaninchen Nr. 18. $2820 \mathrm{~g}$. Curare. Künstliche Atmung.

\begin{tabular}{l|c|c|c}
\hline Zeit & $\begin{array}{c}\text { Blutdruck in } \\
\text { mm } H g\end{array}$ & $\begin{array}{c}\text { Augendruck } \\
\text { in mm } H g\end{array}$ & Bemerkungen \\
\hline $3^{41}$ & 137,5 & - & \\
$3^{50}$ & 140,0 & - & \\
$4^{92}$ & 137,5 & - & \\
$4^{10}$ & 175,0 & 18,6 & \\
$4^{14}$ & 165,0 & 26,8 & \\
$\left.4^{181}\right|_{2}$ & 145,0 & 38,0 & \\
$4^{19}$ & -5 cem Hundeserum intravenös \\
$4^{21}$ & 167,5 & 41,2 & \\
$4^{23}$ & 155,0 & 44,4 & \\
$4^{33}$ & 160,0 & 44,4 &
\end{tabular}

Weiter haben wir die Tatsache festzustellen, dass nicht etwa diabetisches Serum als solches die Eigenschaft des Comaserums aufweist. Wenn auch die Wirkung vielleicht angedeutet sein könnte, so ist dieses Serum doch nicht imstande, den Kochsalzreiz zu unterdrücken.

Kaninchen Nr. 37. 2870 g. Curaresiert. Künstliche Atmang. (Fïg. 14.)

\begin{tabular}{c|c|c|c}
\hline Zeit & $\begin{array}{c}\text { Blutdruck in } \\
\text { mm Hg }\end{array}$ & $\begin{array}{c}\text { Augendruck } \\
\text { in mm } H g\end{array}$ & Bemerkungen \\
\hline $4^{36}$ & 162,5 & 19,6 & \\
$4^{38}$ & 150,0 & 18,6 & $\begin{array}{c}\text { 5 ccm diabetisches Serum (mit Aci- } \\
\text { dose) intravenös }\end{array}$ \\
440 & 167,5 & 17,9 & \\
$4^{42}$ & 155,0 & 15,7 & \\
$4^{44}$ & 145,0 & 15,0 & \\
446 & 155,0 & 14,3 & \\
$4^{48}$ & 135,0 & 13,2 & 0,5 ccm Kochsalzlösung subconjunctiv. \\
$4^{50}$ & 125,0 & 13,5 & \\
$4^{52}$ & 120,0 & 18,2 & \\
$4^{54}$ & 172,5 & 29,0 & \\
$4^{56}$ & 145,0 & 82,7 & \\
$4^{58}$ & 137,5 & 34,7 &
\end{tabular}


Experim. Beiträge zum pathologischen Flüssigkeitswechsel des Auges. 543

\begin{tabular}{c|c|c|c}
\hline Zeit & $\begin{array}{c}\text { Blutdruck in } \\
\text { mm } H g\end{array}$ & $\begin{array}{c}\text { Augendruck } \\
\text { in mm } H g\end{array}$ & Bemerkungen \\
\hline 500 & 155,0 & 34,0 & \\
$5^{01}$ & 137,5 & 32,7 & \\
$5^{06}$ & 140,0 & 27,0 & \\
511 & 140,0 & 23,0 & \\
518 & 140,0 & 21,0 & \\
& 180,0 & 22,0 &
\end{tabular}

Fig. 14, Kaninchen Nr. 37. Diabetisches Serum verhindert nicht den Druckanstieg nach Kochsalzreiz. $1 / 4$ natürl. Grösse.

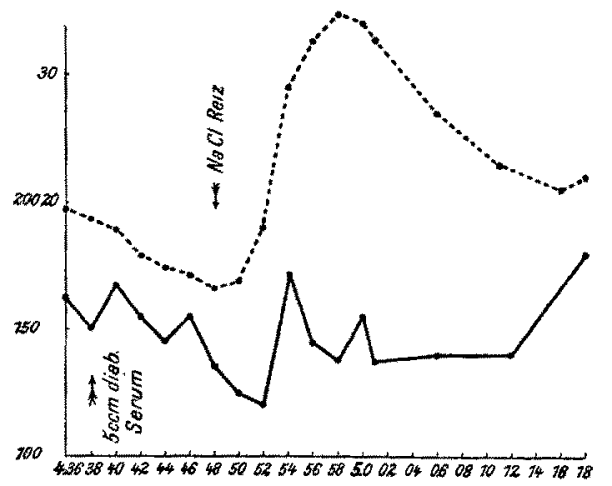

Selbstverständlich lag es nun nahe, zu untersuchen, ob die beim Coma bisher aufgefundenen abnormen Stoffwechselprodukte, Aceton, $\beta$-Oxybuttersäure, etwa für diese uns interessierende Hypotonie verantwortlich $\mathrm{zu}$ machen sind.

Wir konnten aber bisher hierfür keine Anhaltspunkte finden, wie aus den folgenden Versuchen hervorgehen wird. Weder Aceton, noch $\beta$-Oxybuttersäure in Mengen, wie sie im Comablut etwa vorhanden sind, vermochten den intraokularen Druck herabzusetzen oder den Kochsalzreiz zu verhüten.

Kaninchen Nr.45. 2190 g. Curaresiert. Künstliche Atmung. (Vgl. Fig. 15.)

\begin{tabular}{|c|c|c|c|}
\hline Zeit & $\begin{array}{c}\text { Blutdruck in } \\
\text { mm } B g\end{array}$ & $\begin{array}{l}\text { Augendruck } \\
\text { in } \mathrm{mm} H g\end{array}$ & Bemerkungen \\
\hline 1030 & 102,5 & 22,0 & \\
\hline 1032 & 108,5 & 20,3 & \\
\hline 1034 & 105,0 & 19,1 & $4 \mathrm{cem}$ normales menschliches Serum \\
\hline 1035 & - & - & mit $1,0 \mathrm{ccm}$ Aceton. Gleich darauf \\
\hline $10^{38}$ & 105,0 & 18,6 & $0,5 \mathrm{ccm} \quad 10 \%$ ige Kochsalzlösung \\
\hline 1040 & 106,0 & 18,2 & subconjunctival \\
\hline 1042 & 105,0 & 28,7 & \\
\hline 1044 & 105,0 & 34,7 & \\
\hline 1046 & 105,0 & 37,3 & \\
\hline 1048 & 105,0 & 40,7 & \\
\hline 1050 & 105,0 & 42.0 & \\
\hline 1052 & 102,5 & 42,0 & \\
\hline $10^{57}$ & 101,0 & 41,3 & \\
\hline $10^{58}$ & 100,0 & 40,0 & \\
\hline 1101 & 100,0 & 39,3 & \\
\hline $11^{02}$ & 100,0 & 36,7 & \\
\hline
\end{tabular}

v. Graefe's Archiv für Ophthalmologie. LXXXVII, 3. 


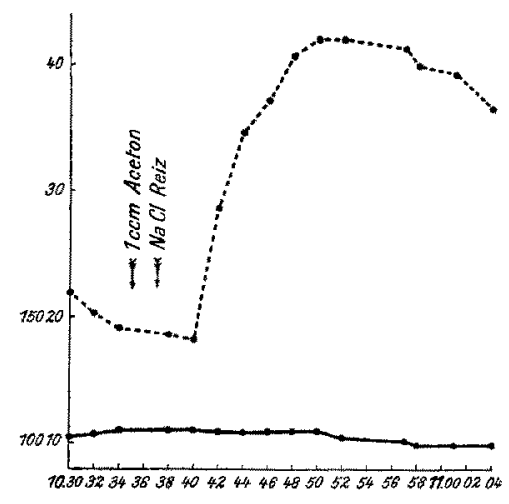

Fig. 15. Kaninchen Nr. 45. Aceton verhindert nicht den Druckanstieg auf "Kochsalzreiz"s. 1/4 natürliche Grösse.

Kaninchen Nr. 48. 2120 g. Curaresiert. Künstliche Atmung. (Fig. 16.)

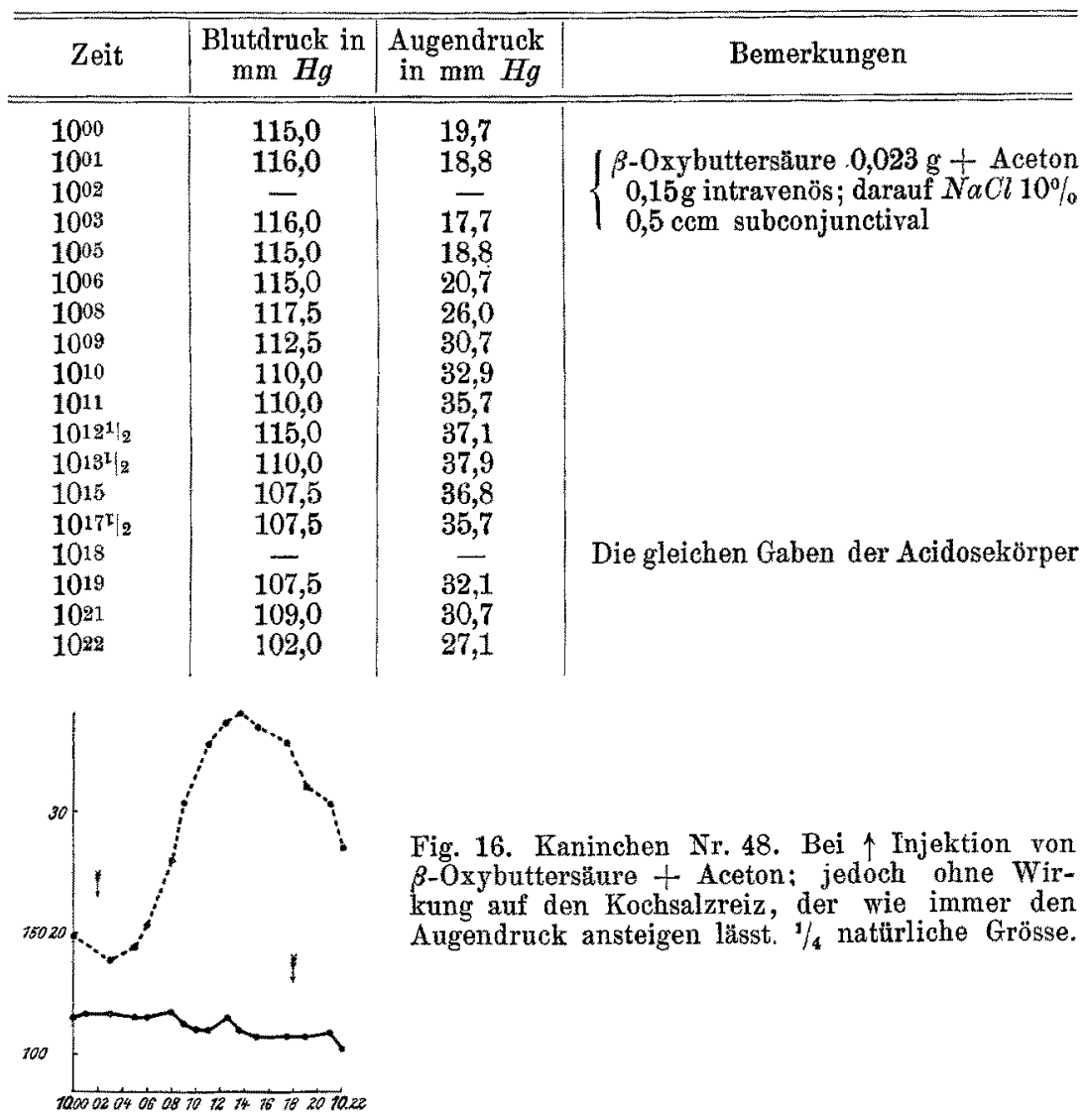

Die $\beta$-Oxybuttersäure und Aceton wurden in Mengen injiziert, wie sie maximal in $5 \mathrm{cem}$ Blutserum von Diabeteskranken gefunden werden. 
Experim. Beiträge zum pathologisehen Flüssigkeitswechsel des Auges. $\mathbf{5 4 5}$

Kaninchen Nr. 49. 3020 g. Curaresiert. Künstliche Atmung. Die dem Tiere zustrơmende Luft wird durch eine mit Aceton gefüllte Flasehe geschickt und beladet sich mit 9 Vol. $\%$ Aceton, wie die gasanalytische Bestimmung mit der von Kochmann u. Streeker angegebenen Methode zeigt ${ }^{1}$ ).

\begin{tabular}{c|c|c|c}
\hline Zeit & $\begin{array}{c}\text { Blutdruck in } \\
\text { mm } H g\end{array}$ & $\begin{array}{c}\text { Augendruck } \\
\text { in mm Hg }\end{array}$ & Bemerkungen \\
\hline $5^{24}$ & 107,5 & - & $\begin{array}{c}\text { Die Acetoneinatmung wird während } \\
\text { des ganzen Versuchs fortgesetzt. }\end{array}$ \\
$5^{26}$ & 105,0 & - & \\
$5^{28}$ & 100,0 & 18,2 & \\
$5^{30}$ & 110,0 & 19,0 & \\
$5^{32}$ & 110,0 & 20,8 & \\
$5^{34}$ & 122,5 & 21,8 & \\
$5^{36}$ & 122,5 & 21,3 & \\
$5^{38}$ & 125,0 & 20,3 & \\
$5^{39}$ & 117,5 & 18,6 & \\
$5^{43}$ & 115,0 & 17,6 & \\
$5^{44}$ & 117,5 & 17,6 & \\
$5^{45}$ & 117,5 & 18,2 & 0,5 cem 10\% ige Kochsalzlös. subconj. \\
$5^{46}$ & 160,0 & 23,2 & \\
$5^{48}$ & 150,0 & 25,9 & \\
$5^{49}$ & 140,0 & 41,2 & \\
$5^{50}$ & 140,0 & 56,2 & \\
$5^{52}$ & 132,0 & 49,0 & \\
$5^{56}$ & 135,0 & 47,5 & \\
& & & \\
\hline
\end{tabular}

Da menschliches Comaserum immerhin schwer zu beschaffen ist, versuchten wir,künstlich beim Hunde ein Coma zu erzengen. Zunächst hofften wir, von Hunden, denen das Pankreas exstirpiert wurde, ein solches Serum zu gewinnen. Es war uns zwar aus der Literatur bekannt, dass nur manchmal bei solchen Hunden ein wirkliches Coma auftritt, aber da wir, wenn unter einer Reihe von Tieren auch nur einige am Coma zugrunde gingen, immerhin grössere Serummengen hätten gewinnen köunen, so schien uns dieser Weg Erfolg zu versprechen. In Wirklichkeit kam es unter

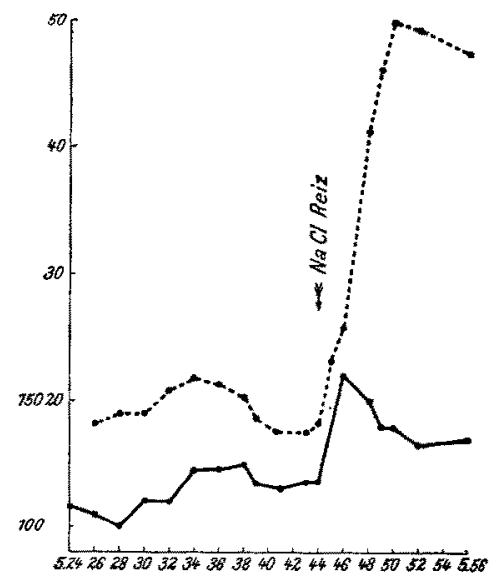

Fig. 17. Kaninchen Nr. 49. Acetoninhalation verhütet nicht den Druckanstieg nach subconjunctivaler Kochsalzinjektion. 1/4 natüriiche Grösse.

12 Hunden nur ein einziges Mal zu einem Coma. In den übrigen

1) Kochmann, M., u. Strecker, W., Biochem. Zeitschr. Bd. XLIII. S. 110. 1912. 
Fällen erlagen die Tiere einer fortschreitenden Kachexie, ohne dass comatöse Erscheinungen zu konstatieren waren.

Interessant war hierbei die Tatsache, dass nur in dem einen Falle, in dem das Tier an einem wirklichen Coma zugrunde ging (grosse Atmung, narkoseähnlicher Zustand, deutliche Exhalation von Aceton und positiver Ausfall der Aceton- und Acetessigsäureprobe im Urin), das Serum beim Kaninchen den intraokularen Druck zu vermindern imstande war und den Einfluss des Kochsalzreizes aufzuheben vermochte. In allen andern Fällen war das Serum ebenso unwirksam wie das normalex Hunde, obwohl die Ausscheidung von Acidosekörpern bei Fleischnahrung durch den Urin ausnahmslos nachgewiesen werden konnte. Die Operation wurde in der üblichen Weise unter streng aseptischen Kautelen vorgenommen. Die Sektion ergab regelmässig die vollständige Exstirpation des Pankreas ${ }^{1}$ ).

Die folgenden Protokolle geben über diese Versuche Aufschluss:

Kaninchen Nr. 27. 3427 g. Curaresiert. Künstliche Atmung. (Fig. 18.)

\begin{tabular}{c|c|c|c}
\hline Zeit & $\begin{array}{c}\text { Blutdruek in } \\
\text { mm } H g\end{array}$ & $\begin{array}{c}\text { Augendruek } \\
\text { in mm } H g\end{array}$ & Bemerkungen \\
\hline 1041 & 150 & 27,7 & \\
1043 & 150 & 25,2 & 5 ccm Serum eines pankreasexstirpier- \\
$10^{44}$ & 160 & - & ten Hundes, der comatös zugrundeging \\
& & & \\
1045 & 160 & 26,4 & \\
1047 & 150 & 22,0 & 5 ccm Serum \\
1049 & 150 & 21,7 & \\
1050 & 165 & 21,7 & \\
1052 & 152 & 19,4 & \\
1055 & 150 & 15,3 &
\end{tabular}

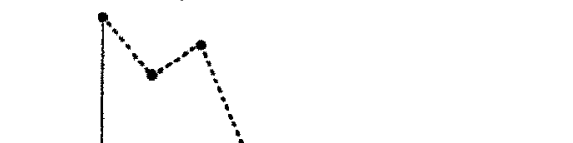

Fig. 18. Kaninchen Nr. 27. Serum eines ,pankreasexstirpierten" Hundes, der im Coma zugrunde ging, vermag den Augendruck zu senken. $1 / 2$ natürliche Grōsse.
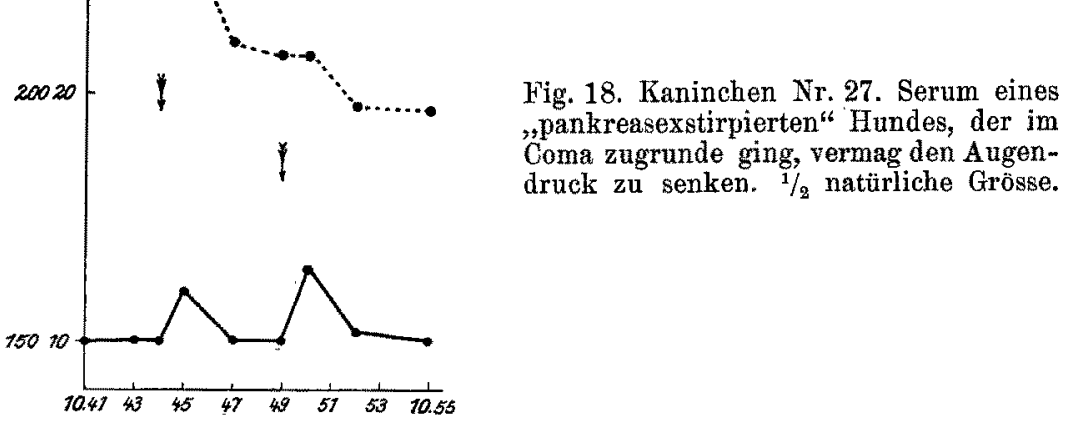

1) Wir möchten nicht verfehlen, an dieser Stelle Herrn Kollegen Prof. A. Hoffman n, Oberarzt an der hiesigen chirurgischen Klinik, der die Operationen ausführte, für seine liebenswürdige Unterstützung den verbindlichsten Dank auszusprechen. 
Experim. Beiträge zum pathologischen Flüssigkeitswechsel des Auges. 547

Kaninchen Nr.24. 2370 g. Nur tonometrische Messung ohne Registrierung des Blutdrucks. Tier nicht aufgebunden, weder curaresiert, noch narkotisiert. (Fig. 19.)

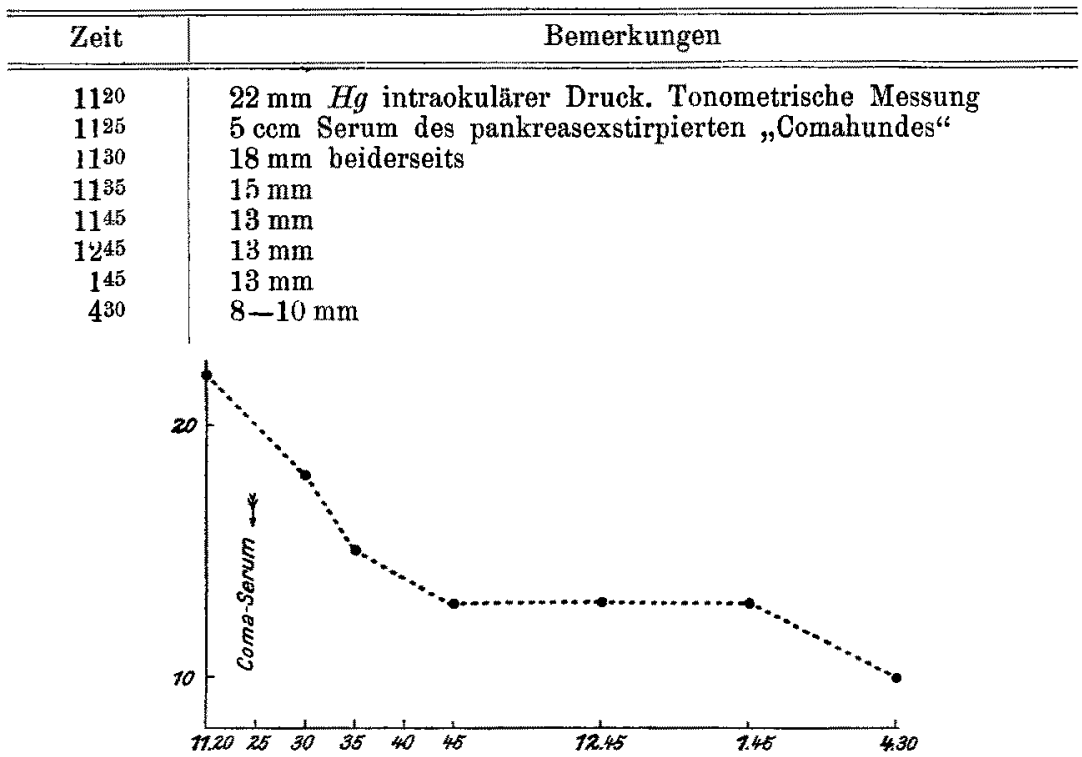

Fig. 19. Kaninchen Nr. 24. Dasselbe Comaserum eines „pankreasexstirpierten“ Hundes zeitigt eine erhebliche Hypotonie.

Vielfache Kontrollmessungen an Tieren, die normales Serum erhalten hatten, ergaben, dass der intraokulare Druck nieht sank. Das Kaninchen Nr. 24 zeigte im übrigen in seinem Verhalten keinerlei Abweichungen von der Norm.

Kaninchen Nr. 47. 2870 g. Curaresiert. Künstliche Atmung. (Fig. 20.)

\begin{tabular}{|c|c|c|c|}
\hline Zeit & $\begin{array}{c}\text { Blutdruck in } \\
\text { mm } H g\end{array}$ & $\begin{array}{l}\text { Augendruck } \\
\text { in } \mathrm{mm} \mathrm{Hg}\end{array}$ & Bemerkungen \\
\hline $3^{47}$ & 115,0 & 16,4 & $5 \mathrm{ccm}$ Serum eines pankreasexstirpier- \\
\hline 348 & 110,0 & 16,0 & $\{$ ten Hundes, das kurz vor dem Tode \\
\hline 350 & 112,5 & 17,6 & | entnommen ist. Intravenöse Injektion. \\
\hline 352 & 110,0 & 16,8 & \\
\hline 354 & 110,0 & 16,8 & \\
\hline $3^{56}$ & 135.0 & 16,8 & $0,5 \mathrm{ccm} 10^{\circ} / \mathrm{ige}$ Kochsalzlös. subconj. \\
\hline 358 & 122,5 & 24,7 & \\
\hline 400 & 112,5 & 37,6 & \\
\hline 402 & 112,5 & 43,7 & \\
\hline 404 & $\mathbf{3 1 0 , 0}$ & 45,8 & \\
\hline 406 & 115.0 & 46,8 & \\
\hline $4^{97}$ & 110,0 & 46,3 & \\
\hline 409 & 110,0 & 45,8 & \\
\hline 411 & 115,0 & 45,3 & \\
\hline 413 & 110,0 & 44,2 & \\
\hline 415 & 110,0 & 43,7 & \\
\hline
\end{tabular}


Dieser Versuch zeigt die völlige Unwirksamkeit des Serums. Der gleiche Befund wurde mit dem Serum der übrigen pankreasexstirpierten Hunde erhoben. Aus schon früher erörterten Gründen möchten wir aber von der Wiedergabe dieser Versuche, mehr als 10 an der Zahl absehen, da sie prinzipiell das gleiche Ergebnis hatten.

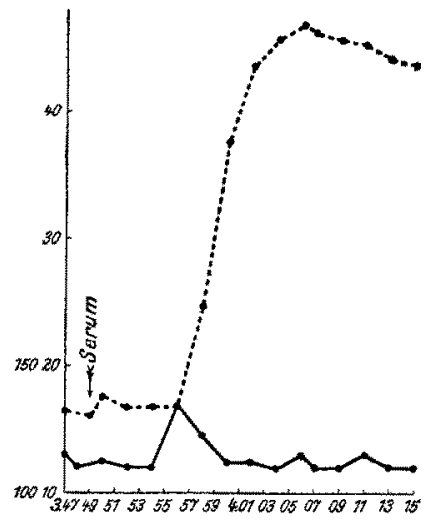

Fig. 20. Kaninchen Nr. 47. Serum eines „pankreasexstirpierten" Hundes ohne Coma senkt nicht den Augendruck und verhütet nicht die Wirkungen des subconjunctivalen Kochsalzreizes. 1/4 nat. Grösse.

Ein anderer Weg, experimentell ein Coma beim Hund zu erzeugen, schien die Phlorrhizinvergiftung beim Hungertier zu sein. Leider wurden auch hier unsere Erwartungen getäuscht, da weder comatöse Zustände auftraten, noch das Serum im Sinne der Druckherabsetzung irgendeine Wirkung aufwies. Aus dieser Versuchsreihe sei folgendes Beispiel wiedergegeben.

Kaninchen Nr. 52. 2560 g. Curare, künstliche Atmung. (Fig. 21.)

\begin{tabular}{|c|c|c|c|}
\hline Zeit & $\begin{array}{c}\text { Blutdruck in } \\
\mathrm{mm} \mathrm{Hg}\end{array}$ & $\begin{array}{l}\text { Augendruck } \\
\text { in mm } I I g\end{array}$ & Bemerkungen \\
\hline 340 & $102, \overline{5}$ & 19,5 & \multirow{13}{*}{$\begin{array}{l}5 \mathrm{ccm} \text { Serum eines phlorrhizinvergif- } \\
\text { teten, } 3 \text { Tage lang hungernden Hun- } \\
\text { des intravenös, } 0,5 \mathrm{ccm} 10 \mathrm{ccm} 10^{\circ} \% \\
\text { ige Kochsalzlösung subconjunetival }\end{array}$} \\
\hline 342 & 102,5 & 19,0 & \\
\hline 343 & 100,0 & 18,0 & \\
\hline $3+4$ & - & - & \\
\hline 345 & 110,0 & 19,5 & \\
\hline 347 & 180,0 & 25,5 & \\
\hline $\begin{array}{l}348 \\
352\end{array}$ & $\begin{array}{l}130,0 \\
115,0\end{array}$ & $\begin{array}{l}30,0 \\
35,3\end{array}$ & \\
\hline 354 & 120,0 & 36,5 & \\
\hline 355 & 122,5 & 35,9 & \\
\hline $3^{59}$ & 120,0 & 34,1 & \\
\hline 400 & 120,0 & 34,1 & \\
\hline 402 & 135,0 & 29,0 & \\
\hline $4^{04}$ & 100,0 & 22,0 & \\
\hline
\end{tabular}

In wenigen Minuten sinkt der Blutdruck auf 0 , der intraokuläre Druek auf $8 \mathrm{~mm} \mathrm{Hg}$. Obwohl also dieses Serum sehr toxisch war, denn das starke Kaninchen ging nach $10 \mathrm{ccm}$ Serum bei intravenöser Einspritzung zugrunde, 
war nach der gewöhnlichen Dosis von $5 \mathrm{cem}$ der Kochsalzreiz nicht wesentlich $\mathrm{zu}$ beeinflussen. Der $18 \mathrm{~kg}$ schwere Hund, der das Serum lieferte, erhielt alle Tage $0,5 \mathrm{~g}$ Phlorrhizin subeutan und schied $23-27 \mathrm{~g}$ Zueker täglich ans. Im Urin war die Acetonprobe schwach, aber deutlich positiv, Acetessigsäure stark positiv.

Fig. 21. Kaninchen Nr. 52. Serum eines phlorrizinvergifteten Hundes senkt weder den Augendruck, noch verhütet es die Wirkungen des Kochsalzreizes. $1 / \mathfrak{a}$ natürliche Grösse.

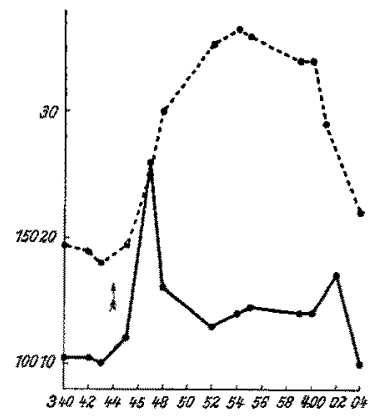

Diese Versuche wiesen also insofern keinen grösseren Erfolg auf, als es uns nicht gelang, mit der Sicherheit eines Experimentes bei Tieren ein Coma zu erzielen und dadurch ein Serum herzustellen, mit dem man die Wirkungen des menschlichen Comaserums nachahmen konnte. So war es auch unmöglich, wirksames Serum in genügender Menge zu erhalten oder herzustellen, um damit weitere Untersuchungen, besonders über den Wirkungsmechanismus vorzunehmen.

Die Feststellung jedoch, dass die menschlichen Comasera den Druckanstieg nach Kochsalzreiz zu unterdrücken vermochten, zeigte uns den Weg, auf dem wir weiter zu kommen hofften. Wir vermuteten, dass hier Gefässwirkungen im Spiele sein könnten, und dies legte uns den Gedanken nahe, nach chemisch wobl definierten Substanzen zu suchen, die ähnliche oder gleiche Effekte auslösen konnten wie unsere wirksamen Sera.

Diese Überlegungen gaben uns Veranlassung zu Versuchen, die im II. und III. Teil der Arbeit geschildert sind. Bevor wir jedoch in ihre Besprechung eintreten, möchten wir hervorheben, dass die Wirkungen des intravenös verabreichten Comaserums beim Kaninchen mit osmotischen Veränderungen der Körperflüssigkeiten nichts zu tun hat; denn einmal waren die verwandten Sera isotonisch, und dann war selbst eine 5\% 5 ige Kochsalzlösung intravenös injiziert nicht imstande, am Kaninchenauge eine Druckverminderung hervorzurufen. Erst eine $10 \%$ ige Natriumchlorialösung konnte eine deutliche Hypotonie verursachen, ohne den nachfolgenden .Kochsalzreiz vollkommen aufheben zu können, während die wirksamen Comasera die intraokulare Druckverminderung viele Stunden unterhielten. 
Kaninehen Nr. 53. 2400 g. Curaresiert. Künstliche Atmung. (Fig. 22.)

\begin{tabular}{|c|c|c|c|}
\hline Zeit & $\begin{array}{c}\text { Blutdruck in } \\
\text { mm } H g\end{array}$ & $\begin{array}{l}\text { Augendruck } \\
\text { in } \mathrm{mm} H g\end{array}$ & Bemerkungen \\
\hline 1002 & 105,0 & 21,9 & \\
\hline 1005 & 102,5 & 21,0 & \\
\hline 1007 & 95,0 & 19,5 & \\
\hline 1008 & - & - & $5 \mathrm{ccm} 5 \%$ Kochsalzlösung intravenös \\
\hline 1009 & 132,5 & 28,1 & \\
\hline 1011 & 120,0 & 36,2 & \\
\hline $10^{13}$ & 118,5 & 39,0 & \\
\hline $10^{14}$ & 105,0 & 37,5 & \\
\hline $10^{15}$ & 105,0 & 36,2 & \\
\hline $10^{16}$ & 100,0 & 34,1 & \\
\hline 1020 & 100,0 & 32,1 & \\
\hline 1021 & 95,0 & 30,0 & \\
\hline 1022 & 95,0 & 28,1 & \\
\hline 1024 & 95,0 & 26,7 & \\
\hline 1026 & 95,0 & 25,2 & \\
\hline 1027 & 92,5 & 23,8 & \\
\hline 1028 & 95,0 & 24,3 & $0,5 \mathrm{~cm} 10 \%$ Kochsalzlosung subconj. \\
\hline $10^{30}$ & 114,0 & 32,1 & \\
\hline $10^{32}$ & 114,0 & 42,4 & \\
\hline $10^{34}$ & 105,0 & 49,3 & \\
\hline 1035 & 109,0 & 53,8 & \\
\hline 1036 & 109,0 & 55,4 & \\
\hline $10^{37}$ & 106,0 & 55,4 & \\
\hline 1038 & 115,0 & 61,5 & \\
\hline 1039 & 110,0 & 61,5 & \\
\hline 1040 & 116,0 & 64,6 & \\
\hline $10^{42}$ & 110,0 & 61,5 & \\
\hline $10^{43}$ & 105,0 & 60,0 & \\
\hline $10^{44}$ & 105,0 & 60,0 & \\
\hline 1046 & 105,0 & 59,2 & \\
\hline 1048 & 114,0 & $\mathbf{5 7}, 0$ & \\
\hline
\end{tabular}

Merkwürdigerweise steigt der Augendruek nach der Injektion der $5 \%$ igen Natriumehloridlösung an. Es möge unentschieden bleiben, ob dies eine Folge der Injektion oder einer Reizung aus andern Gründen ist. Jedenfalls ist die intravenöse Darreichung der hypertonischen Natriumchloridlösung nicht im Sinne einer Hypotonie des Auges wirksam.

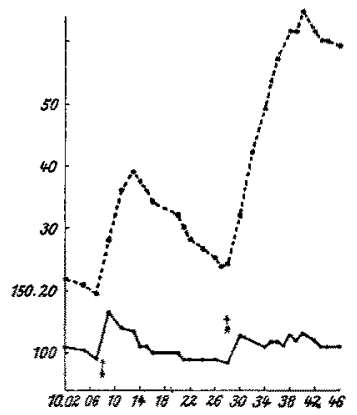

Fig. 22. Kaninchen 53. Die Injektion (intravenös) von $5 \mathrm{~cm} 5 \%$ ige $\mathrm{NaCl}$-Lösung erniedrigt nicht den intraokularen Druek $(\uparrow)$ und vermag den Kochsalzreiz nicht $z$ u verhüten $(\uparrow)^{1 / \%}$ nat. Gr. 
Experim. Beiträge zum pathologischen Flüssigkeitswechsel des Auges. 551

Kaninchen Nr. 51.2420 g. Curaresiert. Künstliche Atmung. (Fig. 23.)

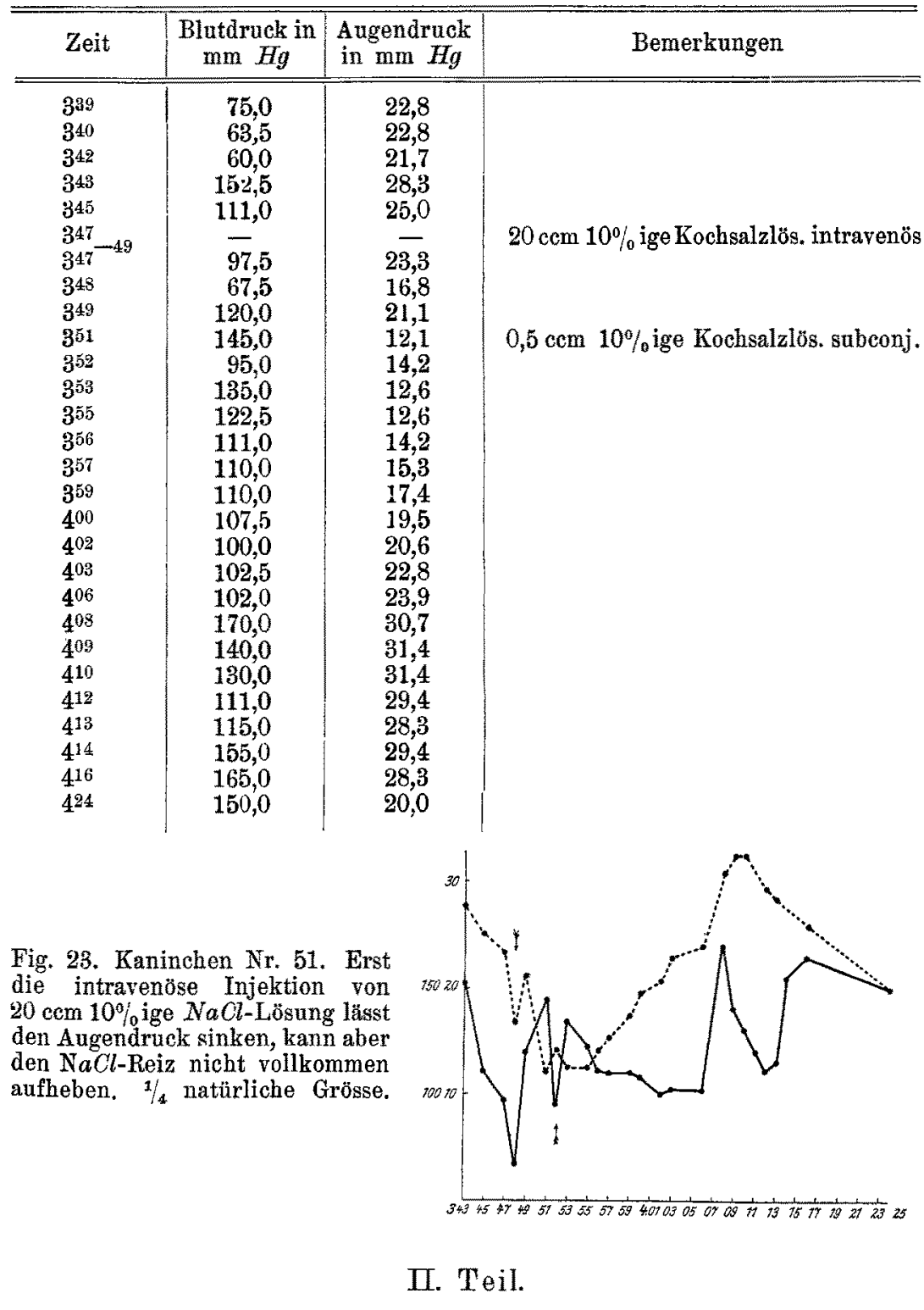

Abhängigkeit des Augendruckes von der arteriellen Blutverteilung.

Die Tatsache, dass das Serum ron Individuen, die an Coma diabeticum erkrankt sind, bei intravenöser Injektion den intraokularen Druck des Kaninchenauges erniedrigen kann und den Druckanstieg nach subconjunctivaler Einspritzung hypertonischer Salzlösungen zu 
verhindern vermag, ohne dass eine wesentliche Anderung des Aortendruckes festzustellen ist, dürfte durch die vorstehenden Versuche experimentell begruindet sein.

Wie diese Erscheinungen aber zu erklären sind, darüber liessen sich zunächst nur Vermutungen aufstellen. Zuerst waren wir der Ansicht, dass es sich dabei wohl um eine spezifische Beeinflussung des Auges durch irgendwelche im Coma auftretenden Substanzen handele. $O b$ eine Wirkung des Serums auf die Produktion und den Abfluss der im Innern des Auges befindlichen Flüssigkeit oder nur eine lokale Gefässwirkung im Sinne einer Vasokonstriktion dabei eine Rolle spiele, war nicht zu entscheiden.

Gewisse Beobachtungen bei unsern Versuchen mit dem Comaserum hatten uns aber doch schon darauf hingewiesen, dass es sich wohl wahrscheinlich nicht um eine spezifische Wirkung auf das Auge handeln werde. Einerseits hatten wir nämlich festgestellt, dass die hypotonisierende Wirkung des Comaserums auch zu beobachten war, wenn der allgemeine Blutdruck stieg, so dass der Gedanke nicht fern lag, es könne sich um eine ähnliche Wirkung handeln, wie nach intravenöser Adrenalininjektion; denn auch hier steigt der allgemeine Blutdruck, während der Augendruck gleich hoch bleibt oder sogar abfällt. Anderseits hatten wir anfangs, als wir die Dosierung des Comaserums noch nicht genügend kannten, die Wahrnehmung gemacht, dass nach hohen Serumgaben der Aortendruck stark erniedrigt wird. Das Serum von Comakranken hatte also unter Umständen eine Wirkung auf den allgemeinen Kreislauf, das eine Mal im Sinne einer Steigerung, das andere Mal in der Richtung einer Senkung des Aortendrucks, während bei passender Dosierung die Höhe des Aortendrucks gleich blieb.

Es entstand nun die Frage: Ist es möglich, dass sowohl bei fallendem, bei steigendem wie bei gleichbleibendem allgemeinen Blutdruck die Augengefässe sich verengern und dadurch den intraokularen Druck ermiedrigen?

Bei oberflächlicher Betrachtung würde man wohl zu einer Verneinung der Frage kommen, da für gewöhnlich angenommen wird, dass Blutdruck und Augendruck sich stets immer in demselben Sinne ändern. Allerdings hat $W$ essely bereits darauf hingewiesen, dass dies keineswegs immer zutrifft, wenn er 1912 in seinem Vortrage auf dem Heidelberger Kongress sagt:

„Bekanntlich ist die Blatverteilung im Organismus eine sebr wechselnde, d. h. nicht nur bei Blutdruckveränderungen, sondern auch bei annähernd gleichbleibendem Aortendruck kann bald dieser, bald jener Organkomplex 
Experim. Beiträge zum pathologischen Flüssigkeitswechsel des Auges. 553

blutreicher oder blutärmer sein. Das bekannteste Beispiel hierfür ist der Antagonismus zwischen der Blutfülle des Haut- und Eingeweidegebietes. Nun stellt das Auge gewissermassen einen Onkometer dar, d. h. sein Binnendruck ist nicht nur vom Druck, sondern auch von der Fülle seiner Gefässe abhängig. Darum muss er selbstverständlich eine Abweichung vom allgemeinen Blutdruck zeigen, sobald zu dessen Änderungen eine Verengerung oder Erweiterung der intraokulären Gefässe hinzutritt, stark genug, um sich neben der Blutdruckwirkung geltend zu machen oder sie sogar zu überkompensieren.

Als ein charakteristisches Beispiel hierfür habe ich früher das Absinken der Augendruckkurve bei Faradisation des Halssympathicus aufgeführt, ferner gezeigt, dass auch bei intravenöser Adrenalininjektion die intraokulare Vasokonstriktion stark genug sein kann, um unter Umständen die Blutdrucksteigerung zu übertreffen und ein Sinken des Augendrucks bei steigendem Carotisblutdruck hervorzubringen, was ich an einem besonders eklatanten Beispiel nochmals veranschaulichen möchte.

Klinisch viel wichtiger war es natürlich, die Wirkung derjenigen Pharmaka zu untersuchen, bei denen eine Augendruçkerhöhung erwartet werden musste. Es war darum das Augenmerk besonders auf diejenigen Stoffe zu richten, welche eine Blutverschiebung im Sinne einer Verengerung des Splanchnicusgebietes bei Erweiterung der Kopf- und Himgefässe hervorrufen.

Von solchen Stoffen habe ich zunächst untersucht: das Amylnitrit, das Coffein, das Antipyrin und den Alkohol.

Um die Wirkung am Auge einwandsfrei zum Ausdruck kommen zu lassen, wurden den Versuchstieren solche Dosen intravenös zugeführt, dass der Carotisdruck ein deutliches Absinken erkennen liess. Sowohl beim Amylnitrit und Coffein als auch besonders beim Antipyrin machte sich dabei, wie Ihnen die einzelnen Kurven zeigen, die periphere Vasodilatation in einem merklichen, oft ganz erheblichen Steigen des Augendrucks geltend, nur beim Alkohol gelang es bisher nicht, eine gleiche Erscheinung zur Anschauung za bringen."

Diese Versuche Wesselys eröffneten die Möghichkeit, die Wirkung des Comaserums in verhältnismässig einfacher Weise durch Beeinflussung des allgemeinen Kreislauts zu erklären. In Anbetracht der Wichtigkeit der Wesselyschen Versuchsergebnisse für unsere experimentellen Untersuchungen waren wir gezwungen, die gleichen und und ähnliche Versuche anzustellen, um uns über diese Verhältnisse auch ein eigenes Urteil bilden zu können. Wir gehen deshalb im folgenden etwas näher auf die Abhängigkeit des intraokularen Drucks rom allgemeinen Kreislauf ein.

Man kann sich die Verhältnisse am besten dadurch plausibel machen, dass man den gesamten Bulbus als einen Ballon mit elastischer Wandung, also gewissermassen als einen Kautschukball auffasst, der mit Flüssigkeit gefüllt ist. Die Blutgefässe können in diesem System 
durch einen mit Wasser gefüllten Gummischlauch dargestellt werden, der durch den Kautschukballon durchführt, ohne dass direkt der Inhalt des Ballons und des Gummischlauches miteinander in Verbindung stehen.

Der Druck in diesem Gummiballon wird steigen und fallen, je nachdem das Volumen, das ist der Inhalt des Auges, vermehrt oder vermindert wird. Dies kann dadurch geschehen, dass entweder die Flüssigkeit innerhalb des Ballons sich an Menge verändert - Zu- oder Abnahme des Kammerwassers -, oder dass sich der Gummischlauch, der das Gefässystem des Auges darstellt, ausdehnt oder zusammenschrumpft.

Dies letztere kann einmal ein aktiver, ein andermal ein passiver Vorgang sein: aktiv ist der Vorgang dann, wenn die Wandung des Gefässystems sich zusammenzieht (Vasokonstriktion) oder erschlafft (Vasodilatation), passiv wird der Vorgang dann sein, wenn das Blut in das Gefäss hineingepresst oder aus dem Auge herausgesangt wird.

Welcher Druck dabei in dem Gummischlauch herrscht, ist für den Druck in dem Ballon vollkommen gleichguiltig; es kommt nur darauf an, welchen Raum der Schlauch innerhalb des Ballons einnimmt, in welchem Füllungszustand er sich befindet.

Im lebenden Auge stellt dieses intraokulare Gefässystem mit seinen Arterien, Kapillaren und Venen eine Endausbreitung der Hirngefässe dar, die einen wesentlichen Teil des Aortensystems ausmachen. Wir müssen infolgedessen untersuchen, in welcher Weise Drucksteigerung oder Drucksenkung in dem Aortensystem auf das Volumen der Hirngefässe und damit der intraokularen Gefässe einwirken.

Was zunächst die Drucksteigerung anlangt, so kann diese dadurch zustande kommen, dass erstens vom Herzen in der Zeiteinheit mehr Blut als in der Norm in das Aortensystem hineingepresst wird, indem entweder durch die Beschleunigung des Herzschlages oder durch Vergrösserung der Kontraktionen das Schlagvolumen des Herzens wächst.

In zweiter Linie ist eine Steigerung des Druckes dadurch möglich, dass vermehrte Widerstände in das Gefässystem eingeschaltet werden. Am häufigsten kommt dies durch eine Vasokonstriktion zustande, welche verschiedene Gebiete des Gefässystems: Abdominal-, Haut-, Hirngefässe erfassen kann.

Eine Senkung des allgemeinen Druckes im Gefässystem muss ihren Grund in einer Verminderung des Schlagrolumens oder einer Vasodilatation finden. Dass zahlreiche Kombinationen möglich sind, 
Experim. Beiträge zum pathologischen Flüssigkeitswechsel des Auges. 555

versteht sich von selbst, und es ist bekannt, dass für gewöhnlich beide Mechanismen, Schlagvolumen und periphere Widerstände, bei einer Vermehrung des Blutdruckes zum Teil in demselben, zum Teil im entgegengesetzten Sinne tätig sind.

Man kann sich auf diese Weise leicht vorstellen, dass unter Umständen beide Faktoren sich das Gleichgewicht halten, so dass bei wesentlichen Veränderungen des Schlagwolumens und der peripheren Widerstände der allgemeine Blutdruck sich doch nieht verändert.

In ähnlicher Weise kann es sich ereignen, dass Teile des Gefässystems sich erweitern, der Blutdruck also sinken müsste, dass dieses Minus aber durch eine Steigerung des Schlagvolumens wieder ausgeglichen wird. Noch häufiger tritt der Fall ein, dass bei Verengerung eines bestimmten Gefässbezirkes ein anderer Teil des Gefässsystems sich erweitert und umgekehrt. Je nachdem nun der eine oder der andere Bezirk das Utbergewicht hat, wird es zu Veränderungen des allgemeinen Blutdruckes kommen.

Aber es ist auch hier der Fall möglich, dass trotz wesentlicher Veränderungen des Kreislaufs der allgemeine Blutdruck der gleiche bleibt. Es ist bekannt und bewiesen 1 ), dass sehr häufig das Splanchnicusgebiet einerseits und das Gefässgebiet der Haut, des Hirns und der Kranzgefässe des Herzens ein gegensätzliches Verhalten aufweisen. Wenn dabei unter Umständen eine wesentliche Änderung des allgemeinen Blutdruckes nicht vorhanden ist, so bedingt die Verengerung, beispielsweise des Splanchnicusgebietes und die Erweiterung der Haut-, Hirn- und Kranzgefässe eine Verschiebung des Blutes, eine Anderung in der Blutverteilung.

In welcher Weise werden nun diese Verhältnisse im Aortensystem den Füllungszustand, das Volumen der Gefässe im Innern des Auges und damit den intraokularen Druck beeinflussen?

Ist die Blutdrucksteigerung durch eine Vergrösserung des Schlagvolumens des Herzens bedingt, ohne dass sich die peripheren Widerstände in grösserem Massstabe ändern, so wird mehr Blut in das gesamte Aortensystem hineingepresst, und die Gefässe erfahren dabei - bis zu einem gewissen Grade - eine passive Dehnung, die sich naturgemäss auch auf die Gefässe des Augeninnern erstreckt. Diese erweitern sich also, und ihre Erweiterung führt zu einer Steigerung auch des Augendruckes.

Bei einer Verringerung des Schlagvolumens des Herzens, die

I) Kochmann, M., Arch. int. de Pharmae, et de Thér. Bd. XIII. p. 329. 1904. 
mit einer Senkung des allgemeinen Blutdruckes einhergeht, werden die Gefässe, auch des Auges, passiv enger werden, ihr Volumen wird kleiner, und eine Senkung des Augendruckes muss die Folge sein.

Ist die Steigerung des Aortendruckes durch eine Vasokonstriktion bedingt, so werden hingegen die Augengefässe je nach dem Sitz dieser Gefässverengerung ganz verschieden beeinflusst werden. Findet die Vasokonstriktion im Splanchnicusgebiet statt, so wird das Blut aus den Unterleibsgefässen in die Haut-, Hirn- und Kranzgefässe des Herzens hineingepresst, diese werden erweitert, und für das Auge ist eine Steigerung des intraokularen Druckes die Folge. Umgekehrt wird eine Senkung des Augendruckes eintreten, wenn die Splanchnicusgefässe sich erweitern und gewissermassen das Blut aus dem Hirn und damit den inneren Augengefässen herausgezogen wird. Auch in diesem Falle wird also der intraokulare Druck eine dem allgemeinen Blutdruck gleichsinnige Änderung erfabren.

Der Sitz der Vasokonstriktion kann aber auch ein anderer sein. Findet die Vasokonstriktion im Gebiet der Haut-, Kranz- und Hirngefässe statt, so wird zwar ebenfalls eine Blutdrucksteigerung im Aortensystem die Folge sein, aber die Gefässe des Auges haben sich dabei verengert, und die Folge wird trotz steigenden Aortendruckes ein Sinken des intraokularen Druckes sein.

Umgekehrt kann ein Fallen des Aortendruckes durch eine Vasodilatation im Gebiete der Haut, des Herzens und des Hirnes hervorgerufen werden, und die Folge ist dann für das Auge eine Erweiterung der intraokularen Gefässe und Steigen des Augendrucks trotz Absinken des allgemeinen Blutdruckes.

Es versteht sich weiterhin von selbst, dass eine Vasokonstriktion im Splanchnicusgebiet durch eine gleichzeitige Vasodilatation der Haut-, Kranz- oder Hirngefässe gerade ausgeglichen oder umgekehrt eine Vasokonstriktion der Hirn-, Haut- und Kranzgefässe durch eine Vasodilatation der Splanchnicusgefässe kompensiert werden kann.

Die Folge wäre eine Veränderung der Blutverteilung, die trotz gleichbleibendem Blutdrucke im ersten Fall zu einer Steigerung, im zweiten zu einer Abnahme des intraokularen Druckes führen muss. Wenn sich nun die einzelnen Vorgänge miteinander kombinieren, z. B. Vergrösserung des Schlagrolumens und gleichzeitig Vasokonstriktion der Augengefässe, so ist es verständlich, in wie mannigfaltiger Weise das Volumen der Augengefässe und damit der intraokulare Druck durch die allgemeinen Kreislaufverhältnisse beeinflusst werden kann. 
Experim. Beiträge zum pathologischen Flüssigkeitswechsel des Auges. 557

Jedenfalls muss auf Grund dieser Überlegungen der Satz aufgestellt werden: Die Veränderungen des Augendrucks stehen nicht in Abhängigkeit vom allgemeinen Blutdruck, sondern lediglich rom Füllungszustand der intraokularen Gefässe - und dieser ist bedingt durch die Verteilung des Blutes im arteriellen Gefässystem. Dabei ist es gänzlich gleichgültig, ob die Augengefässe aktiv oder passiv ihren Eüllungszustand verändern.

Es ist mithin die Möglichkeit gegeben, dass

1. bei steigendem Blutdruck der Augendruck steigt, absinkt oder gleichbleibt,

2. bei sinkendem Blutdruck der Augendruck sinkt, steigt oder auf derselben Höhe bleibt,

3. bei gleichbleibendem Blutdruck der Augendruck gleichbleibt, sinkt oder steigt.

Die Ansicht, dass Blutdruck und intraokularer Druck einander parallel gehen oder sich doch in gleichem Sinne ändern, gilt nur für zwei Fälle unter neun Möglichkeiten. Um nun diesen Erörterungen die experimentelle Grundlage zu verschaffen, ist es eigentlich nur nötig, die beiden Grenzfälle im Tierversuch darzustellen, nämlich:

Sinken des Augendruckes bei Steigen des Aortendruckes und Steigen des intraokularen Druckes beim Abfall des allgemeinen Blutdruckes.

Die erste dieser Forderung - Sinken des Augendruckes bei Steigen des Aortendruckes - musste sich nach unsern Überlegungen dureh die Einwirkung einer Substanz erreichen lassen, die eine Steigerung des allgemeinen Blutdruckes durch eine starke Konstriktion aller peripheren Gefässe; also auch der Hirn- und Augengefässe zustande kommen lässt.

Fine solche Substanz steht uns im Adrenalin zur Verfügung, das auch $W$ essely ${ }^{1}$ ) schon zu seinen Versuchen gebraucht hat. Mit grösserer Sicherheit aber liess sich dieser Vorgang durch die intravenöse Einverleibung ron Bariumchlorid herbeiführen, welches bisher nicht verwendet wurde. Die folgenden Versuche beweisen das eben Gesagte auf das deutlichste.

Kaninchen Nr. 63. $2090 \mathrm{~g}$. Versuchsanordnung wie immer. Tier euraresiert (siehe Fig. 24).

1) Wessely, K., Arch. f. Augenheilk. Bd. LX. S. 1 u. 97.1908. 


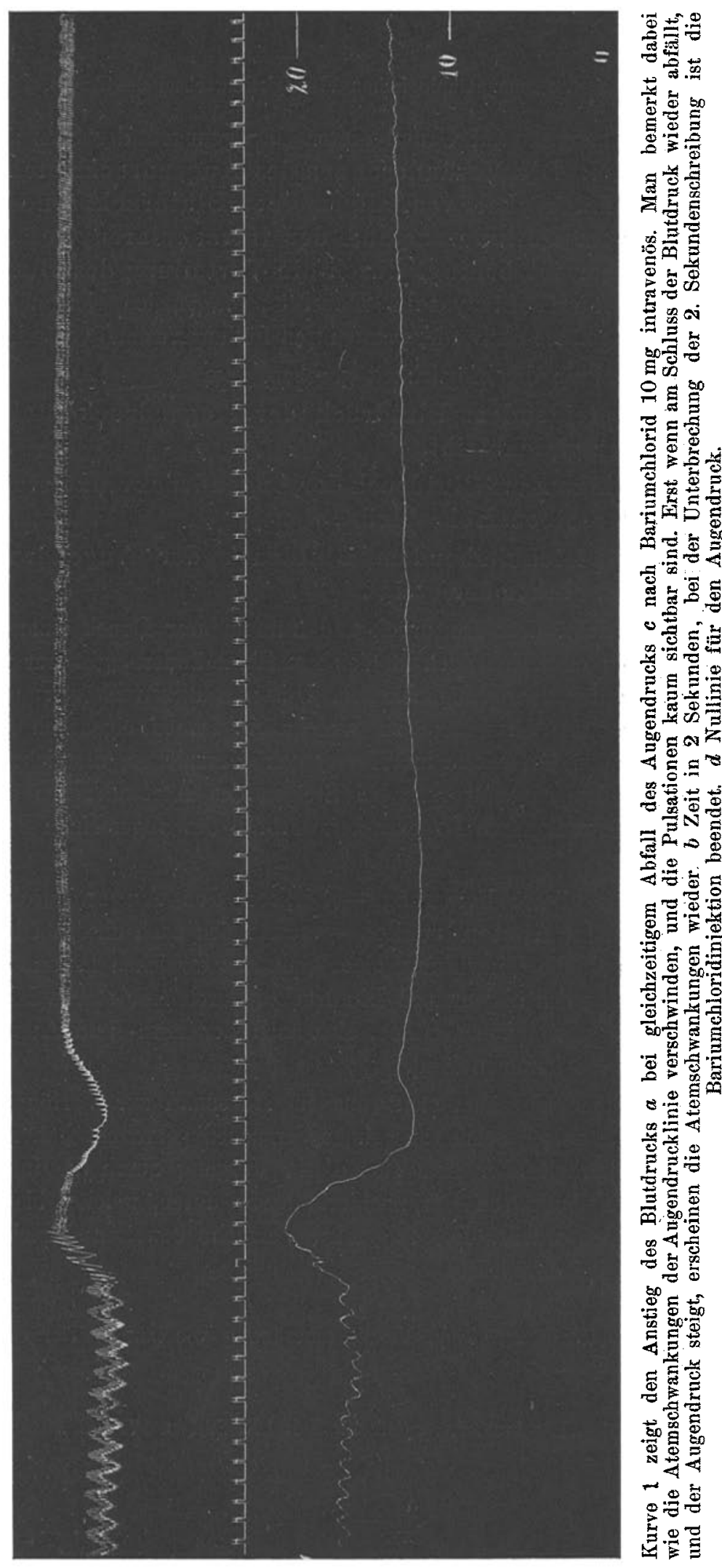


Experim. Beiträge zum pathologischen Flüssigkeitswechsel des Auges. 559

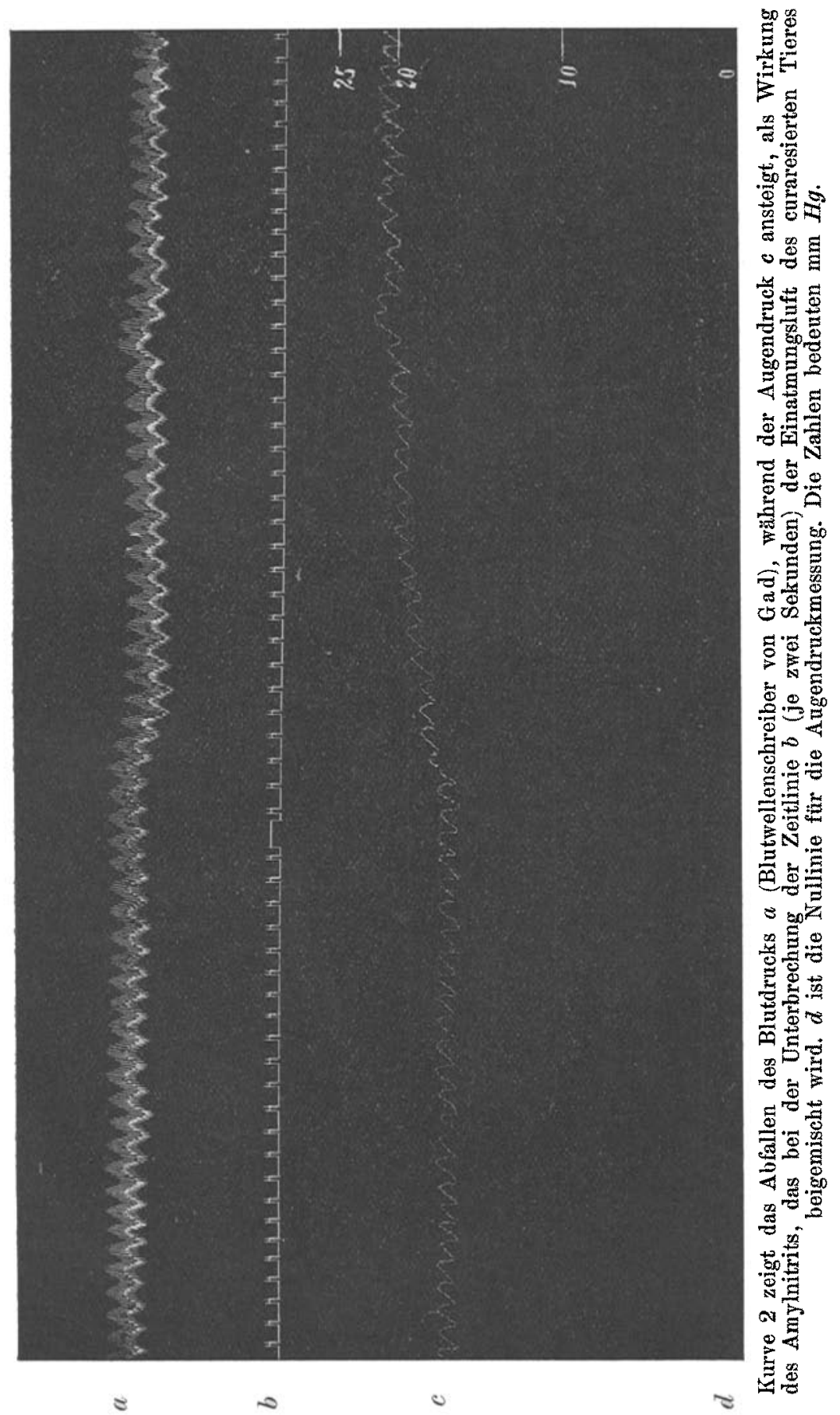

จ. Graefe's Archiv fur Ophthalmologie. LXXXVIII. 3. 


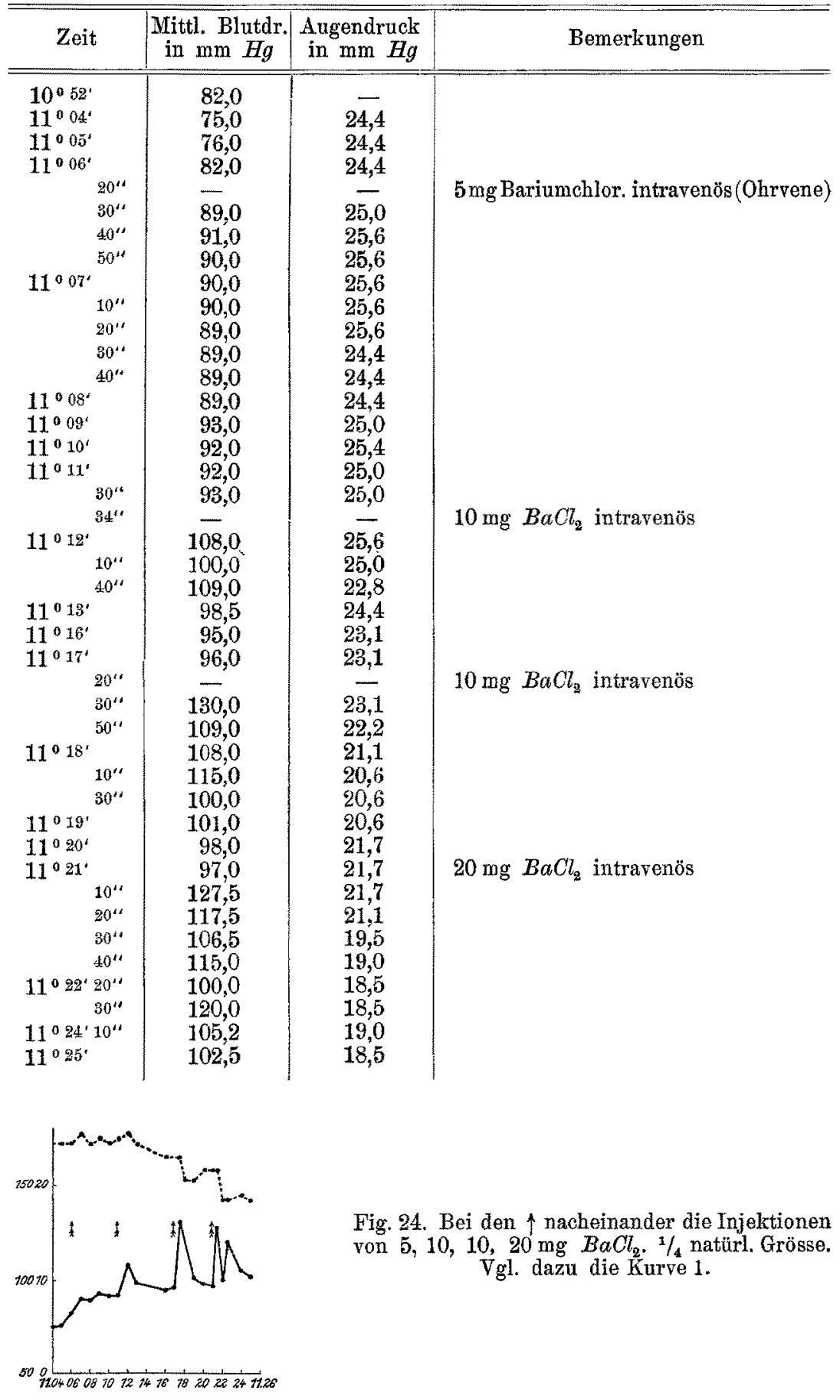


Experim, Beiträge zum pathologischen Flüssigkeitswechsel des Auges. 561

Ergebnis: Nach der Gabe von $5 \mathrm{mg} \mathrm{BaCl}_{2}$ steigt der Augendruck, weil die Vasokonstriktion sich zunächst nur auf das Splanchnicusgebiet beschränkt. Nach den grösseren Gaben tritt auch ein Sinken des Augendrucks ein, da die Gefässverengerung auch die intraokularen Gefässe mitergreift, also Sinken des Augendrucks bei steigendem Blutdruck.

Kaninchen Nr. 59. 2550 g. Curare. Künstliche Atmung. Registriermanometer und Blutwellensehreiber. Die Injektion des Suprarenins gesehieht in die A. subclavia dextra so, dass das Alkaloid durch die A. carotis zum Hirn und dem Ange hingeführt wird. (Fig. 25.)

\begin{tabular}{|c|c|c|c|}
\hline Zeit & $\begin{array}{l}\text { Mittl. Blutdr. } \\
\text { in mm } \mathrm{Hg}\end{array}$ & $\begin{array}{l}\text { Augendruck } \\
\text { in } \mathrm{mm} H g\end{array}$ & Bemerkungen \\
\hline $10^{\circ} 24^{\prime}$ & 116 & 22,0 & \\
\hline $10^{0} 25^{\prime}$ & 116 & 19,5 & $0,1 \mathrm{mg}$ Suprarenin. hydrochl. $=$ \\
\hline $10^{\circ} 26^{4}$ & 116 & 19,5 & $1 \mathrm{ccm} 1: 1000$ ) in den zentralen \\
\hline $10^{\prime \prime}$ & 116 & 19,0 & Stumpf der A. subcl. d. \\
\hline $20^{\prime 4}$ & 125 & 19,2 & \\
\hline $80^{4}$ & 170 & 20,6 & \\
\hline $40^{\prime \prime}$ & 170 & 20,0 & \\
\hline $50^{\prime \prime}$ & 168 & 20,6 & \\
\hline $10^{\circ} 27^{\prime}$ & 160 & 20,6 & \\
\hline $10^{\prime \prime}$ & 165 & 21,1 & \\
\hline $20^{\prime \prime}$ & 160 & 20,0 & \\
\hline $30^{\prime \prime}$ & 145 & 20,0 & \\
\hline $40^{\prime \prime}$ & 130 & 19,0 & \\
\hline $50^{\prime \prime}$ & 112 & 18,6 & \\
\hline $10^{\circ} 28^{i}$ & 102 & 19,0 & \\
\hline $10^{* 4}$ & 91 & 19,0 & \\
\hline $20^{\prime \prime}$ & 85 & 19,5 & \\
\hline $30^{\prime \prime}$ & 91 & 19,0 & \\
\hline $40^{\prime \prime}$ & 107 & 19,0 & \\
\hline $50 " *$ & 125 & 19,0 & $0,1 \mathrm{mg}$ Suprarenin. hydrochlor. \\
\hline $10^{\circ} 29^{\prime}$ & 165 & 19,0 & \\
\hline $10^{\prime \prime}$ & 160 & 19,0 & \\
\hline $90^{\prime \prime}$ & 160 & 19,0 & \\
\hline $30^{\prime \prime}$ & 150 & 19,5 & \\
\hline $40^{\prime \prime}$ & 140 & 19,0 & \\
\hline $50^{\prime \prime \prime}$ & 122 & 18,1 & \\
\hline $10^{\circ} 30^{\circ}$ & 102 & 18,1 & \\
\hline $10^{\prime \prime}$ & 87 & 17,6 & \\
\hline $20^{\prime \prime}$ & 79 & 17,6 & \\
\hline $30^{\prime \prime}$ & 74 & 18,1 & \\
\hline $40^{\prime \prime \prime}$ & 70 & 17,6 & \\
\hline $50^{\prime \prime}$ & 66 & 17,1 & \\
\hline $10^{0} 31^{\prime}$ & 66 & 17,1 & \\
\hline $30 " 4$ & 62 & 16,3 & \\
\hline $10^{\circ} 35^{t}$ & 67 & 15,2 & 0,2 mg Suprarenin. hydrochlor. \\
\hline $30^{\prime \prime}$ & 170 & 20,0 & \\
\hline $10^{\circ} 36^{\circ}$ & 170 & 21,1 & \\
\hline $30^{\prime \prime \prime}$ & 160 & 19,5 & \\
\hline $10^{\circ} 37^{\prime}$ & 132 & 17,6 & \\
\hline $30^{\prime \prime}$ & 103 & 17,1 & \\
\hline
\end{tabular}




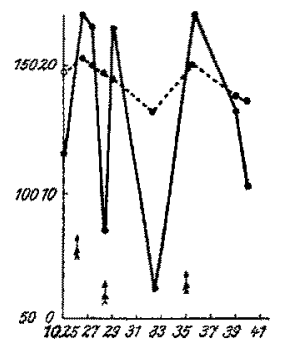

Fig. 25. Kaninchen 59. Bei $\uparrow$ Injektion von Suprarenin. Ungefähres Gleichbleiben des Augendrucks trotz starker Blutdrucksteigerungen. $1 / 4$ nat. Grösse.

Ergebnis: Trotz starkem Steigen des Blutdrucks keine Erhöhung des intraokularen Drucks.

Die zweite Forderung: Steigerung des in traokularen Druckes bei sinkendem Blutdrucke, musste sich durch die Wirkung von Substanzen erreichen lassen, welche die Blutdrucksenkung gerade durch Erweiterung der Hirngefässe neben der der Haut- und Kranzgefässe hervorrufen.

Solche Substanzen sind die Nitrite, von denen wir das Amylnitrit zu unsern Versuchen auswählten, das nach den Untersuchungen von Filehne ${ }^{1}$ ) bei mässigen Gaben seinen Angriffspunkt nicht in der Peripherie, sondern im rasomotorischen Zentrum besitzt. Die folgenden Versuche stimmen mit den Ergebnissen Wesselys rollkommen überein.

Kaninehen Nr. 34. 2900 g. Curaresiert. Künstliche Atmung. Linke Carotis in Verbindung mit dem Gadschen Blutwellensehreiber; rechtes Auge mit dem Wesselyschen Registriermanometer verbunden. (Fig. 26.)

\begin{tabular}{|c|c|c|c|}
\hline Zeit & $\begin{array}{l}\text { Mittl. Blutdr } \\
\text { in } \mathrm{mm} \mathrm{Hg}\end{array}$ & $\begin{array}{c}\text { Intraokulärer } \\
\text { Druck in } \\
\text { mm } H g\end{array}$ & Bemerikungen \\
\hline 3 h $32^{\prime}$ & - & - & Curare $5 \mathrm{ccm} 1 \%$ subcutan \\
\hline $3 \mathrm{~h} 53^{4}$ & 125,0 & - & \\
\hline 3h $54^{\prime \prime}$ & 125,0 & - & \\
\hline $3^{\mathrm{h}} 55^{\prime}$ & $111-112$ & 13,9 & \\
\hline 3h $57^{\circ}$ & 106,0 & 13,9 & \\
\hline $3^{\text {h }} 57^{\prime} 8^{4}$ & - & - & $\begin{array}{l}\text { Amylnitrit tropfenweise in den Luft- } \\
\text { strom der künstlichen Atmung }\end{array}$ \\
\hline $3^{h} 57^{+} 16^{\prime \prime}$ & 73,0 & 14,6 & \\
\hline $3 \mathrm{~h} 58^{\prime}$ & 120,0 & 15,4 & \\
\hline $3 \mathrm{~h} 59^{\prime}$ & 118,0 & 15,4 & \\
\hline $4^{4} 00^{\prime}$ & 112,0 & 18,9 & \\
\hline $4^{\text {h }} 00^{\prime} 30^{\prime} \cdot$ & 83,0 & 20,0 & \\
\hline 4h $01^{\prime}$ & 104,0 & 19,2 & \\
\hline $4^{\text {h }} 02^{\prime}$ & 105,0 & 15,0 & \\
\hline
\end{tabular}

1) Filehne, W., Pflügers Arch. f. d. ges. Physiol. Bd. IX. S. 470, 1874. 
Experim. Beiträge zum pathologischen Flüssigkeitswechsel des Auges. 563

\begin{tabular}{|c|c|c|c|}
\hline Zeit & $\begin{array}{l}\text { Mittl. Blutdr. } \\
\text { in } \mathrm{mm} H g\end{array}$ & $\begin{array}{c}\text { Intraoknlärer } \\
\text { Druck in } \\
\text { mm } H g\end{array}$ & Bemerkungen \\
\hline $4^{\text {h }} 03^{\prime}$ & 84,0 & $\overline{171}$ & $0,5 \mathrm{ccm} 10 \% \mathrm{NaCl}$ subconjunctival \\
\hline 4h $04^{\prime}$ & 97,0 & 17,1 & \\
\hline 4h $05^{\prime}$ & 92,0 & 17,5 & \\
\hline $4 \mathrm{~h} 07^{\prime}$ & 92,0 & 19,2 & \\
\hline $4^{\mathrm{h}} 08^{\prime} 30^{t t}$ & 117,0 & 21,8 & \\
\hline $4^{\text {h }} 09^{\prime}$ & 120,0 & 30,0 & \\
\hline 4 h $10^{\prime}$ & 105,0 & 36,3 & \\
\hline $4^{h} 11^{\prime}$ & 91,0 & 35,0 & \\
\hline $44^{\mathrm{h}} 12^{\mathrm{s}}$ & 85,0 & 30,0 & \\
\hline $4^{\text {h }} 13^{\prime}$ & 86,0 & 30,0 & Pupille eng \\
\hline $4^{\mathrm{h}} 1 \mathrm{t}^{\prime}$ & 90,0 & 32,5 & Amylnitrit ausgesetzt \\
\hline 4 h $15^{\prime} 30^{\prime \prime \prime}$ & 95,0 & 37,5 & \\
\hline $4 \mathrm{~h} 17^{t}$ & 85,0 & 36,3 & \\
\hline $4 \mathrm{~h} 18^{\prime}$ & 105,0 & 43,1 & \\
\hline $4^{\mathrm{h}} 19^{\prime}$ & 96,0 & 46,2 & Amylnitrit 2 Tropfen \\
\hline $4 h 2 l^{\prime}$ & 89,0 & 43,1 & \\
\hline 4 h $22^{\prime}$ & 92,5 & 43,1 & \\
\hline $4^{\text {h. }} 24^{\prime}$ & 140,0 & 43,1 & \\
\hline
\end{tabular}

Fig. 26. Die grossen Zahlen 50, 100, 150 bedeuten den Blutdruck in $\mathrm{mm} \mathrm{Hg}$, die kleineren 10,20 den intraokulären Druck. Auf der Abszisse sind Zeiten vermerkt. 1/4 natürliche Grösse.

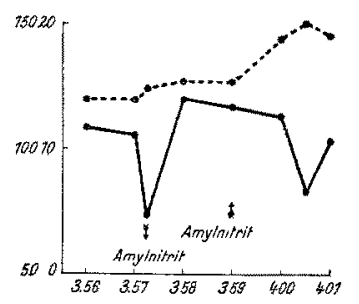

Ergebnis: Steigerung des Augendrucks bei fallendem Blutdruck: Der Kochsalzreiz ist wirksam trotz sinkendem Blutdruck. (Gegensatz zu der Wirkung des Chloralhydrats.) Siehe auch Kurve Nr. 2.

Kaninchen Nr. 55. 2400 g. Curare. Künstliche Atmung. Linke Carotis mit dem Gadsehen Blutwellensehreiber. Rechtes Auge mit dem Wesselyschen Registriermanometer in Verbindung. (Siehe Fig. 27.)

\begin{tabular}{c|c|c|c}
\hline \hline Zeit & $\begin{array}{c}\text { Mittl. Blutdr. } \\
\text { in mm } H g\end{array}$ & $\begin{array}{c}\text { Augendruck } \\
\text { in mm } H g\end{array}$ & Bemerkungen \\
\hline $10^{\circ} 57^{\prime}$ & - & - & 2 ccm Curare subcutan $\left(1^{\circ} \%\right)$ \\
$1^{\circ} 06^{\prime}$ & 120 & - & \\
$1^{\circ} 17^{\prime}$ & 120 & 19,6 & \\
$11^{\circ} 18^{\prime}$ & 120 & 19,6 & \\
$11^{\circ} 19^{\circ}$ & 130 & 19,2 & \\
$11^{\circ} 20^{\circ}$ & 130 & 18,8 & \\
$11^{\circ} 21^{\prime}$ & 120 & 18,4 & Beginn der troptenweisen Zufuhr von \\
$11^{\circ} 21^{\prime} 20^{\prime \prime}$ & 120 & 18,4 & Amylnitrit 10 Tropfen \\
$30^{\prime \prime}$ & 115 & 18,8 & \\
$40^{\prime \prime}$ & 110 & 21,3 & \\
$50^{\prime \prime}$ & 105 & 22,7 & \\
$11^{\circ} 22^{\circ}$ & 105 & 24,0 &
\end{tabular}




\begin{tabular}{|c|c|c|c|}
\hline Zeit & $\begin{array}{l}\text { Mittl. Blutdr. } \\
\text { in } \mathrm{mm} H g\end{array}$ & $\begin{array}{l}\text { Augendruck } \\
\text { in } \mathrm{mm} H g\end{array}$ & Bemerkungen \\
\hline $10^{4}$ & 109 & 24,7 & \\
\hline $20^{\prime \prime}$ & 108 & 26,0 & \\
\hline $30^{\prime \prime}$ & 96 & 26,0 & \\
\hline $40^{4}$ & 96 & 26,0 & \\
\hline $50^{\prime \prime}$ & 94 & 26,0 & \\
\hline $11^{\circ} 23^{\prime}$ & 88 & 25,3 & \\
\hline $10^{\prime \prime}$ & 88 & 24,7 & \\
\hline $20^{\prime \prime}$ & 119 & 27,3 & \\
\hline $30^{4}$ & 95 & 27,3 & \\
\hline $40^{\prime \prime}$ & 93 & 27,3 & \\
\hline $50^{\prime \prime}$ & 86 & 26,0 & \\
\hline $11^{024}$ & 80 & 25,3 & \\
\hline $10^{\prime \prime}$ & 79 & 24,7 & \\
\hline $20^{\prime \prime}$ & 74 & 23,3 & \\
\hline $30^{\prime \prime}$ & 65 & 20,7 & \\
\hline $40^{\prime \prime}$ & 75 & 20,7 & \\
\hline $50^{\prime \prime}$ & 65 & 20,0 & \\
\hline $11^{025}$ & 65 & 18,8 & Amylnitritzufuhr beendet \\
\hline $10^{4}$ & 71 & 18,8 & \\
\hline $20^{\prime \prime}$ & 64 & 18,4 & \\
\hline $30^{\prime \prime}$ & 57 & 18,0 & \\
\hline $40^{\prime \prime}$ & 57 & 18,0 & \\
\hline $50^{\prime 4}$ & 55 & 17,3 & \\
\hline $11^{\circ} 26^{\circ}$ & 56 & 16,8 & \\
\hline $11^{\circ} 27^{\circ}$ & 55 & 16,7 & \\
\hline $11^{0} 28^{\prime}$ & 55 & - & \\
\hline $11^{\circ} 29^{\circ}$ & 55 & 14,8 & \\
\hline $11^{\circ} 30^{\circ}$ & 62 & 14,0 & \\
\hline $11^{\circ} 32^{\prime}$ & 75 & 14,0 & \\
\hline $11^{\circ} 33^{4}$ & 105 & 13,6 & \\
\hline $11^{034^{\circ}}$ & 105 & 14,0 & Amylnitrit 5 Tropfen \\
\hline $20^{\prime}$ & 105 & 14,0 & \\
\hline $30^{\prime \prime}$ & 104 & 14,4 & \\
\hline $40^{\prime \prime}$ & 104 & 14,4 & \\
\hline $50^{s}$ & 87 & 14,8 & \\
\hline $11^{0} 35^{\prime}$ & 82 & 15,0 & \\
\hline $10^{\prime \prime}$ & 76 & 15,2 & \\
\hline $20^{\prime \prime}$ & 85 & 16,0 & \\
\hline $30^{\prime \prime}$ & 76 & 15,6 & \\
\hline $40^{\prime \prime}$ & 70 & 15,6 & Auge reizlos \\
\hline
\end{tabular}

Ergebnis: Erhöhung des intraokularen Drucks bei fallendem Blutdruck.

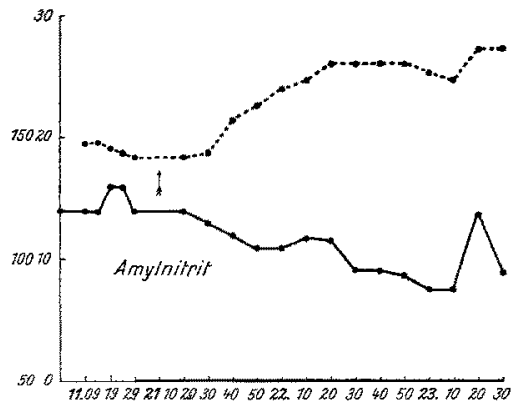

Fig. 27. 1/4 natürliche Grösse. 
Experim. Beiträge zum pathologischen Flüssigkeitswechsel des Auges. 565

Kaninchen Nr. 54. 2920 g. Curare. Künstliche Atmung. Linke Carotis mit dem Gadschen Blutwellenschreiber, rechtes Auge mit dem Wesselyschen Registriermanometer in Verbindung.

\begin{tabular}{|c|c|c|c|}
\hline Zeit & $\begin{array}{c}\text { Mittl. Blutdr. } \\
\text { in } \mathrm{mm} H g\end{array}$ & $\begin{array}{l}\text { Augendruck } \\
\text { in } \mathrm{mm} \mathrm{Hg}\end{array}$ & Bemerkungen \\
\hline $10^{\circ} 30^{\prime}$ & - & - & $2 \mathrm{ccm}$ Curare subcutan $1 \%$ \\
\hline $10^{\circ} 45$ & $\overline{110}$ & - & $0,5 \mathrm{ccm}$ Curare intravenös \\
\hline $10^{\circ} 48^{\prime}$ & 119 & - & \\
\hline $10^{\circ} 52^{\prime}$ & 130 & - & \\
\hline $10^{\circ} 54^{4}$ & 132 & - & \\
\hline $10^{\circ} 56^{\circ}$ & 128 & 27,1 & \\
\hline $11^{\circ} 58^{\circ}$ & 133 & $26, \mathbf{5}$ & \\
\hline $11^{0} 00^{\circ}$ & 135 & 25,8 & \\
\hline $11^{0} 03^{x}$ & 121 & 23,2 & \\
\hline $11^{\circ} 04^{\prime}$ & 122 & 22,6 & \\
\hline $11^{0} 06^{4}$ & 119 & 21,9 & \\
\hline $11^{0006^{\prime} 50^{\prime \prime}}$ & 116 & 21,3 & Amylnitrit 5 Tropfen \\
\hline $11^{\circ} 07^{*}$ & 116 & 21,3 & \\
\hline $10^{14}$ & 118 & 21,9 & \\
\hline $20^{\circ}$ & 116 & 23,2 & \\
\hline $30^{\prime 4}$ & 106 & 23.9 & \\
\hline $40^{64}$ & 109 & 25,2 & \\
\hline $50^{\prime \prime}$ & 160 & 27,7 & \\
\hline $11^{\circ} 08^{\circ}$ & 127 & 26,5 & \\
\hline $10^{\prime \prime}$ & 120 & 26,5 & \\
\hline $20^{\prime \prime}$ & 115 & $.25,8$ & \\
\hline $30^{n}$ & 115 & 25,2 & \\
\hline $11^{\circ} 10^{\prime}$ & 115 & 23,2 & \\
\hline $11^{\circ} 11^{\prime}$ & 117 & 23,2 & \\
\hline $10^{\prime \prime}$ & 115 & 23,9 & Amylnitrit 15 Tropfen \\
\hline $20^{4+}$ & 111 & 25,8 & \\
\hline $25^{\prime \prime}$ & 95 & 25,8 & \\
\hline $30^{\prime \prime}$ & 113 & 27,1 & \\
\hline $40^{\prime \prime}$ & 110 & 27,7 & \\
\hline $50^{\prime \prime}$ & 112 & 24,7 & \\
\hline $11^{\circ} 12^{\prime}$ & 100 & 28,4 & \\
\hline $30^{\circ}$ & 106 & 27,1 & \\
\hline $40^{\prime \prime}$ & 112 & 27,1 & \\
\hline $11^{\circ} 13^{\prime}$ & 109 & 25,8 & \\
\hline $11^{\circ} 14^{\prime \prime}$ & 115 & 24,5 & \\
\hline $30^{\prime \prime}$ & 115 & 23,9 & Amylnitrit 20 Tropfen \\
\hline $11^{\circ} 15^{\prime}$ & 90 & 25,8 & \\
\hline $20^{\prime \prime}$ & 85 & 25,8 & \\
\hline $11^{0} 16^{4}$ & 82 & 23,2 & \\
\hline $50^{\prime \prime}$ & 85 & 21,9 & \\
\hline $11^{0} 18^{\circ}$ & 85 & 20,0 & \\
\hline $11^{\circ} 19^{4}$ & 67 & 20,6 & \\
\hline $50^{\prime \prime}$ & 70 & 19,6 & \\
\hline $11^{\circ} 20^{\circ}$ & 67 & 19,6 & \\
\hline $11^{\circ} 81^{\prime}$ & 71 & 19,4 & $0,5 \mathrm{ccm} 10 \% \mathrm{NaCl}$ subconjunetival \\
\hline $11^{0} 23^{r}$ & 86 & 19,6 & \\
\hline $11^{\circ} 24^{\prime}$ & 90 & 19,2 & \\
\hline $11^{0} 25$ & 101 & 19,6 & \\
\hline $11^{\circ} 27^{\circ}$ & 101 & 20,6 & \\
\hline $11^{\circ} 28^{4}$ & 100 & 23,2 & \\
\hline $11^{\circ} 29^{4}$ & 100 & 24,5 & \\
\hline $11^{\circ} 30^{\circ}$ & 10) & $2 \overline{7}, 1$ & \\
\hline
\end{tabular}




\begin{tabular}{c|c|c|c}
\hline Zeit & $\begin{array}{c}\text { Mittl. Blutdr. } \\
\text { in mm } H g\end{array}$ & $\begin{array}{c}\text { Augendruck } \\
\text { in mm } H g\end{array}$ & Bemerkungen \\
\hline \hline $11^{\circ} 31^{\circ}$ & 100 & 30,5 & \\
$1^{\circ} 31^{\circ}$ & 102 & 32,5 & \\
$1^{\circ} 33^{\circ}$ & 110 & 36,5 & \\
$11^{\circ} 34^{\circ}$ & 115 & 38,2 & \\
$11^{\circ} 37^{\circ}$ & 110 & 40,0 & \\
$11^{\circ} 38^{\circ}$ & 110 & 40,8 & \\
$11^{\circ} 39^{\circ}$ & 110 & 40,8 & \\
$11^{\circ} 40^{\circ}$ & 112 & 42,3 & \\
$11^{\circ} 41^{\circ}$ & 110 & 40,8 & \\
$11^{\circ} 42^{\circ}$ & 110 & 40,0 & \\
$11^{\circ} 45^{\circ}$ & 110 & 40,0 & \\
\hline
\end{tabular}

Ergebnis: Anstieg des Augendrucks nach Amylnitritdarreichung, zuerst bei gleichbleibendem, dann bei sinkendem Blutdruck. Schliesslich ist nach 20 Tropfen Amylnitrit die Blutdrucksenkung so stark, dass infolge "Verblutung" in die Unterleibsgefässe der intraokulare Druck sinkt, der Kochsalzreiz ist aber noch wirksam, im Gegensatz zum Verbalten bei der Senkung des Blutdrucks durch Choralhydrat.

Kaninchen Nr. 68. $2440 \mathrm{~g}$. Curare. Künstliche Atmung, die in das rechte Auge eingefuthrte Hohlnadel mit $10 \%$ iger $\mathrm{NaCl}$-Lösung gefüllt und mit dem Registriermanometer verbunden, linke Carotis an den Blutwellenschreiber angeschlossen.

\begin{tabular}{|c|c|c|c|}
\hline Zeit & $\begin{array}{l}\text { Mittl. Blutdr } \\
\text { in mm } H g\end{array}$ & $\begin{array}{l}\text { Augendruok } \\
\text { in } \operatorname{mm} B g\end{array}$ & Bemerkungen \\
\hline $3^{0} 1 \overline{5}^{\prime}$ & - & - & $2 \mathrm{ccm}$ Curare $1 \%$ subeutan \\
\hline $3^{0} 21^{4}$ & 99,0 & - & e \\
\hline $3^{0} 31^{\prime}$ & - & - & $0,5 \mathrm{ccm}$ Curare intravenös \\
\hline $3^{0} 34^{*}$ & 102,0 & 40,0 & \\
\hline $3^{0} 36^{4}$ & 98,0 & 40,0 & \\
\hline $3^{0} 37^{\prime}$ & 92,0 & 40,0 & \\
\hline $3^{0} 38^{4}$ & 91,0 & 40,0 & \\
\hline $3039^{\prime}$ & 90,0 & 42,2 & \\
\hline $3^{0} 41^{\prime}$ & 91,0 & 43,3 & \\
\hline $3^{*} 41^{\prime} 30^{\prime \prime}$ & 99,0 & 47,8 & \\
\hline $3^{\circ} 43^{\prime}$ & 92,5 & 48,9 & \\
\hline $3^{0} 44^{\prime}$ & 99,0 & 50,0 & \\
\hline $3^{0} 45^{\prime}$ & 96,0 & 51,0 & \\
\hline $3^{0} 46^{\prime}$ & 95,0 & 52,0 & \\
\hline $3^{0} 47^{*}$ & 90,0 & 50,0 & \\
\hline $3^{0} 47^{*} 20^{s}$ & - & - & Amylnitrit 3 Tropfen per inhalationem \\
\hline $40^{\prime \prime}$ & 61,0 & 34,7 & \\
\hline $50^{\prime \prime}$ & 67,0 & 42,2 & \\
\hline $3^{0} 48^{\prime} 30^{\prime \prime}$ & 99,0 & 55,0 & \\
\hline $3^{\circ} 52^{\prime}$ & 98,0 & $\mathbf{5 7 , 0}$ & \\
\hline $3^{0} 53^{\prime} 30^{\prime \prime}$ & 100,0 & 57,0 & Suprarenin. hydrochlor. $0,5 \mathrm{mg}$ intrav. \\
\hline $3^{0} 55^{4}$ & 100,0 & 55,0 & \\
\hline $3^{\circ} 56^{\prime}$ & 102,0 & 52,0 & \\
\hline $3^{0} 57^{\prime}$ & 104,0 & 53,0 & \\
\hline
\end{tabular}


Experim. Beiträge zum pathologischen Flüssigkeitswechsel des Auges. 567

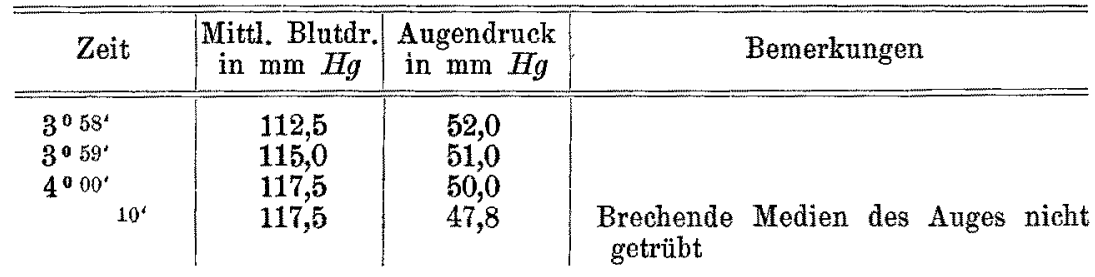

Ergebnis: Infolge der Füllung der in das Auge eingeführten Kanuile mit hypertonischer Kochsalzlösung steigt der Augendruck. Durch die Erweiterung der Hirn-, Haut- und Kranzgefässe wird nach Amylnitriteinatmung den intraokularen, maximal dilatierten Gefässen Blut entzogen und infolgedessen ihr Volumen vermindert; daher Sinken des Augendrucks, ebenso wie nach intravenöser Darreichung von Suprarenin, das die Gefässe verengert. Es hängt also die Art der Wirkung vom Zustand der Gefässe ab, nicht allein von der generellen Wirkung des chemischen Agens.

Kaninchen Nr. 66. 2220 g. Curare. Künstliehe Atmung. Rechtes Auge mit dem Registriermanometer, linke Carotis mit dem Blutwellensehreiber verbunden. Die ins Auge eingeführte Hohlnadel ist mit $20 \%$ iger $\mathrm{NaCl}$-Lösung $\mathrm{g}$ efüllt.

\begin{tabular}{|c|c|c|c|}
\hline Zeit & $\begin{array}{l}\text { Mittl. Blutdr. } \\
\text { in mm } \mathrm{Hg}\end{array}$ & $\begin{array}{l}\text { Augendrack } \\
\text { in } \mathrm{mm} \mathrm{Hg}\end{array}$ & Bemerkungen \\
\hline $10^{\circ} 30^{\circ}$ & - & - & $2 \mathrm{ccm}$ Curare $1 \%$ subcutan \\
\hline $10^{\circ} 41^{\prime}$ & 96 & - & \\
\hline $10^{\circ} 43^{\circ} 30^{\prime \prime}$ & 95 & 31,5 & \\
\hline $10^{\circ} 44^{\prime}$ & 94 & 32,5 & \\
\hline $10^{\circ} \frac{44^{\prime}}{2} 30^{\prime \prime \prime}$ & 94 & 33,5 & \\
\hline $10^{\circ} 45^{\prime} 30^{\prime \prime}$ & 95 & 37,5 & \\
\hline $10^{\circ} 46^{\prime} 30^{\prime \prime}$ & 93 & 39,0 & \\
\hline $10^{0} 47^{\prime} 30^{\prime \prime}$ & 92 & 43,0 & \\
\hline $10^{\circ} \leq 8^{\prime} 30^{\prime \prime}$ & 91 & 44,0 & \\
\hline $10^{\circ} 49^{\prime} 30^{\prime \prime}$ & 90 & 46,0 & \\
\hline $10^{\circ} 51^{\prime}$ & 92 & 46,0 & \\
\hline $10^{\circ} 53^{\prime}$ & 90 & 49,0 & \\
\hline $10^{\circ 5} 6^{\prime}$ & 90 & 49,0 & \\
\hline $12^{\prime \prime}$ & - & - & Amylnitrit 5 Tropfen \\
\hline $30^{.4}$ & 70 & 41,0 & \\
\hline $10^{\circ} 57^{\prime}$ & 71 & 44,0 & \\
\hline $10^{659^{4}}$ & 88 & 47,0 & \\
\hline $11^{001}$ & 81 & 49,0 & \\
\hline $11^{\circ} 04^{\circ}$ & 80 & 47,0 & \\
\hline $11^{\circ} 07^{\circ}$ & 96 & 55,0 & \\
\hline $30^{* 4}$ & - & - & $\begin{array}{l}\text { 0,5 ccm Suprarenin. hydrochloric. } 1 \% \\
\text { subconjunctival }\end{array}$ \\
\hline $11^{0} 08^{*}$ & 93 & 52,8 & \\
\hline $30^{\prime \prime}$ & 89 & 49,0 & \\
\hline $11^{\circ} 10^{\circ}$ & 89 & 46,0 & \\
\hline $11^{\circ} 11^{4}$ & 89 & 44,0 & \\
\hline
\end{tabular}




\begin{tabular}{c|c|c|c}
\hline Zeit & $\begin{array}{c}\text { Mittl. Blutdr. } \\
\text { in mm } H g\end{array}$ & $\begin{array}{c}\text { Augendruck } \\
\text { in mm } H g\end{array}$ & Bemerkungen \\
\hline \hline $11^{\circ} 12^{\prime}$ & 89 & 43,0 & \\
$11^{\circ} 15^{\prime}$ & 88 & 41,0 & $\begin{array}{c}\text { Reine Trübung der brechenden Me- } \\
\text { dien des Auges }\end{array}$
\end{tabular}

Ergebnis: Der Augendruck steigt bei dieser Versuchsanordnung genau so, wie nach subconjunctivalem Kochsalzreiz. Amylnitrit senkt bei maximaler Erweiterung der intraokularen Gefässe den Augendruck; Suprarenin wirkt ebenso. In beiden Fällen wird die Füllung der Augengefässe geringer, im ersten Falle durch Abströmen von Blut in die durch Amylnitrit erweiterten Hirn- und Hautgefässe, im zweiten Falle durch Vasokonstriktion der intraokularen Gefässe.

Zum Vergleich mögen die Versuche dienen, bei denen die Blutdrucksteigerung durch Vergrösserung des Schlagvolumens oder durch eine hauptsächlich im Splanchnicusgebiet auftretende Vasokonstriktion zustande kommt. Hier muss sich natürlich der Augendruck in dem gleichen Sinne ändern wie der Blutdruck. Unter Einverleibung des Coffeins und Strychnins oder durch die Kompression der Bauchaorta werden solche Verhältnisse eintreten kömnen.

Kaninchen Nr. 65. 2870 g. Äthernarkose, sonst Versuchsanordnung wie immer.

\begin{tabular}{|c|c|c|c|}
\hline Zeit & $\begin{array}{l}\text { Mittl. Blutdr. } \\
\text { in mm } H g\end{array}$ & $\begin{array}{l}\text { Augendruck } \\
\text { in } \mathrm{mm} H g\end{array}$ & Bemerkungen \\
\hline $12^{\circ} 32^{\prime} 30^{\prime \prime}$ & 74 & 16,5 & $\begin{array}{l}\text { Laparatomie. Bauchaorta auf eine } \mathrm{Fa}- \\
\text { denschlinge gelegt }\end{array}$ \\
\hline $12^{039^{\prime}} 30^{\prime \prime}$ & $\begin{array}{r}74 \\
110\end{array}$ & $\begin{array}{l}16,5 \\
19,0\end{array}$ & Fadenschlinge angezogen \\
\hline $40^{\prime \prime}$ & 61 & 16,0 & \\
\hline $50^{\prime \prime}$ & 120 & 20,0 & " \\
\hline $\begin{array}{l}12^{0} 34^{\prime} \\
20^{\circ}\end{array}$ & $\begin{array}{r}60 \\
120\end{array}$ & $\begin{array}{l}15,0 \\
20,0\end{array}$ & \\
\hline $40^{\circ}$ & 60 & 17,0 & \\
\hline $12^{\circ} 37^{\prime}$ & 80 & 16,5 & $10 \mathrm{mg} \mathrm{BaCl}_{2}$ intravenös \\
\hline $12^{\circ} 38^{\circ}$ & 110 & 16,0 & \\
\hline $12^{\circ} 39^{\prime}$ & 125 & 18,0 & $30 \mathrm{mg} \mathrm{BaCl}_{2}$ intravenös \\
\hline $12^{\circ} 4 a^{\prime}$ & 119 & 16,5 & \\
\hline $12^{\circ} 42^{t}$ & 115 & $\begin{array}{r}18,0 \\
9,5\end{array}$ & \\
\hline $12^{\circ} 46^{\prime}$ & 101 & 9,5 & \\
\hline
\end{tabular}

Ergebnis: Durch Aortenkompression Steigen, durch $\mathrm{BaCl}_{2}$ Sinken des Augendrucks. Ehe der Augendruck auf den Minimaldruck fällt, ist der Widerstreit der passiven Dehnung der Augengefässe durch Steigerung des allgemeinen Blutdrucks und der intraokularen Vasokonstriktion zu bemerken. 
Experim. Beiträge zum pathologischen Flüssigkeitswechsel des Auges. 569

Kaninchen Nr.62. 2260 g. Curare, sonst Versuchsanordnung wie immer

\begin{tabular}{|c|c|c|c|}
\hline Zeit & $\begin{array}{l}\text { Mittl. Blutdr } \\
\text { in } \mathrm{mm} \mathrm{Hg}\end{array}$ & $\begin{array}{l}\text { Augendruck } \\
\text { in } \mathrm{mm} \mathrm{Hg}\end{array}$ & Bemerkungen \\
\hline $10^{\circ} 09^{\prime}$ & - & - & $2 \mathrm{ccm}$ Curare $1 \%$ subcutan \\
\hline $10^{\circ} 22^{\prime}$ & - & - & $0,5 \mathrm{ccm}$ intravenös \\
\hline $10^{0} 29^{\prime}$ & 85,0 & 25,4 & \\
\hline $10^{\circ} 37^{\circ}$ & 85,0 & 25,4 & \\
\hline $\begin{array}{l}10^{\circ} 38^{\circ} \\
10^{\circ} 39^{\circ}\end{array}$ & $\begin{array}{c}85,0 \\
85-86\end{array}$ & $\begin{array}{l}25,4 \\
26,1\end{array}$ & Strychnin. nitric. $0.3 \mathrm{~cm}$ einer $1 \%$ \\
\hline & & & igen Lösung \\
\hline $30^{\circ}$ & 85,0 & 26,1 & \\
\hline $\begin{array}{l}40^{\prime \prime} \\
50^{\prime \prime}\end{array}$ & 87,0 & 26,5 & \\
\hline $10040^{50^{\circ}}$ & $\begin{array}{l}142,5 \\
150,0\end{array}$ & 29,6 & \\
\hline $10^{0} 40^{\prime} 30^{4}$ & $\begin{array}{l}150,0 \\
127,0\end{array}$ & $\begin{array}{l}30,6 \\
29,2\end{array}$ & \\
\hline $10^{\circ} 41^{\prime}$ & 132,5 & 28,1 & \\
\hline $30^{\prime 4}$ & 130,0 & 26,9 & \\
\hline $10^{\circ} 42^{\prime}$ & 130,0 & 26,1 & \\
\hline $30^{* 4}$ & 130,0 & 25,8 & \\
\hline $10^{\circ} 43^{\prime}$ & 122,0 & 25,4 & \\
\hline $10^{0} 4 \bar{s}^{\prime}$ & 120,0 & 24,6 & \\
\hline $10^{\circ} 46^{4}$ & 120,0 & 22,3 & \\
\hline
\end{tabular}

Ergebnis: Steigen des intraokularen Druckes bei Erhöhung des allgemeinen Blutdrucks, weil dieser hauptsächlich durch $\nabla$ asokonstriktion im Splanchnicusgebiet gesteigert ist.

Kaninchen Nr. 60. 2420 g. Curare. Künstliche Atmung. Registriermanometer. Blutwellenschreiber.

\begin{tabular}{|c|c|c|c|}
\hline Zeit & $\begin{array}{l}\text { Mittl. Blutdr. } \\
\text { in } \mathrm{mm} H g\end{array}$ & $\begin{array}{l}\text { Augendruck } \\
\text { in } \mathrm{mm} H g\end{array}$ & Bemerkungen \\
\hline $10^{\circ} 23^{\prime}$ & 102 & - & \\
\hline $10^{\circ} 25^{\prime}$ & 105 & 21,1 & \\
\hline $30^{*+}$ & 105 & 21,1 & $\begin{array}{l}5 \mathrm{ccm} 0,5 \% \text { ige Coffeinlösung in den } \\
\text { zentralen Stumpf der A. subclar.dextr. }\end{array}$ \\
\hline $50^{\circ}$ & 105 & 21,1 & \\
\hline $11^{\circ} 26^{\prime}$ & 106 & 21,1 & \\
\hline $50^{\prime \prime}$ & $137-138$ & 26,3 & \\
\hline $11^{0} 28^{*}$ & 126 & 21,6 & \\
\hline $11^{0} 32^{\prime} 30^{\prime \prime}$ & 120 & 17,8 & \\
\hline $11^{0} 39^{\circ}$ & $107-108$ & 16,7 & $0.5 \mathrm{ccm} 0.5 \%$ Coffein \\
\hline $11^{\circ} 40^{\prime}$ & 115 & 20,5 & \\
\hline $11^{\circ} 41^{\circ} 50^{\circ}$ & 120 & 17,8 & \\
\hline $11^{04} 3^{\circ}$ & 115 & 17,2 & \\
\hline
\end{tabular}

Ergebnis: Coffein steigert den Blutdruck und damit auch den Augendruck, da die Erhöhung des arteriellen Drucks auf Zunahme des Schlagvolumens des Herzens und Vasokonstriktion im Splanchnicusgebiet $z u$ beziehen ist. Dass auch eine aktive Erweiterung der 
Hirn- und somit auch der Augengefässe durch Coffein hervorgerufen wird (Wiechowski ${ }^{1}$ ) lässt sich in unsern Versuchen nicht feststellen.

Umgekehrt wird der intraokulare Druck mit dem Augendruck absinken müssen, wenn z. B. unter der Einwirkung des Chloralhydrats eine Schwächung des Herzens und Erweiterung der Bauchgefässe statthat. Um Wiederholungen zu vermeiden, sei auf das Protokoll und die Figur S. 591 verwiesen.

Ziehen wir jetzt aus diesen Versuchen die Nutzanwendung auf unsere Resultate mit dem Comaserum, so können wir nunmehr ungezwungen folgende Annahme machen:

Die hypotonisierende Wirkung des Comaserums in einem fremdartigen Organismus lässt sich bis auf weiteres darauf zurückführen, dass infolge der Wirkung der im Serum auftretenden Substanzen der Augendruck ohne wesentliche Änderung des Blutdruckes deshalb absinkt, weil die Blutrerteilung bei den gespritzten Kaninchen eine andere geworden ist, indem durch eine Erweiterung des Splanchnicusgebietes sekundär eine Vasokonstriktion der Haut- und Hirngefässe eintritt.

Eine spezifische Beeinflussung des Auges selbst, seiner sekretorischen Apparate usw, für das Sinken des Augendruckes und das Ausbleiben der Drucksteigerung unter subconjunctivalem Kochsalzreiz nach der intravenösen Einverleibung des Comaserums anzunehmen, ist demnach nicht mehr notwendig ${ }^{2}$ ).

Diese unsere Untersuchungen über die Abhängigkeit des intraokularen Druckes von der arteriellen Blutrerteilung haben für uns drei wichtige Konsequenzen gehabt.

Zunächst erscheint es uns nicht ausgeschlossen, dass die Wirkung des Comaserums, die wir beim Kaninchen als eine Kreislaufwirkung auffassten, auch bei der Hypotonie des Auges im Coma des Menschen eine Rolle spielen könnte. $\mathrm{Ob}$ diese von uns festgestellten Wirkungen oder die von Hertel (loc. cit.) angenommenen osmotischen Änderungen in Wirklichkeit die Druckherabsetzung bedingen, werden erst weitere Versuche lehren müssen. Vielleicht kommen, wie so oft im lebenden

i) Wiechowski, W., Arch. f. experim. Pathol. r. Pharm. Bd. XLVIII. S. 376.1902.

2) Den experimentellen Nachweis, dass das Sinken des Augendrucks nach intravenöser Einverleibung von Comaserum auf Veränderungen der Blutverteilung tatsächlich zurückzuführen ist, kounten wir aus Mangel an Comaserum noch nicht direkt erbringen, hoffen aber, ihn durch onkometrische Versuche noch nachholen za können. 
Experim. Beiträge zum pathologischen Flüssigkeitswechsel des Auges. 571

Organismus unter pathologischen Verhältnissen, beide Mechanismen in Betracht, vielleicht sind auch noch andere Faktoren, die uns vorderhand noch entgehen, dafür massgebend. Es genügt, an dieser Stelle auf die mannigfachen Möglichkeiten für das Zustandekommen der Hypotonie beim menschlichen Coma hingewiesen zu haben.

Die zweite Konsequenz aus unsern Untersuchungen über die Abhängigkeit des intraokularen Druckes von den Gesetzen der Blutverteilung war folgende: Welche abnormen Stoffwechselprodukte im Comaserum nun speziell als Ursache dieser Störung der Blutverteilung anzusehen sind, ob es sich um eine einzige Substanz oder um mehrere handelt, deren Wirkungen sich vielleicht kombinieren, welches die chemische Konstitution derselben ist, ob die Stoffwechselprodukte Eiweissablömmlinge sind oder eine andere Genese haben, alle diese Fragen verdienen es gewiss, weiterhin mit allen Kräften erforscht zu werden.

Aber einer Mühe brauchten wir uns zunächst nicht weiter $\mathrm{zu}$ unterziehen; wir brauchten zunächst nicht die sehr schwierig zu lösende Frage in Angriff nehmen, ob etwa eine unbekannte, nur auf das Auge spezifisch wirksame Substanz für diese Hypotonie in Betracht käme.

Diese Konsequenz legte uns aber drittens den Gedanken nahe, anstatt mit dem schwer zu beschaffenden und immerhin unzuverlässigen Comaserum durch chemisch wohl definierte Substanzen experimentell-therapeutisch den Versuch zu machen, auf dem Wege der Beeinflussung des Kreislaufes die Drucksteigerung im Auge zu verhüten.

In Anbetracht der Wichtigkeit dieser Frage für die Glaukomtherapie schienen uns dahin führende Versuche lohnend genug zu sein.

Da diese Versuche jetzt zu einem gewissen Abschluss gekommen sind, so wollen wir sie im folgenden veröffentlichen und hervorheben, dass sich vielleicht auf diesem Wege ein therapeutischer Erfolg erzielen liesse. Für diese Versuche war es notwendig, experimentell eine Drucksteigerung im Auge hervorzurufen. Wir erwählten dazu die subconjunctivale Injektion hochprozentiger Kochsalzlösung, den Kochsalzreiz, wie er kurz genannt wird. Wir waren uns dabei aber selbstverständlich sehr wohl bewusst, dass diese Drucksteigerung keineswegs mit dem glaukomatösen Druckanstieg in Parallele zu setzen ist. Bei jeder Drucksteigerung im Augeninnern handelt es sich zwar um ein Missverhältnis zwischen Zunahme des Augeninhaltes und dem Abfluss der intraokularen Flüssigkeit. 
Bei der glaukomatösen Drucksteigerung ist nach den herrschenden Ansichten im wesentlichen der Abfluss behindert; bei der durch den Kochsalzreiz hervorgerufenen Drucksteigerung ist nach den Versuchen Wesselys (loc. cit.) der Zufluss anormal vermehrt.

Trotz dieses grundlegenden Unterschiedes mussten wir aber den Kochsalzreiz als drucksteigerndes Mittel anwenden, weil es zurzeit an einer andern bequem anzuwendenden Methode gebricht.

Bevor wir jedoch mit den therapeutischen Versuchen begannen, war es nötig, über den feineren Mechanismus dieser Drucksteigerung ins klare zu kommen.

\section{Teil.}

\section{Mechanismus des durch subconjunctivalen Kochsalzreiz bedingten} intraokularen Druckanstieges.

Wessely (loc. cit.), dem wir auf diesem Gebiete die meisten Untersuchungen verdanken, gelangt auf Grund seiner Experimente zu der Ansicht, dass die Flüssigkeitsvermehrung im Innern des Auges durch eine Transsudation aus den Gefässen bedingt würde, und dass diese Transsudation die Folge einer reaktiven Hyperämie sei, der ein reflektorischer Vorgang infolge des subconjunctivalen Kochsalzreizes zugrunde liege. Wessely verwirft also die Ansicht, dass die hypertonische Kochsalzlösung in das Innere des Auges eindringt, hier als osmotischer oder chemischer Reiz wirkt und dadurch die Mehrabsonderung des zweifellos vermehrten Kammerwassers bedingt.

Als Beweis für seine Anschauungen führt der Autor die Ergebnisse analytischer Versuche an, welche eine prozentuale Vermehrung des Kochsalzes oder vielmehr der Chloride nicht erkennen lassen. Gegen diese Ansicht lässt sich jedoch eine Reihe von Einwänden erheben, die nicht unberechtigt sind. Zunächst ist es ziemlich unwahrscheinlich, dass auf dem Wege des Reflexes die Gefässwandungen so verändert würden, dass nicht allein eine Hyperämie, sondern auch eine Transsudation einer eiweisshaltigen Flüssigkeit, wie sie Wessely im Kammerwasser selbst festgestellt hat, die Folge ist. Wir glauben, dass es in der Pathologie kaum einen Fall gibt, wo dies ohne direkte Wirkung des schädigenden Agens auf die Gefässwandungen möglich wäre.

Der zweite Einwand ist der, dass sehr wohl Kochsalz in das Innere des Auges eingedrungen ist, ohne dass sich die prozentische Zusammensetzung des Kammerwassers geändert hat; denn die Ver- 
Experim. Beiträge zum pathologischen Flüssigkeitswechsel des Anges. 573

mehrung der Flüssigkeitsmenge, die Wessely ja tatsächlich nachgewiesen hat, verhindert eben eine Erhöhung der Konzentration an Chloriden. Anders ausgedrückt: die in das Innere des Auges hineingelangte hypertonische Kochsalzlösung wird durch Flïssigkeitsübertritt aus den Gefässen sofort wieder isotonisch gemacht.

Schliesslich ist aber auch noch der Einwand zulässig, dass bei der einfachen Titration der Chloride durch salpetersaures Silber organisch gebundenes Kochsalz in nicht ionaler Form dem Nachweis entgangen ist.

Um die Richtigkeit der Wesselyschen Ansicht von der reflektorisch bedingten Drucksteigerung nach subconjunctivaler Einspritzung hypertonischer Kochsalzlösung zu prïfen, gingen wir zunächst in der Weise vor, dass wir versuchten, diesen Reflex zu unterdrücken.

Ein Reflex kommt bekanntlich dadurch zustande, dass eine sensible oder sensorische Reizung eine motorische oder sekretorische Ausserung auslöst. Zwischen der sensiblen und motorischen Seite des Reflexes ist der Reflexbogen eingeschaltet, der die Umschaltung vornimmt und die Verbindung der sensiblen und motorischen Bahnen herstellt. Jeder Reflex lässt sich dadurch unterdrücken, dass an irgendeiner Stelle der Reflexbahn die nervöse Leitung unterbrochen wird. Sehr leicht lässt sich dies dadurch bewerkstelligen, dass die sensiblen Endigungen durch lokale Anästhetica ansgeschaltet werden; anästhesiert man beispielsweise die Cornea, so wird der Cornealreflex unterdrückt.

So musste es auch gelingen, durch die Einwirkung lokaler Anästhetica den von Wessely angenommenen Reflex auszuschalten, der durch eine Reizung sensibler Fasern in der Conjunctiva in Gang gesetzt sein sollte.

Die ersten Versuche schienen dies auch in der Tat zu bestätigen; denn indem wir zunächst die Stellen, an der die hypertonische Kochsalzlösung subconjunctival injiziert werden sollte, vorher durch ziemlich konzentrierte Lösungen verschiedener lokaler Anästhetica anästhesierten, wurde der Kochsalzreiz vollkommen oder doch wenigstens teilweise unwirksam.

Sehr bald aber erkannten wir, dass es sich bei der Verwendung starker Lösungen dieser Anästhetica am Auge gar nicht um die Unterdrückung eines Reflexes im Sinne von Wessely, sondern um lokale und allgemeine Wirkungen auf die Gefässe des Auges handelt. Dies wird aus den folgenden Versuchen einwandfrei hervorgehen.

So sehen wir in diesen Versuchen, dass z. B. durch Tropa- 
cocain, $\beta$-Eucain, Alypin, Acoin die Wirkung der subconjunctivalen Kochsalzinjeltion, soweit sie sich auf eine intraokulare Drucksteigerung bezieht, häufig, wenn auch nicht immer, ausgeschaltet werden kann.

Kaninchen Nr. 4. 1800 g. Gewöhnliche Versuchsanordnung.

\begin{tabular}{|c|c|c|c|}
\hline Zeit & $\begin{array}{l}\text { Mittl. Blutdr. } \\
\text { in } \mathrm{mm} H g\end{array}$ & $\begin{array}{l}\text { Augendruck } \\
\text { in } \mathrm{mm} H g\end{array}$ & Bemerkungen \\
\hline $3^{\circ} 28^{\prime}$ & 96,0 & 19,1 & $\begin{array}{l}0,25 \mathrm{ccm} \text { einer } 0,85 \% \text { igen } \mathrm{NaCl} \text {-Lö- } \\
\text { sung subconjunctival }\end{array}$ \\
\hline $3^{\circ} 30^{\circ}$ & 120,0 & 21,1 & \\
\hline $3^{\circ} 32^{4}$ & 110,0 & 21,1 & \\
\hline $3^{0} 33^{2}$ & - & - & $\begin{array}{l}\text { In die subconjunct, Quaddel } 0,25 \mathrm{ccm} \\
\text { einer } 20 \% \text { igen } \mathrm{NaCl} \text {-Lösung }\end{array}$ \\
\hline $\begin{array}{l}3^{0} 34^{4} \\
3^{0} 85^{4}\end{array}$ & $\begin{array}{l}110,0 \\
117,5\end{array}$ & $\begin{array}{l}25,6 \\
30,9\end{array}$ & \\
\hline $3^{\circ} 36^{\circ} 30^{\prime \prime}$ & 110,0 & 36,3 & \\
\hline $3^{0} 38^{4}$ & 109,0 & 41,5 & \\
\hline $3^{\circ} 40^{\prime}$ & 105,0 & 41,5 & \\
\hline $3^{\circ} 41^{\prime}$ & 110,0 & 46,6 & \\
\hline $3^{0} 44^{\prime}$ & 103,5 & 46,6 & \\
\hline $3^{0} 46^{1}$ & 110,0 & 43,1 & \\
\hline $3^{\circ} 48^{4}$ & 107,5 & 40,8 & \\
\hline $3^{0} 50^{4}$ & 101,0 & 34,5 & \\
\hline $3^{0} 53^{4}$ & 100,0 & 30,0 & \\
\hline
\end{tabular}

Ergebnis: Der Versuch zeigt den Druckanstieg im Auge, der hier ebenso eintritt, als wenn von vornherein $0,5 \mathrm{~cm}$ einer $10 \%$ igen Kochsalzlösung inijziert worden wäre. Er bildet die Kontrolle zu den Versuchen, in denen zunächst eine Lösung eines lokalen Anästheticums injiziert wurde und nachher in die anästhetische Quaddel die hypertonische Kochsalzlösung.

Kaninchen Nr, 58. Äthernarkose, sonst Versuchsanordnung wie immer.

\begin{tabular}{|c|c|c|c|}
\hline Zeit & $\begin{array}{l}\text { Mittl. Blutdr. } \\
\text { in. mm } H g\end{array}$ & $\begin{array}{l}\text { Augendruck } \\
\text { in } \mathrm{mm} H g\end{array}$ & Bemerkungen \\
\hline $10^{\circ} 00^{\circ}$ & 121,0 & - & \\
\hline $10^{\circ} 10^{\circ}$ & - & - & $\begin{array}{l}\text { Narkosebeginn mit } 9 \% \text { Äther in der } \\
\text { Einatmungsluft }\end{array}$ \\
\hline $10^{\circ} 13^{\prime}$ & 119,0 & - & \\
\hline $10^{\circ} 10^{\circ}$ & 113,5 & 一 & \\
\hline $10^{0} 17^{\circ}$ & 106,0 & - & \\
\hline $10^{\circ} 18^{\prime}$ & $\overline{10}$ & $\overline{75}$ & \\
\hline $\begin{array}{l}10^{\circ} 20^{\circ} \\
10^{\circ} 21^{*}\end{array}$ & 101,5 & 27,5 & $5 \%$ Tropacocainlösung dauernd in de \\
\hline & & & Conjunctivalsack instilliert \\
\hline $10^{\circ} 22^{\circ}$ & 90,0 & 26,0 & \\
\hline $10^{\circ} 23^{\prime}$ & 87.5 & $\overline{255}$ & \\
\hline $10^{\circ} 24^{\prime}$ & 87,0 & 25,5 & \\
\hline
\end{tabular}


Experim. Beiträge zum pathologischen Flüssigkeitswechsel des Auges. 575

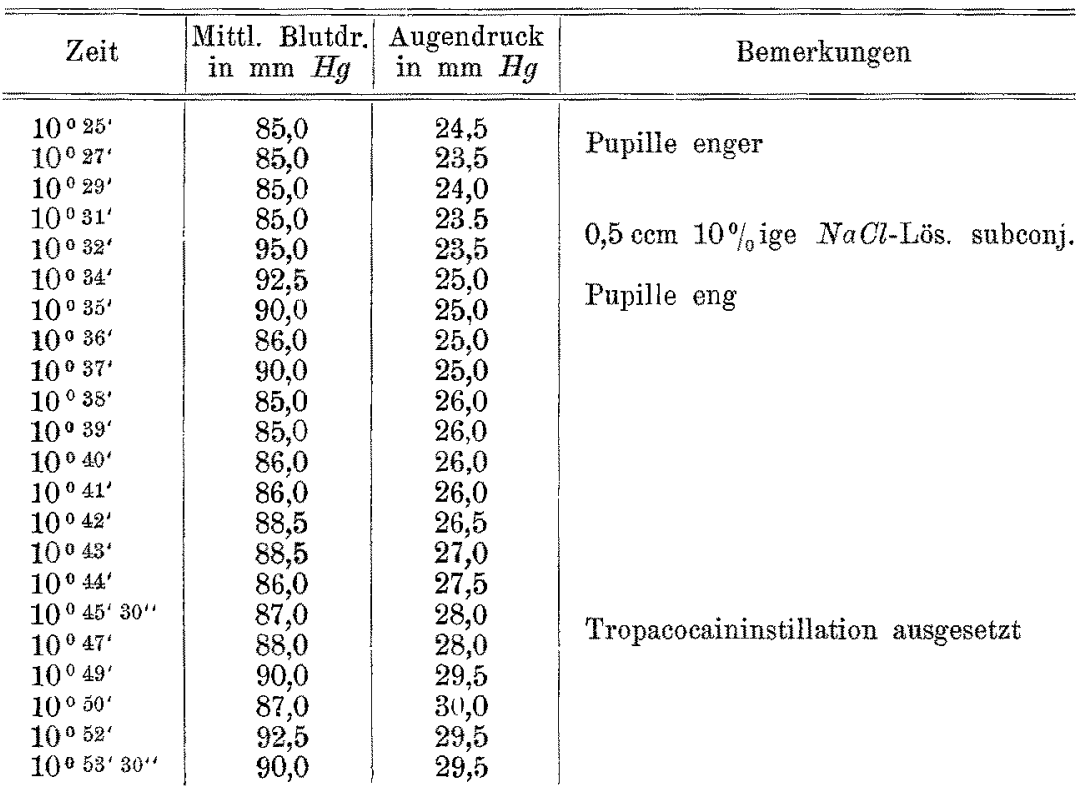

Ergebnis: Tropacocain verhindert bei Instillation in den Bindehautsack den Anstieg des intraokularen Druckes auf subconjunctivalen Kochsalzreiz. Ebenso wie bei dem Alypinversuch (Kaninchen Nr. 77) ist dies auf eine intraokulare Anämie, bzw. Vasokonstriktion zurückzufiihren, die durch eine Vasodilatation im Splanchnicusgebiet bedingt ist und sich durch Sinken des allgemeinen Drucks kund gibt.

Kaninchen Nr. 46. 2350 g. Äthernarkose, sonst Versuchsanordnung wie immer.

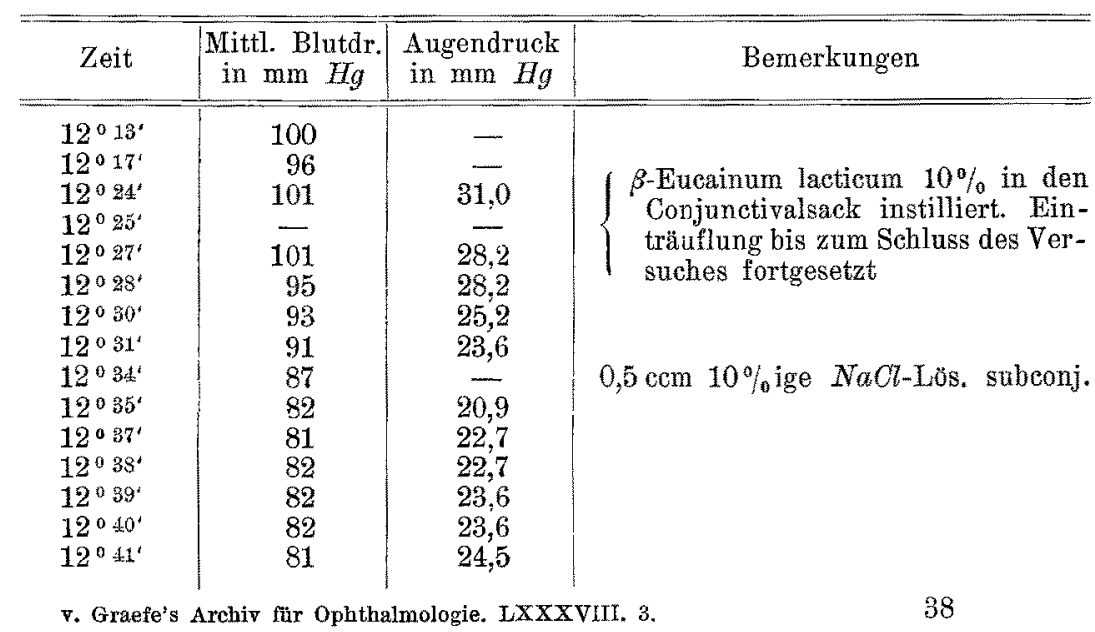




\begin{tabular}{c|c|c|c}
\hline Zeit & $\begin{array}{c}\text { Mittl, Blntdr. } \\
\text { in mm } H g\end{array}$ & $\begin{array}{c}\text { Augendruck } \\
\text { in mm } H g\end{array}$ & Bemerkungen \\
\hline \hline $12^{\circ} 43^{\prime}$ & 79 & 24,5 & \\
$12^{\circ} 44^{\prime}$ & 79 & 24,5 & \\
$12^{\circ} 45^{\prime}$ & 82 & 24,5 & \\
$12^{\circ} 46^{\prime}$ & 81 & 24,5 & \\
$12^{\circ} 47^{\prime}$ & 82 & 24,5 & \\
$12^{\circ} 48^{\prime}$ & 82 & 25,5 & \\
$12^{\circ} 49^{\prime}$ & 80 & 24,5 & \\
$12^{\circ} 50^{\prime}$ & 79 & 23,6 & \\
& & &
\end{tabular}

Ergebnis: Eucain unterdrückt die Wirkungen des subconjunctivalen Kochsalzreizes, aber nicht infolge der Hemmung eines von Wessely angenommenen Reflexes, sondern infolge einer Veränderung der Blutverteilung zwischen Abdomial- and Kopfgefässen, die sich durch ein Sinken des Blutdrucks kennzeichnet.

Kaninchen Nr. 11. 1880 g. Curare. Künstliche Atmung. Versuchsanordnung wie immer.

\begin{tabular}{|c|c|c|c|}
\hline Zeit & $\begin{array}{l}\text { Mittl. Blutdr. } \\
\text { in mm } H g\end{array}$ & $\begin{array}{l}\text { Augendruck } \\
\text { in } \operatorname{mm} \mathrm{Hg}\end{array}$ & Bemerkungen \\
\hline $3^{\circ} 29^{\prime}$ & 101,0 & 19,0 & \\
\hline $3^{0} 30^{t}$ & - & - & $\beta$-Eucain lactic. $10 \% 0,5 \mathrm{ccm}$ subconj. \\
\hline $3^{\circ} 31^{\prime}$ & 96,5 & 17,6 & \\
\hline $3^{0} 32^{*}$ & 90,0 & 16,2 & $\begin{array}{l}\text { In die subconjunctivale Eucainquaddel } \\
0,5 \text { ccm } 20 \% \text { ige } N a C l \text {-Lösung }\end{array}$ \\
\hline $3^{0} 36^{4}$ & 66,0 & 13,4 & \\
\hline $3^{\circ} 44^{\prime}$ & 65,0 & 14,4 & \\
\hline $3^{0} 50^{\prime}$ & 75,0 & 19,0 & \\
\hline $4^{\circ} 05^{\prime}$ & 80,0 & 18,3 & \\
\hline
\end{tabular}

Ergebnis: Der intraokulare Druckanstieg bleibt aus, und zwar infolge cirkulatorischer Veränderungen auf Eucaininjektion und nicht durch Unterdrückung eines Reflexes.

Kaninchen Nr. 13. 2025 g. Curare. Künstliche Atmung, sonst Versuchsanordnung wie immer. Siehe Fig. 28.

\begin{tabular}{|c|c|c|c|}
\hline Zeit & $\begin{array}{l}\text { Mittl. Blutdr. } \\
\text { in } \mathrm{mm} H g\end{array}$ & $\begin{array}{l}\text { Augendruck } \\
\text { in } \mathrm{mm} \mathrm{Hg}\end{array}$ & Bemerkungen \\
\hline $10^{\circ} 45^{\prime}$ & - & - & $\begin{array}{l}2 \mathrm{ccm} \text { Curare } 1 \% \text { subcutan, } 11^{\circ} 5 \mathrm{~S}^{\prime} \\
0,5 \mathrm{ccm} \text { intravenös }\end{array}$ \\
\hline $\begin{array}{l}11^{\circ} 007^{\prime} \\
11^{\circ} 08^{\prime} \\
11^{\circ} 09^{\prime} \\
111^{\circ} 10^{\prime}\end{array}$ & $\begin{array}{l}116,0 \\
115,0 \\
115,0 \\
118,0\end{array}$ & $\begin{array}{l}17,4 \\
16,3 \\
15,5 \\
16,3\end{array}$ & \\
\hline
\end{tabular}


Experim. Beiträge zum pathologischen Flüssigkeitswechsel des Auges. 577

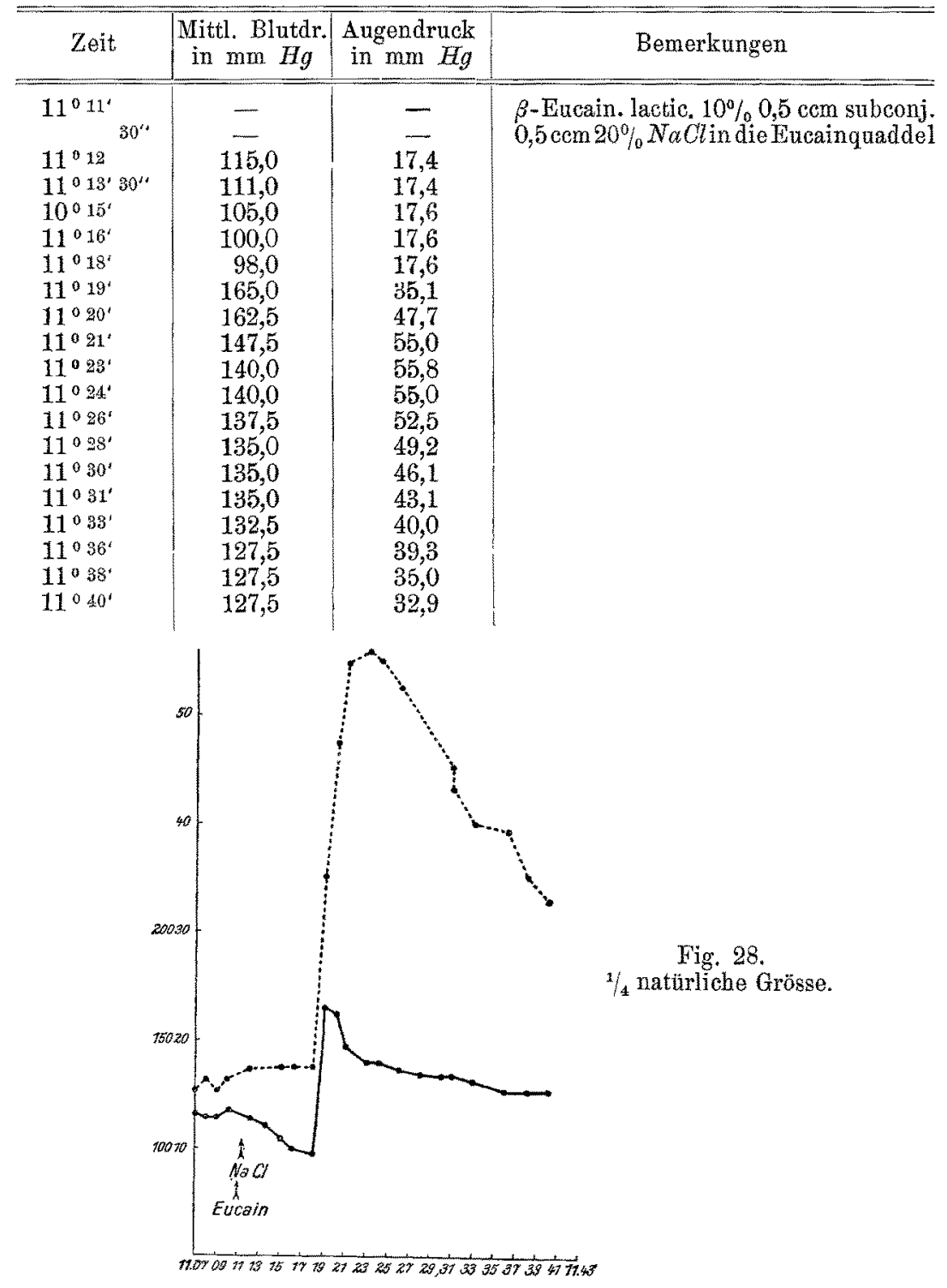

Ergebnis: Der Versuch beweist, dass die Aufhebung des Druckanstieges nach subconjunctivalem Kochsalzreiz durch Eucain nur so lange gelingt, als die Wirkung des Allkaloids anf den Kreislauf anhält. Klingt diese ab, so kommt die Drucksteigerung, natürlich verzögert, zustande.

Kaninchen Nr. 49. $2940 \mathrm{~g}$. Äthernarkose, sonst Versuchsanordnung wie immer. 


\begin{tabular}{|c|c|c|c|}
\hline Zeit & $\begin{array}{l}\text { Mittl. Blutdr. } \\
\text { in mu } H g\end{array}$ & $\begin{array}{l}\text { Augendruck } \\
\text { in } \mathrm{mm} \not \mathrm{Hg}\end{array}$ & Bemerkungen \\
\hline $9^{\circ} 47^{\circ}$ & 95,0 & - & $\begin{array}{l}\text { Äthernarkose mit } 8 \% \text { Ather in der } \\
\text { Inspirationsluft }\end{array}$ \\
\hline $9^{0} 49^{*}$ & 95,0 & - & \\
\hline $9^{\circ} 52^{*}$ & 90,0 & - & $\begin{array}{l}\beta \text {-Eucain. lacticum } 10^{6} \% \text { ins linke } \\
\text { Auge instilliert }\end{array}$ \\
\hline $9^{\circ} 58^{\prime}$ & 92,5 & 一 & $\begin{array}{l}\text { Der in traokulare Druck wird rechts } \\
\text { gemessen }\end{array}$ \\
\hline $9^{\circ} 56^{4}$ & 92,5 & 24,2 & \\
\hline $9^{\circ} 58^{\prime}$ & 87,5 & 23,3 & \\
\hline $9^{\circ} 59^{4}$ & 90,0 & -5 & $0,5 \mathrm{ccm} 10 \% \mathrm{NaCl}$. subconj. rechts \\
\hline $10^{\circ} 01^{\prime}$ & 102,5 & 25,8 & \\
\hline $10^{\circ} 02^{4}$ & 101,0 & 25,8 & \\
\hline $10^{\circ} 03^{\prime}$ & 100,0 & 25,8 & \\
\hline $10^{\circ} 04^{\circ}$ & 99,0 & 25,8 & \\
\hline $10^{\circ} 05^{\prime}$ & 96,0 & 25,8 & \\
\hline $10^{\circ} 06^{\prime}$ & 97,0 & 25,8 & \\
\hline $10^{\circ} 07^{\prime}$ & 98,0 & 24,2 & \\
\hline $10^{\circ} 08^{\prime}$ & 96,0 & 24,2 & \\
\hline $10^{\circ} 09^{\prime-}$ & 96,0 & 23,3 & \\
\hline
\end{tabular}

Ergebnis: Die Drucksteigerung auf subconjunctivalen Kochsalzreiz bleibt auch hier aus, obwohl die Instillation auf dem linken Auge geschieht, und der Reiz rechts appliziert wird. Der Blutdruck zeigt keine grösseren Veränderungen. Der Versuch beweist daher, dass der Kochsalzreiz nicht auf einen Reffexvorgang zurückzufuihren ist, und dass das Ausbleiben der intraokularen Drucksteigerung auf cirkulatorische Einflüsse bezogen werden muss.

Kaninchen Nr. 8. 2200 g. Curare. Künstliche Atmung, sonst gewöhnliche Versuchsanordnung.

\begin{tabular}{|c|c|c|c|}
\hline Zeit & $\begin{array}{l}\text { Mittl. Blutdr. } \\
\text { in } \mathrm{mm} \mathrm{Hg}\end{array}$ & $\begin{array}{l}\text { Augendruck } \\
\text { in } \mathrm{mm} H g\end{array}$ & Bemerkungen \\
\hline $3^{\circ} 30^{\circ}$ & 122,5 & 23,3 & \\
\hline $3^{\circ} 31^{\prime} 30^{44}$ & 115,0 & 21,1 & \\
\hline $3^{0} 33^{\prime}$ & 165,0 & 21,1 & $\begin{array}{l}1 \mathrm{ccm} \text { einer Lösung, die } 5 \% \text { Alypin } \\
\text { und } 10 \% \mathrm{NaCl} \text { enthält subconjunct. }\end{array}$ \\
\hline $3^{034^{\prime}}$ & 160,0 & 21,5 & \\
\hline $3^{0} 36^{\circ}$ & 145,0 & 26,3 & \\
\hline $3^{\circ} 37^{\circ} 30^{\prime \prime}$ & 145,0 & 35,8 & \\
\hline $3^{\circ} 39^{\circ}$ & 132,5 & 42,7 & \\
\hline $3^{0} 41^{\prime}$ & 130,0 & 47,2 & \\
\hline $3^{0} 42^{4} 30^{44}$ & 130,0 & 47,2 & \\
\hline $3^{0} 44^{\circ}$ & 130,0 & 45,6 & \\
\hline $3^{\circ} 46^{\prime}$ & 130,0 & 43,9 & \\
\hline $3^{0} 48^{2}$ & 130,0 & 40,5 & \\
\hline $3^{0} 50^{\circ}$ & 125,0 & 40,5 & \\
\hline $3^{0} 53^{4}$ & 130,0 & 38,1 & \\
\hline $3^{\circ} 55^{4}$ & 130,0 & 36,1 & \\
\hline $3^{\circ} 57^{4}$ & 130,0 & 34,4 & \\
\hline $4^{\circ} 00^{\prime}$ & 130,0 & 33,0 & \\
\hline
\end{tabular}


Experim. Beitrăge zum pathologischen Flüssigkeitswechsel des Auges. 579

\begin{tabular}{c|c|c|c}
\hline \hline Zeit & $\begin{array}{c}\text { Mittl. Blutdr. } \\
\text { in mm } \mathrm{Hg}\end{array}$ & $\begin{array}{c}\text { Augendruck } \\
\text { in mm } \mathrm{Hg}\end{array}$ & Bemerkungen \\
\hline \hline $4^{\circ} 03^{\prime}$ & 127,5 & 33,7 & \\
$4^{\circ} 06^{\circ}$ & 127,5 & 32,2 & \\
$4^{\circ} 15^{\prime}$ & 126,0 & 35,8 & \\
$4^{\circ} 17^{\prime}$ & 120,0 & 31,4 &
\end{tabular}

Ergebnis: Die gleichzeitige subconjunctivale Injektion von Alypin und $10 \%$ iger $\mathrm{NaCl}$-Lösung verhindert nicht den intraokularen Druckanstieg.

Kaninchen Nr. 77. 2430 g. Äthernarkose mit $7 \%$ Äther in der Einatmungsluft. Sonst Versuchsanordnung wie immer.

\begin{tabular}{|c|c|c|c|}
\hline Zeit & $\begin{array}{l}\text { Mittl. Blutdr } \\
\text { in mm } \mathrm{Hg}\end{array}$ & $\begin{array}{l}\text { Augendruck } \\
\text { in } \mathrm{mm} \mathrm{H} H\end{array}$ & Bemerkungen \\
\hline $4^{0} 12^{\prime}$ & 135,0 & - & \\
\hline $\begin{array}{l}4^{\circ} 12^{\prime} 30^{\prime \prime} \\
4^{\circ} 13^{\prime} 30^{\prime \prime}\end{array}$ & $\begin{array}{l}137,5 \\
1350\end{array}$ & $\overline{310}$ & $\begin{array}{l}\text { Dauernd Instillation einer } 10 \% \text { ige } \\
\text { Alypinlösung (in } 0,85 \% \mathrm{NaCl} \text { ) }\end{array}$ \\
\hline $4^{0} 14^{\prime} 30^{\prime \prime}$ & 135,0 & $\begin{array}{l}31,0 \\
28,5\end{array}$ & Cornealreflex negativ \\
\hline $4^{0} 16^{+} 30^{\prime \prime}$ & 127,5 & 25,4 & Auch Kniereflex nicht mehr anslösbar \\
\hline $4^{0} 17^{*} 30^{\prime \prime}$ & 132,5 & 24,6 & \\
\hline $4^{0} 21^{\prime}$ & 120,0 & 23,1 & \\
\hline $4^{0} 23^{\prime}$ & 116,0 & 21,5 & $0,5 \mathrm{ccm} 10 \%$ ige $\mathrm{NaCl}$-Lös. subconj. \\
\hline $4^{0} 24^{\prime} 30^{\prime \prime}$ & 110,0 & 23,1 & \\
\hline $4^{0} 25^{\circ} 30^{\prime \prime}$ & 127,0 & 23,8 & \\
\hline $4.026^{\circ} 30^{\prime}$ & 120,0 & 24,6 & \\
\hline $4^{0} 28^{\circ} 30^{\prime \prime}$ & 120,0 & 25,4 & \\
\hline $4^{0} 29^{\circ}$ & 120,0 & 26,2 & \\
\hline $4^{0} 30^{\circ}$ & 121,0 & 26,2 & \\
\hline $4^{0} 32^{4}$ & 122,5 & 26,2 & \\
\hline $4^{0} 93^{\prime}$ & 117,5 & 26,2 & \\
\hline $4^{0} 34^{\prime}$ & 117,5 & 26,2 & \\
\hline $4^{0} 38^{t}$ & 117,5 & 26,2 & \\
\hline $4^{\circ} 40^{\circ}$ & 115,0 & 25,4 & \\
\hline
\end{tabular}

Ergebnis: Auf Kochsalzreiz tritt beim alypinisierten Auge in Äthernarkose, die an und für sich den Druckanstieg nicht hindert, keine Drucksteigerung ein. Der allgemeine Blutdruck sinkt zwar nach der Alypininjektion, ist aber in absoluten Massen noch hoch. Das Ausbleiben der Drucksteigerung im Auge wurde zunächst auf die Unterdrückung des von Wessely angenommenen Reflexes bezogen, ist aber, wie die andem Versuche zeigen, auf eine relative Anämie der intraokulären Gefässe infolge veränderter Blutverteilung zurückzuführen.

Kaninchen Nr. 44. $2990 \mathrm{~g}$. Äthernarkose mit $8 \%$ Äther in der Inspirationsluft. Sonst die frühere Versuchsanordnung. 


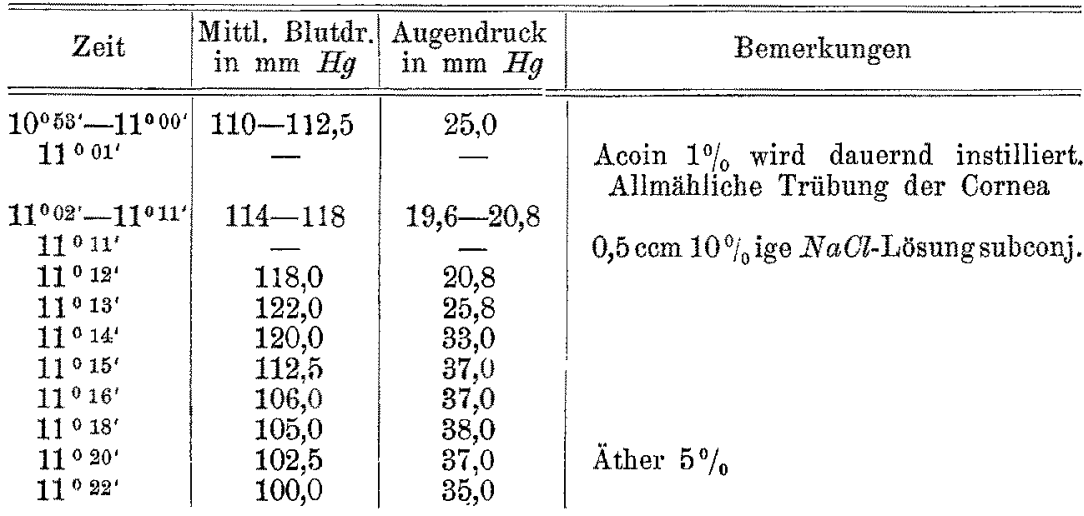

Ergebnis: Trotz einer vollkommenen Anästhesierung mit Acoin ist der Kochsalzreiz wirksam. Der allgemeine Blutdruck zeigt dabei ein nicht sehr erhebliches Absinken, was jedoch die Höhe der intraokulären Drucksteigerung immerhin abschwächend beeinflusst.

Kaninchen Nr. 75. 2260 g. Curare. Künstliche Atmung.

\begin{tabular}{c|c|c|c}
\hline Zeit & $\begin{array}{c}\text { Mittl. Blutdr. } \\
\text { in mm } H g\end{array}$ & $\begin{array}{c}\text { Augendruck } \\
\text { in mm } H g\end{array}$ & Bemerkungen \\
\hline $9^{\circ} 38^{2}-9^{\circ} 43^{\circ}$ & $119-121$ & $18-16$ & \\
$9^{\circ} 43^{\prime} 30^{\circ}$ & - & - & $\begin{array}{c}0,5 \text { ccm einer Lösung von } 10 \% \mathrm{NaCl} \\
+1 \% \text { Acoin }\end{array}$ \\
$9^{\circ} 47^{\prime}$ & 122,5 & 18,0 & \\
$9^{\circ} 48^{\prime}$ & 119,0 & 18,0 & \\
$9^{\circ} 50^{\circ}$ & 105,0 & 19,0 & \\
$9^{\circ} 55^{\circ}$ & 105,0 & $22,1-22,9$ & \\
$10^{\circ} 02^{\prime}$ & 105,0 & 19,0 &
\end{tabular}

Ergebuis: Die Drucksteigerung im Auge nach subconjunctivalem $\mathrm{NaCl}$-Reiz ist nur sehr wenig angedeutet. Doch ist dieses Verhalten auf die durch Acoin bedingten cirkulatorischen Einflüsse zurückzuführen; wahrscheinlich ist die Curaresierung auch nicht unbeteiligt an dem Ausbleiben der intraokularen Drucksteigerung.

Schon manche der vorstehenden Versuche mit Alypin, Eucain und auch Acoin zeigten, dass, wenn die cirkulatorischen Störungen gering waren oder im Laufe des Versuches vorübergingen, der Kochsalzreiz seine Wirkungen entfaltete, obwohl die Anästhesie bestehen blieb. In einwandsfreierer Weise gelang es aber, durch die Anästhesie mit Novocain, das in den zur Verwendung gelangenden Mengen keinerlei Veränderungen am Kreislauf bedingte, aber doch sehr gut anästhesierte, zu zeigen, dass der Kochsalzreiz zur vollen Ausbildung kam. 
Experim. Beiträge zum pathologischen Flüssigkeitswechsel des Auges. 581

Kaninchen Nr. 21. 1680 g. Äthernarkose mit $7 \%$ Äther in der Einatmungsiuft, sonst Versuchsanordnung wie immer.

\begin{tabular}{|c|c|c|c|}
\hline Zeit & $\begin{array}{l}\text { Nittl. Blutdr. } \\
\text { in } \mathrm{mm} H g\end{array}$ & $\begin{array}{l}\text { Augendruck } \\
\text { in } \mathrm{mm} H g\end{array}$ & Bemerkungen \\
\hline $\begin{array}{l}3^{\circ} 21^{*}-3^{0} 30^{4} \\
3^{0} 33^{\prime}\end{array}$ & $\begin{array}{c}150-145 \\
140,0\end{array}$ & 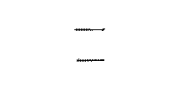 & $\begin{array}{l}\text { Novocaininstillation } 10 \% \text { in den Con- } \\
\text { junctivalsack }\end{array}$ \\
\hline $\begin{array}{l}3^{\circ} 35^{\prime}-3^{\circ} 41^{\prime} \\
3^{0} 41^{\circ}\end{array}$ & $140-141$ & $28,5-27,5$ & $0,5 \mathrm{ccm} 10 \%$ ige $\mathrm{NaCl}$-Lösung subconj. \\
\hline $3^{0} \pm 2^{\prime}$ & 145,0 & 33,0 & \\
\hline $3^{0} 45^{t}$ & 146,0 & 38,9 & \\
\hline $3^{0} 48^{4}$ & 142,5 & 43,3 & \\
\hline $3^{0} 3 z^{\prime}-3^{0} 54^{\prime}$ & 142,5 & 48,1 & Cornea vollkommen klar \\
\hline
\end{tabular}

Ergebnis: Der Kochsalzreiz ist vollkommen wirksam, obwobl durch dauernde Berieselung des Anges mit 10\% Novocain eine vollstäudige Lähmung sämtlicher sensiblen Fasern und Nervenendigungen zu erzielen ist. Blutdruck ist dabei intakt, die brechenden Medien des Auges sind nicht getrübt.

Kaninchen Nr. 6. $2250 \mathrm{~g}$. Curare. Künstliche Atmung. Die übrige Versuchsanordnung wie immer.

\begin{tabular}{|c|c|c|c|}
\hline Zeit & $\begin{array}{l}\text { Nittl. Blutdr. } \\
\text { in mm } H g\end{array}$ & $\begin{array}{l}\text { Augendruck } \\
\text { in } \mathrm{mm} H g\end{array}$ & Bemerkungen \\
\hline $3^{0} 24^{\prime}-3^{0} 95^{\prime}$ & 102,5 & 17,5 & \\
\hline $3^{\text {f }} 25^{\prime} 30^{4}$ & - & & $0,5 \mathrm{ccm} 5 \%$ Novocain subconjunctival \\
\hline $3^{0} \because 6^{\prime}$ & 102,5 & 17,4 & \\
\hline $3^{\circ} 27^{\prime} 30^{4}$ & - & - & $\begin{array}{l}0,5 \mathrm{ccm} 20 \% \mathrm{NaCl} \text { in die Norocain- } \\
\text { quaddel }\end{array}$ \\
\hline $3^{0} 28^{\prime}$ & 162,5 & 18,9 & \\
\hline $3^{\circ} 30^{\prime}$ & 140,0 & 36,0 & \\
\hline $3^{\circ} 36^{\prime}$ & 127,5 & 58,1 & \\
\hline $3^{0} 48^{\prime}$ & 125,0 & 50,6 & \\
\hline
\end{tabular}

Ergebnis: Die durch subconjunctivale Injektion hypertonischer Kochsalzlösung bedingte Drucksteigerung wird durch Novocainisierung nicht verändert. Der Blutdruck ist gesteigert, doch ist der Anstieg des intraokularen Druckes auf $58 \mathrm{~mm} \mathrm{Hg}$ mit der allgemeinen Blutdrucksteigerung nicht in Zusammenhang zu bringen. Der Versuch lehrt ebenso wie der vorige, dass der Kochsalzreiz einen zur intraokulären Drucksteigerung führenden Reflexvorgang nicht auslöst, da Novocain trotz völliger Anästhesierung der sensiblen Apparate die Drucksteigerung nicht verhindert.

Durch diese Versuche war es also bewiesen, dass es sich bei der Drucksteigerung infolge subconjunctivalen Kochsalzreizes nicht um einen reflektorischen Vorgang handeln konnte. Es blieb daher nichts anderes 
übrig, als anzunehmen, dass die hypertonische Kochsalzlösung doch in das Innere des Auges uibertritt und hier entweder als osmotischer oder chemischer Reiz eine vermehrte Flüssigkeitsproduktion hervorruft.

Dass das Eindringen von Kochsalzmengen, welche vorübergehend die Isotonie des Kammerwassers stören, zur intraokularen Drucksteigerung führt, die ganz identisch ist mit dem subconjunctivalen Kochsalzreiz, haben wir dadurch nachgewiesen, dass wir den vordersten Abschnitt des Wesselyschen Registriermanometers, d. h. die in das Auge einzuführende Nadel mit starkprozentigen Kochsalzlösungen anfüllten. Dann diffundieren aus der feinen Offnung der Nadel kleine Mengen der Salzlösungen in das Kammerwasser, und wir sehen sofort den intraokularen Druck steigen, ohne dass es zu einer Salzkatarakt kam, da die Nadelöffnung nach vorn lag und nicht in unmittelbarer Nähe der Linse. Wir haben, wie aus späteren Protokollen noch hervorgehen wird, diese Methode wiederholt angewandt, um schöne und gleichmässige Druckanstiege im Augeninnern zu erhalten. Um jedoch unsere Annahme zu' beweisen, dass auch nach der subconjunctivalen Kochsalzinjektion die hypertonische Kochsalzlösung in das Augeninnere ïbertritt, stellten wir neue analytische Versuche an, indem wir Methoden zum quantitativen Nachweis der Chloride anwandten, die es erlaubten, auch das Chlor in nicht ionaler Form zu bestimmen. Zunächst versuchten wir dies mit Hilfe der mikrochemischen Methode der Chloridbestimmung nach Rogée und Fritsch ${ }^{1}$ ), die uns aber in Übereinstimmung mit J. Bang' ${ }^{2}$ ) nur schwankende Ergebnisse lieferte.

Dagegen konnten wir die Wikromethode J. Bangs ${ }^{3}$ ) mit Vorteil benutzen. Thre Ausführung gestaltet sich folgendermassen:

In ein $25 \mathrm{cem}$ fassendes Kölbchen wird das mittels einer trockenen Rekordspritze entnommene Kammerwaser hineingebracht, aus dem Unterschied des Kölbchengewichtes vor und nach Einbringen des Kammerwassers dessen Menge festgestellt. Nun werden $5 \mathrm{cem}$ einer Lösung von $5 \%$ Magnesiumsulfat und $30 \%$ chlorfreier Salpetersäure kochend heiss hinzugesetzt. Nach $1 / 2$ Stunde werden zu der erkalteten Flüssigkeit ${ }^{1} / 10^{-}$-norm. Silbernitratlösung in bestimmter Menge, sowie nach Umschütteln eine kleine Messerspitze geglähten und chlorfrei gewaschenen Kieselgurs zugesetzt. Das Ganze wird bis zur Marke aufgefüllt und auf ein kleines Faltenfilter gebracht. Von dem wasserklaren Filtrat werden $20 \mathrm{~cm}$ zur Titration genommen, ebenso viel cem einer Kaliumjodidjodatlösung wie $1 / 100^{-n o r m}$. Silbernitratlösung mit einigen Tropfen Stärkekleister zugegeben und ans der

1) Rogée, H., z. Fritsch, G, Biochem. Zeitschr. Bd. LilV. S. 53. 1913.

2) Bang, J., Biochem. Zeitschr. Bd. LVI. S. 158. 1913.

s) Bang, J., Biochem. Zeitschr. Bd. XLIX. S. 19. 1913. 
Menge der noch weiter bis zum Umschlag zuzufügenden Silbernitratlösung, auf die die Kaliumjodidjodatlösung eingestellt ist, die Menge der zur Bildung der Choride sehon verbrauchten Silbernitratlosung jodometrisch bestimmt. Die Titration nach Mohr mit Kaliumehromat als Indikator liefert nach Bangs (loc. cit.) Untersuchungen nicht genügend genaue Ergebnisse.

Nachdem wir uns durch zablreiche Versuchsanalysen ibberzeugt hatten, dass wir die Methode sicher beherrschten, bestimmten wir am Kaninchen den Gehalt des Kammerwassers an Chloriden nach subconjunctivalen Injektionen von $0,5 \mathrm{ccm}$ einer $10 \%$ igen Kochsalzlösung. Die Entnahme des Kammerwassers geschah nach verschieden langer Zeit, die von 5-30 Minuten schwankte. Zur Kontrolle und zum Vergleich analysierten wir immer das Kammerwasser des nicht gereizten Auges. Die folgenden Protokolle geben über diese Versuche Aufschluss.

Übersichtstabelle.

Kochsalz-, bzw. Chlorbestimmung nach subeonjunctivaler Injektion von $0,5 \mathrm{ccm}$ $10 \%$ ige $\mathrm{NaCl}$-Lösung bei normalen Tieren.

\begin{tabular}{|c|c|c|c|c|c|c|c|c|c|}
\hline \multicolumn{2}{|c|}{$\begin{array}{l}\text { Kanin- } \\
\text { chen }\end{array}$} & \multirow{2}{*}{$\begin{array}{l}\text { Entuahme } \\
\text { des } \\
\text { Kammer- } \\
\text { wassers } \\
\text { nach dem } \\
\text { NaCl-Reiz } \\
\text { in Min. }\end{array}$} & \multicolumn{2}{|c|}{$\begin{array}{l}\text { Menge des } \\
\text { Kammer- } \\
\text { wassers in mg }\end{array}$} & \multicolumn{2}{|c|}{$\begin{array}{c}\text { Absolute } \\
\text { Kochsalz- } \\
\text { menge in mg }\end{array}$} & \multicolumn{2}{|c|}{$\begin{array}{l}\text { Kochsalz- } \\
\text { menge auf } \\
\text { loog Kammer- } \\
\text { wasser in mo }\end{array}$} & \multirow{2}{*}{$\begin{array}{l}\text { Kochsalz- } \\
\text { menge des } \\
\text { gereizten } \\
\text { Auges. } \\
\text { Kontrolle } \\
=100\end{array}$} \\
\hline $\mathrm{Nr}$. & $\begin{array}{l}\text { Ge- } \\
\text { wicht }\end{array}$ & & $\begin{array}{l}\text { Kon- } \\
\text { troll- } \\
\text { auge }\end{array}$ & $\begin{array}{l}\text { Ge- } \\
\text { reiztes } \\
\text { Auge }\end{array}$ & $\begin{array}{l}\text { Kon- } \\
\text { troll- } \\
\text { auge }\end{array}$ & $\begin{array}{l}\text { Ge- } \\
\text { reiztes } \\
\text { auge }\end{array}$ & $\begin{array}{l}\text { Kon- } \\
\text { troll- } \\
\text { auge }\end{array}$ & $\begin{array}{l}\text { Ge- } \\
\text { reiztes } \\
\text { Auge }\end{array}$ & \\
\hline 15 & 2380 & 0 & 884 & & 2,23 & & 78 & $777,6^{2}$ & 99 \\
\hline 87 & 23 & & 88 & & 1,94 & & 67 & & \\
\hline 79 & 23 & 10 & 223 & 7 & 1,76 & 1, & 78 & 4 & 11 \\
\hline 39 & $21 \%$ & 10 & 209 & 2 & 1,6 & 1, & 769 & 5 & 10 \\
\hline 17 & 25 ? & 15 & 52 & ه & 1,9 & 1, & 767 & 762.3 & 9 \\
\hline 40 & 226 & & 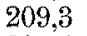 & & 1, & 1, & 73 & 722,3 & \\
\hline 16 & & 2 & 9 & & 1, & 1. & 816 & 898,0 & 10 \\
\hline 7 & 265 & 30 & 336 & 35 & 2,30 & 2,4 & 683,9 & 689,1 & 101 \\
\hline 50 & 2030 & 30 & 180,6 & 255,4 & 1,47 & 1,94 & 809,8 & 758,7 & 94 \\
\hline
\end{tabular}

Wir sehen also, dass der Gehalt des Kammerwassers an Chloriden auch in prozentischer Hinsicht schon nach 5 Minuten erhöt ist, und dass das Kammerwasser erst nach 15 Minuten wieder einen Kochsalzgehalt aufweisen kann, der dem des normalen Auges gleichkommt.

Es war nun interessant - und soll gleich an dieser Stelle auseinander gesetzt werden — zu exfahren, ob sich eine Erhöhung der Konzentration an Chloriden auch nachweisen liess, wenn die Wirkung des Köhsalzreizes durch gewisse Eingriffe unterdrückt worden war. Wie wir später zeigen werden, eignet sich hierza die Finverleibung von Chloralhydrat oder Chloroform sehr gut. Die Versuche wurden also in gleicher Weise wiederholt, nur mit dem Unterschied, dass sie an chloralisierten und chloroformierten Tieren rorgenommen wurden. 
Dieselben ergaben, dass die Chloride des Kammerwassers, trotzdem der Kochsalzreiz scheinbar unwirksam war, eine prozentische Zuna'nme erfahren haben:

Übersichtstabelle.

Kochsalz-, bzw. Chlorbestimmung nach subconjunctivaler Injektion von $0,5 \mathrm{ccm}$ $10 \%$ ige $\mathrm{NaCl}$-Lösung bei chloralisierten Tieren.

\begin{tabular}{|c|c|c|c|c|c|c|c|c|c|}
\hline \multicolumn{2}{|c|}{$\begin{array}{l}\text { Kanin- } \\
\text { chen }\end{array}$} & \multirow{2}{*}{$\begin{array}{l}\text { Entruahme } \\
\text { des } \\
\text { Kammer- } \\
\text { wassers } \\
\text { nach dem } \\
\text { NaCl-Reiz } \\
\text { in Min. }\end{array}$} & \multicolumn{2}{|c|}{$\begin{array}{l}\text { Menge des } \\
\text { Kammer- } \\
\text { wassers in mg }\end{array}$} & \multicolumn{2}{|c|}{$\begin{array}{c}\text { Absolute } \\
\text { Kochsalz- } \\
\text { menge in mg }\end{array}$} & \multicolumn{2}{|c|}{$\begin{array}{c}\text { Kochsalz- } \\
\text { menge auf } \\
100 \mathrm{~g} \text { Kammer- }\end{array}$} & \multirow{2}{*}{$\begin{array}{c}\text { Kochsalz- } \\
\text { menge des } \\
\text { gereizten } \\
\text { Auges. } \\
\text { Kontrolle } \\
=100\end{array}$} \\
\hline $\mathrm{Nr}$ & $\begin{array}{c}\text { Ge- } \\
\text { wicht }\end{array}$ & & $\begin{array}{l}\text { Kon- } \\
\text { troll- } \\
\text { ange }\end{array}$ & $\begin{array}{l}\text { Ge- } \\
\text { reiztes } \\
\text { Auge }\end{array}$ & $\begin{array}{l}\text { Kon- } \\
\text { troll- } \\
\text { ange }\end{array}$ & $\begin{array}{l}\text { Ge- } \\
\text { reiztes } \\
\text { Auge }\end{array}$ & $\begin{array}{l}\text { Kon- } \\
\text { troll- } \\
\text { auge }\end{array}$ & $\begin{array}{l}\text { Gs- } \\
\text { reiztes } \\
\text { Auge }\end{array}$ & \\
\hline 10 & & 5 & & & 1, & 2 & 68 & 2 & \\
\hline 5 & $\left.1790^{1}\right)$ & 5 & 17 & & 1,2 & 1 , & 70 & & \\
\hline 16 & 9740 & 10 & & & 1,4 & & 68 & 10 & 1 \\
\hline 24 & 1 & 10 & 20 & & 1, & 1 , & 625 & 675 & 10 \\
\hline 3 & 32 & 15 & 26 & & & & & 689,2 & \\
\hline & & 1 & & & 1, & & & 770 & \\
\hline 00 & 2250 & 20 & 274,6 & $20, y$ & 1,8 & 1,61 & 678,0 & 675,8 & 100 \\
\hline
\end{tabular}

Wenn wir uns die Frage vorlegen, ob die gefundene Konzentrationserhöhung genügt, um die intraokulare Drucksteigerung zu erklären, so miissen wir folgende Berechnung anstellen: Es sind beispielsweise in dem gereizten Auge auf $100 \mathrm{~g}$ Kammerwasser 67,5 $\mathrm{mg} \mathrm{NaCl}$ mehr gefunden worden als im normalen Kontrollauge. Wenn nach Bellarmin off (cit. nach Leber, in Graefe-Saemisch, Bd. II, S. 207, Leipzig 1913) das Kammerwasser des Kaninchens insgesamt auf $0,28 \mathrm{ccm} \mathrm{zu}$ veranschlagen ist, so würde diese Menge $0,18 \mathrm{mg} \mathrm{mehr}$ Kochsalz enthalten als das Kontrollauge. Um die Isotonie herbeizuführen, bedarf es einer Flüssigkeitsvermehrung von etwa $15-18 \mathrm{cmm}$, die einer Druckzunahme von über $50 \mathrm{~mm} \mathrm{Hg}$ entsprechen würde. $\mathrm{Ob}$ die eben berechneten Kochsalzmengen in vollem Umfange in Betracht kommen, könnte zweifelhaft erscheinen, da wir ohne $Z$ wang annehmen dürfen, dass sie, zum Teil an das ausgeschiedene Eiweiss gebunden, iiberhaupt nicht in ionaler Form rorhanden sind. Wohl könnte dies aber bei den chloralisierten Tieren der Fall sein, bei denen die Vermehrung des Eiweissgehaltes im Kammerwasser sehr gering ist.

Noch auf einem andern Weg liess sich der Nachweis führen, dass hypertonische Salzlösung, deren subconjunctivale Injektion zu der intraokularen Drucksteigerung führt, in das Innere des Auges ein-

1) Intraokulärer Druck mit Hilfe des Schiötzschen Tonometers gemessen beiderseits $21 \mathrm{~mm} H g$.

2) Kontrollauge $23 \mathrm{~mm} H g$, gereiztes Auge $25 \mathrm{~mm} H g$.

3) Kontrollauge $21 \mathrm{~mm} \mathrm{Hg}$, gereiztes Auge $25 \mathrm{~mm} \mathrm{Hg}$. 
Experim. Beiträge zum pathologischen Flüssigkeitswechsel des Auges. 585

dringt, wenn man statt des schwer, nur mit komplizierten Mikromethoden quantitativ bestimmbaren Kochsalzes, die entsprechende Jodverbindung oder andere schon durch qualitative Methoden nachweisbare Körper zur Auslösung der Drucksteigerung benutzt. Auch Wessely') hatte das gleiche Verfahren eingeschlagen, und es war ihm in der Tat auch gelungen, nach subconjunctivaler Injektion von Jodiden Jod im Kammerwasser nachzuweisen. Wir können in dieser Beziehung die Ergebnisse Wesselys bestätigen, ebenso den Befund, dass die Jodide in äquimolekularer Konzentration einen stärkeren Reiz ausiiben wie die analogen Chloride. Wir sind dadurch zu der Annähme genötigt, dass hier neben dem osmotischen Reiz auch ein spezifischer Reiz des Jods auf die Gefässe vorliegt, oder dass das Chlorion eine geringere Wirkung als das Jodion ausübt. Verwendet man salicylsaures Natrium oder Antipyrin in 10\% iger Lösung zu subconjunctivalen Injektionen, so kommt es ebenfalls zu einer gleichen Drucksteigerung wie nach Kochsalzreiz. Mit Hilfe von Eisenchloridlösung liessen sich beide Substanzen mit Leichtigkeit im Kammerwasser nachweisen.

Die stärkere Wirkung des Natriumjodids möge folgende Figur mit Protokollen veranschaulichen.

Kaninchen Nr. 71. $3150 \mathrm{~g}$. Curaresiert, sonst gewöhnliche Versuchsanordnung (siehe Fig. 29).

\begin{tabular}{|c|c|c|c|}
\hline Zeit & $\begin{array}{l}\text { Mittl. Blutdr. } \\
\text { in } \mathrm{mm} H g\end{array}$ & $\begin{array}{l}\text { Augendruck } \\
\text { in } \mathrm{mm} H g\end{array}$ & Bemerkungen \\
\hline $10^{\circ} 35^{\prime}$ & 115,0 & - & \\
\hline $10^{\circ} 37^{\circ} 30^{\prime \prime}$ & 117,5 & 25,0 & \\
\hline $10^{\circ} 39^{4}$ & 120,0 & 24,3 & \\
\hline $10^{0} \mathrm{A1}^{*}$ & 124,0 & 24,3 & \\
\hline $10^{\circ} 42^{*}$ & - & - & $5 \mathrm{~cm}$ Comaserum intravenös \\
\hline $10^{\circ} 42^{\prime} 30^{\prime \prime}$ & 135,0 & 26,4 & \\
\hline $10^{\circ} 43^{\prime}$ & 120,0 & 23,6 & \\
\hline $10^{\circ} 4 \bar{\theta}^{\prime}$ & 117,5 & 19,4 & \\
\hline $10^{\circ} 46^{\prime}$ & 117,5 & 18,1 & \\
\hline $10^{\circ} 47^{\prime}$ & $=$ & - & $0,5 \mathrm{ccm} N \mathrm{NaJ} \quad 12,8 \%$ subconjunctival \\
\hline $10^{\circ} 48^{\circ}$ & 150,0 & 19,4 & \\
\hline $10^{\circ} 49^{\prime}$ & 130,0 & 22,1 & \\
\hline $10^{\circ} 50^{\prime}$ & 130,0 & 26,4 & \\
\hline $10^{0} 51^{\prime} 30^{\prime \prime}$ & 124,0 & 32,7 & \\
\hline $10^{\circ} 53^{\prime}$ & 125,0 & 38,2 & \\
\hline $10^{\circ} 54^{\prime}$ & 125,0 & 43,6 & \\
\hline $10^{\circ} 55^{\prime} 30^{\circ}$ & 124,0 & 45,4 & \\
\hline $10^{\circ} 57^{\prime}$ & 126,5 & 47,2 & \\
\hline $10^{\circ} 59^{\prime}$ & 126,0 & 49,1 & \\
\hline $11^{0} 01^{\prime}$ & 125,0 & 49,1 & \\
\hline $11^{\circ 02^{\prime}}$ & 125,0 & 47,2 & \\
\hline
\end{tabular}

1) Wessely, K., Arch. f. exper. Pathol. u. Pharmakol. Bd. XLIX. S. 6.1903. 


\begin{tabular}{c|c|c|c}
\hline Zeit & $\begin{array}{c}\text { Mittl. Blutar. } \\
\text { in mm } H g\end{array}$ & $\begin{array}{c}\text { Augendruck } \\
\text { in mm } H g\end{array}$ & Bemerkungen \\
\hline $11^{\circ} 03^{\prime} 30^{\prime \prime}$ & 125,0 & 43,2 & \\
$11^{\circ} 05^{\circ}$ & 125,0 & 41,8 & \\
$11^{\circ} 07^{\prime}$ & 125,0 & 36,2 &
\end{tabular}

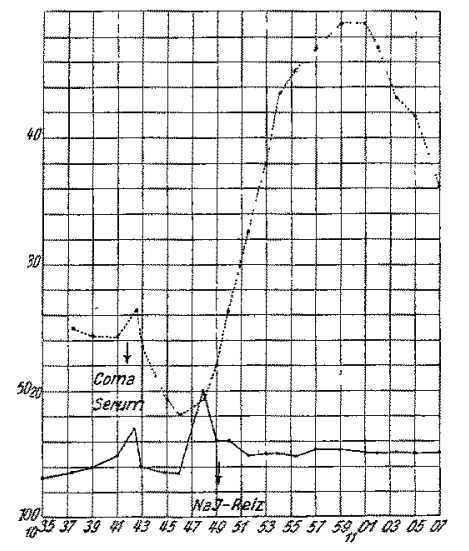

Fig. 29. Kaninchen Nr. 71. Natriumjodid, in einer der $5 \%$ igen $\mathrm{NaCl}$-Lös. äquimolekularen Verdünnung, bedingt ein starkes Ansteigen des Augendrucks. $1 / 4$ der natürlichen Grösse.

Ergebnis: Das nicht sehr wirksame Comaserum lässt den Augendruck etwas sinken, verhindert aber nichtden Druckanstieg durch Natriumjodidlösung, die einer $5 \%$ igen $\mathrm{NaCl}$-Lösung äquimolekular ist. Dieser Druckanstieg soll durch diesen Versuch vor allem dargestellt werden.

In einem andern Versuch, Kaninchen Nr. 70, $3150 \mathrm{~g}$, bleibt der Blutdruck ziemlich gleichmässig, der Augendruck steigt nach $0,5 \mathrm{ccm}$ 25,6\% iger NaJ-Lösung, äquimolekular einer 10\% bei subconjunctivaler Injektion von $20,0 \mathrm{~mm}$ auf $60,0 \mathrm{~mm} \mathrm{Hg}$ innerhalb 15 Minuten, um dann allmählich abzufallen.

Im gereizten Auge liessen sich in $0,3020 \mathrm{~g}$ Kammerwasser durch $0,85 \mathrm{ccm}{ }^{1 /} 100^{-n o r m}$. Thiosulfat $=1,08 \mathrm{mg} J$ nachweisen. Dies entspricht in $100 \mathrm{~g}$ Kammerwasser $357,6 \mathrm{mg} \mathrm{Jod}=410 \mathrm{mg} \mathrm{NaJ}$, die $160,2 \mathrm{mg}$ $\mathrm{NaCl}$ äquivalent ist. Im normalen Auge war Jod nicht nachweisbar.

Durch den Übertritt von Chloriden, Jodiden und anderen Substanzen in höheren Konzentrationen kommt es also zu einer Vermehrung der Flüssigkeit im Innern des Auges. Dass dies nicht ohne Schädigung der Gefässe vor sich geht, erhellt aus der Tatsache, dass sich grössere Mengen Eiweiss im Kammerwasser nachweisen lassen. Ja, es könnte dieser vermehrte Eiweissübertritt in das Kammerwasser direkt als Schutzrealtion des Auges auf diesen Reiz hin angesprochen werden.

Bisher war der quantitative Eiweissnachweis im Kammerwasser durch Fällung mit Esbachschem Reagens geliefert worden; die Trübung, die durch Zusatz des Reagens zum Kammerwasser auftritt, 
Experim. Beiträge zum pathologischen Flüssigkeitswechsel des Auges. 587

wurde mit der Trübung oder dem Niederschlag verglichen, die in Lösungen von bestimmtem Eiweissgehalt vorhanden sind. Gewöhnlich wurde Blutserum als Vergleichsobjekt verwandt, dessen Eiweissgehalt etwa $8-10 \%$ beträgt.

Wessely') konnte mit Hilfe dieser Methode zeigen, dass im normalen Kammerwasser nur Spuren von Eiweiss $(0,02 \%)$ vorhanden sind, dass dagegen nach dem subconjunctivalen Kochsalzreiz grössere Mengen auftreten, deren Maximum ungefähr 12 Minuten nach dem Kochsalzreiz erreicht war, um nach $\left.{ }^{3}\right|_{4}$ Stunden wieder allmählich abzunehmen; aber selbst nach fünf Stunden war der Gehalt noch vermehrt.

Wir priften auch diese Versuche Wesselys allerdings mit einer andern Methode nach, deren Anwendung sich vielleicht auch sonst in der Augenheilkunde von Nutzen erweisen wird. Wir gingen in der Weise vor, dass wir nicht das Eiweiss als solches, sondern den Stickstoff nach der Mikromethode von J. Bang ${ }^{2}$ ) bestimmten, die wir allerdings in wesentlichen Punkten abänderten.

Es zeigte sich, dass auch im Normalauge mehr Stickstoff rorhanden ist als dem Eiweiss entsprechen könnte. In der Tat wird ja dabei auch gleichzeitig der nicht an Eiweiss gebundene Stickstoff bestimmt, der wohl zum grössten Teil als Harnstoff vorhanden ist. Wie eine grosse Anzahl von Kontrollanalysen zeigte, variiert dieser Stickstoffanteil nur in verhältnismässig engen Grenzen.

Wenn nun der Stickstoffgehalt des Kammerwassers des gereizten und nicht gereizten Auges miteinander verglichen wird, so wird man das Plus im gereizten Auge als Eiweissstickstoff ansprechen dïrfen. Durch Multiplikation der Differenzzahl mit 6,25 kann man so den Zuwachs von Eiweiss im gereizten Auge nach subconjunctivalen Kochsalzinjektionen feststellen. Wir glauben, dass diese Methode, die zwar nicht das Eiweiss direkt bestimmt, doch genanere Werte gibt, als die nur auf Schätzung beruhende Bestimmung mit Hilfe des Esbachschen Reagenses, auf deren Ungenauigkeit durch die systematischen Untersuchungen von Hugo Schulzis hingewiesen wurde.

Die Technik der Mikro-Kjeldah Imethode ist folgende ${ }^{4}$ ):

In ein $50 \mathrm{cem}$ fassendes $\mathrm{Kjeldahlkölbchen} \mathrm{wird} \mathrm{das} \mathrm{durch} \mathrm{vorsichtige}$ Punktion gewonnene Kammerwasser hineingespritzt. Durch Wägung des

1) Wessely, K., Inang.-Diss. Heidelberg.

2) Bang, J., u. Larsson, K. O., Biochem. Zt. Bd. LI. S. 193. 1913.

s) Schulz, H., Deutsche med. Wochensehr. Bd. XXXII. S. 558. 1886.

$\left.{ }^{4}\right)$ Die Abänderungen des Mikrokjeldahls und Beleganalysen sind von M. Kochmann, Biochem. Zt. Bd., LXIII, S. 479, 1914, veröffentlicht. 
Kölbchens vor und nach der Beschickung mit dem Kammerwasser wird die zur Analyse verwandte Menge ermittelt. Zerstörung der organisehen Substanz und Überführen des Stickstoffes in schwefelsaures Ammonium dureh Erhitzen mit $1,5 \mathrm{ccm}$ konzentrierter Schwefelsäure unter Zusatz von vier Tropfen $10^{\circ} /{ }_{0}$ gger Kupfersulfatlösung und eines hirsekorngrossen Krystalles von Kaliumsulfat. Sollte vom Kammerwasser etwas am Halse des Kölbchens hängen geblieben sein, so wird dies mit destilliertem Wasser in den Kolben hineingespültt. Nach völliger Zerstörung abkühlen lassen. Zusatz von $10 \mathrm{ccm}$ destilliertern Wasser, Abkühlen unter dem Wasserhahn, Zugabe von $10 \mathrm{~cm}$ $25 \%$ ige Kalilauge (nicht Natronlange!), wiederum Abkühlen unter dem Wasserhahn und erneute Zugabe von $10 \mathrm{ccm}$ der Lauge. Zum Überdestillieren des Ammoniaks wird nunmehr das Köbohen sehnell an den Destillationsapparat angesetzt, der aus dem kleinen Kupferkühler mit Quarzrohr bestelt, das auf der einen Seite durch einen Gummischlanch mit einem etwa $40 \mathrm{~cm}$ langen Hartglasrohr von $3-4 \mathrm{~mm}$ lichter Weite verbunden ist. Dieses trägt einen durchbohrten Gummistopfen, der fest auf das Kolbchen aufgesetzt wird. Das andere Ende des sehräg abgesehliffenen Quarzrohres reicht bis dicht über den Flüssigkeitsspiegel eines kleinen Becherglases von $25 \mathrm{ccm}$ Inhalt, indem sich $10 \mathrm{ccm}{ }^{1 / 100}$-norm. Salzsäure befinden. Die nicht dureh das überdestillierte Ammoniak gebundene Salzsäure wird durch ${ }^{1} / 100^{-n o r m . ~ N a t r o n-~}$ lauge unter Verwendung von Cochenilletinktur als Indikator und Büretten mit $1 / 20$ ccm Teilung zurücktitriert. Da die Cochenilletinktur selbst aber eine schwache Säure ist, die auf $0,05 \mathrm{ccm}$ bei unserem Präparat $0,1 \mathrm{~cm} 1 / 100^{- \text {norm. }}$ $\mathrm{NaOH}$ gebraucht, so muss der Indikator in genau zugemessener Menge zugesetzt und bei der Titration in Rechnung gestellt werden. Verfäbrt man aber wie angegeben, so ist die umständliche und sicherlich schwierigere jodometrische Messung J. Bangs unnötig.

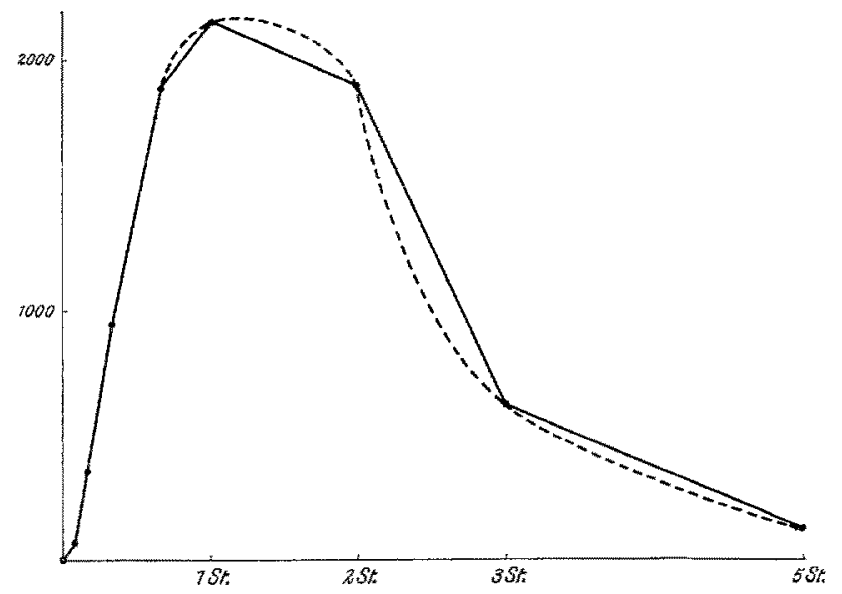

Fig 30. Die ausgezogenen Linien sind die Verbindungen der analytisch festgelegten Punkte, um die sich die gestrichelte Kurve als Verlauf der Eiweisstranssudation ins Kammerwasser zeichnen lässt. Die Zahlen am Rande bedeuten mg Eiweiss. $1 / 4$ natürliche Grösse.

Aus den Analysen ergibt sich die Genauigkeit der Methode: 
Experim. Beiträge zum pathologischen Flässigkeitswechsel des Auges. 589

Übersichtstabolle

über die $N$-Bestimmung im Kammerwasser bei normalen Kaninchen nach subconjunetivaler Injelktion von $0,5 \mathrm{ccm} 10 \%$ iger Kochsalzlösung (siche Figur 30).

\begin{tabular}{|c|c|c|c|c|c|c|c|c|c|c|}
\hline \multicolumn{2}{|c|}{$\begin{array}{l}\text { Kanin- } \\
\text { chen }\end{array}$} & \multirow{2}{*}{ 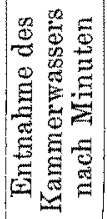 } & \multirow{2}{*}{\multicolumn{2}{|c|}{\begin{tabular}{|c|c|}
\multicolumn{2}{|c|}{ Menge des } \\
Kammer- \\
wassers in $g$ \\
Kon- \\
troll- & Ge- \\
auge & Auges \\
\end{tabular}}} & \multicolumn{2}{|c|}{$\begin{array}{l}N \text { - Gehalt } \\
\text { in } \mathrm{mg}\end{array}$} & \multicolumn{2}{|c|}{$\begin{array}{c}\text { In } 100 \mathrm{~g} \text { Kam- } \\
\text { merwasser } \\
N \text {-Gehalt }\end{array}$} & \multicolumn{2}{|c|}{$\begin{array}{l}\text { Differenz zwischen dem } \\
N \text {-Gehalt beider Augen }\end{array}$} \\
\hline $\mathrm{Nr}$. & $\begin{array}{c}\text { Ge- } \\
\text { wicht }\end{array}$ & & & & $\begin{array}{l}\text { Kon- } \\
\text { troll- } \\
\text { auge }\end{array}$ & $\begin{array}{c}\text { Ge- } \\
\text { reiztes } \\
\text { Auge }\end{array}$ & $\begin{array}{c}\text { Kon- } \\
\text { troll- } \\
\text { auge }\end{array}$ & $\mid$\begin{tabular}{c|} 
Ge- \\
reiztes \\
Auge
\end{tabular} & $N$ in $\mathrm{mg}$ & $\begin{array}{l}\text { auf } \mathrm{mg} \\
\text { Eiweiss }\end{array}$ \\
\hline 1 & & 0 & & & & & & & & \\
\hline 2 & & 5 & & & & & & 81 & & \\
\hline 3 & & 5 & & & & & & 85 & 18 & 70 \\
\hline 4 & & 5 & & & & & 41 & 48 & 6 & \\
\hline 5 & & 10 & & & & & 51 & 109,06 & 57.99 & 36 \\
\hline 6 & & & & & & & & & & \\
\hline 7 & & & & & & & 45 & & & 18 \\
\hline 8 & & 6 & & & & & 49 & 40 & & $2230_{1}$ \\
\hline 9 & & & & & & & & & & $00=5$ \\
\hline & & & & & & & & & & 1901 \\
\hline & & & & & & & & & & 627 \\
\hline & & & & & & & & & & \\
\hline & 1900 & & & & & & & 15 & & 133 \\
\hline
\end{tabular}

Mittlerer $N$-Gehalt sämtlicher normalen Angen $50,66 \mathrm{mg} N$ in $100 \mathrm{~g}$ Kammerwasser, was einem Harnstoffgehalt von $0,1086 \mathrm{~g}$ entspräche. Es wäre interessant, dureh einen Vergleich des nicht an Eiweiss gebundenen Blatstickstoffs und dem $N$-Gehalt des Kammerwassers Aufschluss darüber $z u$ erhalten, ob beide einen. gleichen Wert aufweisen.

Aus den quantitativen Bestimmungen folgt, dass wir die Angaben Wesselys über den Eiweissgehalt des Kammerwassers nach" subconjunctivalen Kochsalzreizen nicht vollkommen bestätigen können; denn der Eiweissgehalt des Kammerwassers nach subconjunctivaler Kochsalzinjektion ist schon nach fünf Minuten deutlich rermehrt, und das Maximum erst nach etwa einer Stunde erreicht, um dann allmählich bis zur Norm abzusinken, die ungefähr nach fünf Stunden wieder erlangt ist.

Das Maximum des Eiweissgehaltes im Kammerwasser nach subconjunctivalem Kochsalzreiz fällt also keineswegs mit dem Gipfelpunkt des intraokularen Druckanstieges zusammen, da der letztere etwa schon nach 10-13 Minuten erreicht ist.

Dieses Verhalten lässt sich nur so erklären, dass die direkte Scbädigung durch die Salzlösung eine so erhebliche gewesen ist, dass bis nach einer Stunde dauernd Eiweiss, welches nur schwer wieder weggeschafft werden kann, durch die Gefässe hindurchtritt und sich infolgedessen anreichert.

Würde nach der Annahme Wesselys die Drucksteigerung auf 
einen reflektorischen Vorgang zurïckzuführen sein, so würde das Erreichen des Gipfelpunktes des Druckanstieges und des Eiweissgehaltes zu verschiedenen Zeiten kaum zu erklären sein. Darum sprechen auch die Ergebnisse der quantitativen Eiweissbestimmung für die direkte Einwirkung der Salzlösung auf die Gefässe und das Eindringen in den Bulbus selbst.

Viel schwieriger ist eine Erklärung dafür zu gewinnen, dass die Drucksteigerung eigentlich schon nach ganz kurzer Zeit zurückgeht, obwohl nach den Untersuchungen Wesselys, die wir bestätigen können, in der subconjunctivalen Quaddel noch nach längerer Zeit eine Hypertonie der ausgepressten Gewebsflüssigkeit nachzuweisen ist.

Entweder kann die konzentrierte Salzlösung nicht mohr in das Bulbusinnere hineindringen - und man könnte daran denken, dass infolge des Eiweissgehaltes die vermehrte Viskosität eine Behinderung darstellt - oder aber das subconjunctival injizierte Salz tritt auch weiterhin in das Kammerwasser über, wird aber durch einen vermehrten Flüssigkeitsstrom schnell bis zur Isotonie verdünnt. Dann muss man aber die weitere Annahme machen, dass diesem vermehrten Flüssigkeitsstrom aus den Gefässen ein noch grösserer Abfluss aus dem Auge gegenübersteht, so dass der Bulbusinhalt und mithin der Druck auf die Norm zurückgehen können, und dass nach Erreichen dieses Zieles der Abfluss der vermehrten Flüssigkeitsproduktion die Wage hält.

Welche von diesen Möglichkeiten - vielleicht lassen sich noch andere ausfindig machen - in Wirklichkeit in Betracht kommt, lässt sich zurzeit wohl mit Sicherheit nicht entscheiden.

Die zweite Annahme würde jedenfalls zur Folge haben, dass der Flüssigkeitswechsel des Auges nach subconjunctivaler Kochsalzinjektion auch über die Zeit der Drucksteigerung hinaus erheblich gesteigert wäre, was für die therapeutische Bedeutung des subconjunctivalen Kochsalzreizes von grösster Wichtigkeit wäre.

\section{Teil.}

Aufhebung der intraokularen Drucksteigerung nach subconjunctivalem Kochsalzreiz durch therapeutische Massnahmen vom allgemeinen Kreislauf aus.

Nachdem wir so das Zustandekommen der Drucksteigerung nach subconjunctivalem Kochsalzreiz erklärt haben, können wir dazu übergehen, die experimentell-therapeutischen Versuche mitzuteilen, welche 
Experim. Beiträge zum pathologischen Flüssigkeitswechsel des Auges. 591 die Aufgabe hatten, die intraokulare Drucksteigerung nach Kochsalz $\mathrm{zu}$. unterdrüicken.

Dass dies durch lokale Applikation von Adrenalin gelingt, ist bekannt. Auch die intravenöse Darreichung des Adrenalins liess die Drucksteigerung wesentlich geringer ausfallen. In unsern Versuchen an chloralisierten und chloroformierten Tieren ist aber nicht das Auge und seine Gefässe der primäre Angriffspunkt des therapeutischen Eingriffes, sondern das Auge und seine Gefässe werden erst sekundär in Mitleidenschaft gezogen.

Kaninchen Nr. 85. 1690 g. Curare. Künstliche Atmung, sonst die gewöhnliche Versuchsanordnung. Siehe Fig. 31.

\begin{tabular}{|c|c|c|c|}
\hline Zeit & $\begin{array}{l}\text { Mittl. Blutdr. } \\
\text { in } \mathrm{mm} H g\end{array}$ & $\begin{array}{l}\text { Augendruck } \\
\text { in } \mathrm{mm} H g\end{array}$ & Bemerkungen \\
\hline $12^{\circ} 33^{\prime}$ & 107,5 & 20,0 & \\
\hline $12^{\circ} 34^{*}$ & 107,5 & 19,4 & \\
\hline $12^{\circ} 36^{\prime}$ & 110,0 & 19,0 & \\
\hline $12^{0} 37^{\prime}$ & 134,0 & 20,0 & $\begin{array}{l}0,5 \mathrm{ccm} \text { Chloralhydrat } 10 \% \text { intravenös } \\
=0,05 \mathrm{~g}\end{array}$ \\
\hline $12^{\circ} 88^{\prime}$ & 107,5 & 18,9 & \\
\hline $12^{\circ} 39^{\prime}$ & 110,0 & 17,6 & $0,1 \mathrm{~g}$ Chloralhydrat \\
\hline $12040^{\circ}$ & 82,5 & 17,6 & \\
\hline $12^{\circ} 41^{\prime}$ & 70,0 & 16,5 & \\
\hline $12^{\circ} 43^{\prime}$ & 62,5 & 16,5 & $0,1 \mathrm{~g}$ Chloralhydrat \\
\hline $12^{\circ} 44^{\prime}$ & 65,0 & 15,3 & \\
\hline $12^{\circ} 45^{\prime}$ & 67,0 & 14,7 & $1 \mathrm{ccm} \mathrm{NaCl} 10 \%$ ig. subconjunctival \\
\hline $12^{\circ} 46^{2}$ & 85,0 & 14,1 & $0,1 \mathrm{~g}$ Chlorallhydrat \\
\hline $12^{\circ} 47^{\prime}$ & 75,0 & 15,3 & \\
\hline $12^{\circ} 48^{\prime}$ & 80,0 & 15,5 & $0,1 \mathrm{~g}$ Chloralhydrat \\
\hline $12^{\circ} 49^{\prime}$ & 62,5 & 14,1 & \\
\hline $12^{0} 50^{\circ}$ & 60,0 & 13,5 & \\
\hline $12^{\circ} 51^{\prime}$ & 60,0 & 12,9 & Pupille gan $z$ eng \\
\hline $12^{0} 54^{t}$ & 60,0 & 12,9 & \\
\hline $12^{\circ} 55^{\prime}$ & 65,5 & 12,9 & \\
\hline $12^{\circ} 56^{\prime} 30^{\prime \prime}$ & 68,5 & 14,1 & \\
\hline $12^{\circ} 59^{\prime}$ & 73,0 & 15,9 & \\
\hline $1^{\circ} 01^{\prime}$ & 61,0 & 14,1 & \\
\hline $1^{0} 03^{\circ}$ & $6 i, 0$ & 15,3 & \\
\hline $1^{0} 0 \vec{s}^{t}$ & 67,0 & 15,9 & \\
\hline $1^{0} 06^{\prime}$ & 66,0 & 15,3 & \\
\hline $1^{0} 08^{\circ}$ & 66,0 & 15,3 & \\
\hline \multicolumn{4}{|c|}{$\begin{array}{l}\text { Fig. 31. Taninchen Nr. 85. Chloral- } \\
\text { bydrat lässt den Augendruck sinken } \\
\text { und verhütet den durch Kochsalzreiz } \\
\text { bedingten Anstieg des intraokularen } \\
\text { Druckes. }\end{array}$} \\
\hline
\end{tabular}

v. Graefe's Archiv fūr Ophthalmologie. IXXXviII. 3. 
Ergebnis: Chloralhydrat hebt durch seine Wirkung auf den Kreislauf, Schädigung des Herzens und Erweiterung der Splanchnicusgefässe mit Verengerung der Hirngefässe, den Einfluss des subconjunctivalen Kochsalzreizes auf, indem es den intraokularen Druckanstieg nicht zustande kommen lässt.

Kaninchen Nr. 96. 2010 g. Chloralhydratnarkose, sonst gewöhnliche Versuchsanordnung.

\begin{tabular}{|c|c|c|c|}
\hline Zeit & $\begin{array}{l}\text { Mittl. Blutdr. } \\
\text { in mm } H g\end{array}$ & $\begin{array}{l}\text { Augendruck } \\
\text { in } \mathrm{mm} H g\end{array}$ & Bemerkungen \\
\hline $9^{\circ} 3$ & - & - & $\begin{array}{l}\text { Chloralhydrat } 15 \mathrm{ccm} 10 \% \text { ige Lösung } \\
=1,5 \mathrm{~g} \text { per os }\end{array}$ \\
\hline $\begin{array}{c}10^{\circ} 39^{\prime}-10^{0} 48^{\prime} \\
10^{\circ} 44^{\prime} \text { bis } \\
10^{\circ} 47^{\prime} 30^{\prime \prime}\end{array}$ & $\begin{array}{l}57,5-55,0 \\
59,0-71,0\end{array}$ & $\begin{array}{c}18,75 \\
18,75-19,0\end{array}$ & $1 \mathrm{ccm} 10 \% \mathrm{NaCl}$ subconjunctiral \\
\hline $\begin{array}{c}10^{\circ} 45^{\prime} \\
10^{\circ} 49^{\prime} 30^{\prime \prime} \text { bis }\end{array}$ & $61,0-71,0$ & $17,25-17,75$ & Pupille eng \\
\hline $\begin{array}{c}10^{\circ} 54^{\prime} \\
10^{\circ} 56^{\circ}-11^{011^{*}}\end{array}$ & $70,0-61,0$ & $17,75-16,75$ & \\
\hline
\end{tabular}

Ergebnis: Chloralhydrat hindert durch seine Wirkung auf die Blutverteilung den intraokularen Druckanstieg nach subconjunctivalem Kochsalzreiz.

Kaninchen Nr. 92. $1470 \mathrm{~g}$. Chloroformnarkose, sonst die übliche Anordnung.

\begin{tabular}{|c|c|c|c|}
\hline Zeit & $\begin{array}{c}\text { Mittl. Blutdr. } \\
\text { in } \mathrm{mm} \mathrm{Hg}\end{array}$ & $\begin{array}{l}\text { Augendruck } \\
\text { in mm } H g\end{array}$ & Bemerkungen \\
\hline $\begin{array}{l}4^{0} 06^{\prime} \\
4^{0} 07^{\prime} 30^{\prime} \\
4^{0} 09^{\prime} \\
4^{0} 11^{\prime} \\
4^{0} 12^{\prime} \\
4^{0} 13^{\prime} \\
4^{0} 15^{\prime} \\
4^{0} 15^{\prime} 30^{\prime \prime} \\
4^{0} 16^{\prime} \\
4^{0} 17^{\prime} \\
4^{0} 18^{\prime} \\
4^{\circ} 19^{\prime} \\
4^{0} 20^{\prime} \\
4^{0} 21^{\prime} \\
4^{0} 22^{\prime} \\
4^{0} 23^{\prime} \\
4^{0} 24^{\prime} \\
4^{0} 34^{\prime}\end{array}$ & $\begin{array}{r}100,0 \\
106,0 \\
103,0 \\
105,0 \\
102,0 \\
95,0 \\
97,0 \\
104,0 \\
103,5 \\
95,0 \\
87,5 \\
85,0 \\
96,0 \\
96,0 \\
85,0 \\
76,0 \\
75,0 \\
60,0\end{array}$ & $\begin{array}{l}20,9 \\
20,9 \\
20,0 \\
19,6 \\
18,2 \\
17,7 \\
17,7 \\
18,6 \\
18,6 \\
18,2 \\
18,2 \\
18,2 \\
18,2 \\
20,0 \\
19,6 \\
18,6 \\
18,6 \\
18,2\end{array}$ & $\begin{array}{l}\text { Chloroform } 1,8 \% \text { in d. Inspirationsluft } \\
\mathrm{NaCl} 10 \% 0,5 \mathrm{cem} \text { subconjunctival }\end{array}$ \\
\hline
\end{tabular}

Ergebnis: Obwohl der allgemeine Blutdruck die ersten fünf Minuten nach dem Kochsalzreiz keine Erniedrigung zeigt, also scheinbar keine grösseren Kreislaufveränderungen vor sich gegangen sind, bleibt die Wirkung des Kochsalzreizes aus, da in Wirklichkeit eine 
Experim. Beiträge zum pathologischen Flüssigkeitswechsel des Anges. 593

Verschiebung der Blutverteilung stattgefunden hat, die zu einer Überfüllung des Splanchnicusgebietes gefïhrt und die Augengefässe an Volumen verkleinert hat. (Kurvenbeispiel siehe Fig. 32.)

Kaninchen Nr. 98. Chloroformnarkose, sonst gewöhnliche Versuchsanordnung.

\begin{tabular}{|c|c|c|c|}
\hline Zeit & $\begin{array}{l}\text { Mittl. Blutdr. } \\
\text { in mm } H g^{\prime}\end{array}$ & $\begin{array}{l}\text { Augendruck } \\
\text { in mm } H g\end{array}$ & Bemerkungen \\
\hline $10^{\circ} 56^{4}$ & - & 一 & $\begin{array}{l}\text { Chlorofomnarkose } 1,8 \% \text { Chloroform } \\
\text { in der Einatmungsluft }\end{array}$ \\
\hline $10^{0} 57^{\prime}-11^{0} 12^{\prime}$ & $\underset{95,0}{111,0-103,5}$ & $\overline{293}$ & \\
\hline $11^{\circ} 15^{\prime}$ & 92 & 21,5 & $0,5 \mathrm{ccm} 10 \% \mathrm{NaCl}$ subconjunctival \\
\hline $11^{\circ} 16^{t}$ & 92,0 & 20 & \\
\hline $11^{\circ} 17^{*}$ & 89,0 & 20,0 & Pupille eng \\
\hline $\begin{array}{c}11^{0} 18^{2} \\
11^{019^{*}-1}-11^{034}\end{array}$ & $\begin{array}{c}91,0 \\
94-88\end{array}$ & $\begin{array}{c}20,0 \\
20.0-21,5.2\end{array}$ & \\
\hline & & & \\
\hline
\end{tabular}

Ergebnis: Infolge der durch Chloroform bedingten Blutrerteilung, Ûberfüllung des Splanchnicusgebietes und Anämie des Hirnsystems, kommt die intraokulare Drucksteigerung durch subconjunctivalen Kochsalzreiz nicht zustande. Der Blutdruck selbst sinkt nur in mässigem Grade.

\begin{tabular}{|c|c|c|c|c|c|}
\hline $\begin{array}{l}\text { Kaninchen } \\
\mathrm{Nr} \text {. }\end{array}$ & Gewicht & $\begin{array}{c}\text { Blutdruel } \\
\text { vor } \\
\text { dem subconj }\end{array}$ & $\begin{array}{l}\text { in } \operatorname{mm} H g \\
\text { nach } \\
\text { net. } N a C l \text {-Reiz }\end{array}$ & $\begin{array}{l}\text { Augendruc } \\
\text { vor } \\
\text { dem subconj }\end{array}$ & $\begin{array}{l}\text { in } \mathrm{mm} H g \\
\text { nach } \\
\text { anct. } \mathrm{NaCl} \text {-Reiz }\end{array}$ \\
\hline $\begin{array}{l}24 \\
25\end{array}$ & $\begin{array}{l}2195 \\
2180\end{array}$ & $\begin{array}{c}106-80 \\
100\end{array}$ & $100-94-101$ & $\begin{array}{c}19,3-18,6 \\
32,5\end{array}$ & $\begin{array}{c}18,1-23,8-20,0 \\
32,5\end{array}$ \\
\hline
\end{tabular}

Ergebnis: Beide Versuche zeigen das Ausbleiben der intraokularen Drucksteigerung auf subconjunctivalen Kochsalzreiz während der Chloroformnarkose. Dabei ist es gleichgültig, ob der Augendruck anfangs hoch oder niedrig ist, auch die Höhe des allgemeinen Blutdrucks spielt dabei keine Rolle, sondern lediglich die oben beschriebene Art der Blutverteilung.

Dass nicht die Narkose als solche etwa den intraokularen Druckanstieg nach Kochsalzreiz zu verhindern vermag, geht aus den folgenden Versuchen hervor, in denen der Kochsalzreiz in der Äthernarkose vorgenommen wurde.

Kaninchen Nr.23. $1820 \mathrm{~g}$. Äthernarkóse, sonst die übliche Anordnung.

\begin{tabular}{c|c|c|c}
\hline \hline Zeit & $\begin{array}{c}\text { Mittl. Blutdr. } \\
\text { in } \mathrm{mm} H g\end{array}$ & $\begin{array}{c}\text { Augendruck } \\
\text { in mm } H g\end{array}$ & Bemerkungen \\
\hline $3^{0} 45^{\circ}$ & 95,0 & $\mathbf{1 7 , 0}$ & $\begin{array}{c}\text { Tiefe Narkose mit Erlöschen von Cor- } \\
\text { neal- und Kniereflex }\end{array}$
\end{tabular}




\begin{tabular}{|c|c|c|c|}
\hline Zeit & $\begin{array}{l}\text { Mittl. Blutdr. } \\
\text { in } \mathrm{mm} H g\end{array}$ & $\begin{array}{l}\text { Augendruck } \\
\text { in } \mathrm{mm} H g\end{array}$ & Bemerkungen \\
\hline $3^{0} \unlhd 6^{x}$ & 114,0 & 18,7 & $0,5 \mathrm{ccm} \mathrm{NaCl} 10 \%$ subconjunctival \\
\hline $3^{0} 47^{\prime}$ & 108,5 & 22,6 & \\
\hline $3^{\circ} 48^{+}$ & 105,0 & 26,5 & \\
\hline $3^{0} 49^{\prime}$ & 105,0 & 35,4 & \\
\hline $3^{\circ} 50^{\prime}$ & 105,0 & 40,1 & \\
\hline $3^{0} 5112_{2}^{0}$ & 104,5 & 45,5 & \\
\hline $3^{\circ} 53^{\prime}$ & 104,0 & 47,0 & \\
\hline $3^{0} 54^{\prime}$ & 108,0 & 48,5 & \\
\hline $3^{0} 55^{t}$ & 100,0 & 49,3 & \\
\hline $3^{0} 57^{\prime}$ & - & - & \\
\hline $3^{\circ} 58^{\prime}$ & 100,0 & 48,5 & \\
\hline $3^{0} 59^{\prime}$ & 100,0 & 48,5 & \\
\hline $4^{\circ} 01^{\prime}$ & 98,5 & 48,1 & \\
\hline $4^{004}$ & 97,5 & 46,3 & \\
\hline $4^{\circ} 06^{1}$ & 97,5 & 44,8 & \\
\hline $4008^{\prime}$ & 92,5 & 42,6 & \\
\hline $4^{0} 10^{\prime}$ & 92,5 & 40,4 & Narkose beendet \\
\hline $4^{\circ} 11^{t}$ & 89,0 & 36,2 & \\
\hline $4^{\circ} 18^{\prime}$ & 87,5 & 34,6 & \\
\hline $4^{0} 19^{\prime}$ & 96,0 & 31,2 & \\
\hline
\end{tabular}

Ergebnis: Die Athernarkose hindert nicht den Druckanstieg auf subconjunctivalen Kochsalzreiz.

Kaninchen Nr. 89. 1950 g. Äthernarkose, sonst die übliche Versuchsanordnung.

\begin{tabular}{|c|c|c|c|}
\hline Zeit & $\begin{array}{l}\text { Mittl. Blutdr. } \\
\text { in mm } H g\end{array}$ & $\begin{array}{l}\text { Augendruck } \\
\text { in } \mathrm{mm} H g\end{array}$ & Bemerkungen \\
\hline $\begin{array}{l}12^{\circ} 16^{\circ} \\
12^{\circ} 19^{\circ}\end{array}$ & 142,5 & - & Beginn der Äthernarkose \\
\hline $12^{\circ} 22^{\prime}-12^{0} 46^{\prime}$ & $125,0-140,0$ & $26,5-22,9$ & \\
\hline $\begin{array}{l}12^{0} 47^{\prime} \\
1249^{\prime} 30^{*}\end{array}$ & $\begin{array}{l}140,0 \\
140,0\end{array}$ & $\begin{array}{l}22,9 \\
26.5\end{array}$ & $0,5 \mathrm{~cm} \mathrm{NaCl} 10 \%$ subconjunctival \\
\hline $12^{\circ} 55$ & 135,5 & 46,6 & \\
\hline $12^{0} 57^{2} 30^{\prime \prime}$ & 130,0 & 49,4 & Narkose beendet. \\
\hline $1^{0} 06^{4}$ & 125,0 & 40,6 & Versuch abgebrochen \\
\hline
\end{tabular}

Ergebnis: Die Narkose als solche hindert nicht den intraokularen Druckanstieg nach subconjunctivalem Kochsalzreiz.

Von Bedeutung scheint uns dabei eine Gegenüberstellung des einen Chloroformversuches mit dem in Äthernarkose angestellten zu sein.

Bei ungefähr gleichschweren Tieren, die auch fast den gleichen Blutdruck aufweisen, wird das eine Mal durch Chloroform der intraokulare Druckanstieg vollkommen aufgehoben, das andere Mal gelangt er in der Äthernarkose zur vollen Ausbildung, ja es scheint fast, dass derselbe besonders stark ausfällt. Es ist dies nicht anders zu erklären als durch die Annahme, dass eben die Kreislaufver- 
Experim. Beiträge zum pathologischen Flüssigkeitswechsel des Auges. 595

hältnisse in beiden Fällen rollkommen verschieden sind. Beim Chloroform tritt eine Erweiterung des Splanchnicusgebietes ein, die eine sekundäre oder gleichzeitige Vasokonstriktion im Auge neben andern Gefässbezirken - zur Folge hat, während in der Athernarkose das Gefässgebiet des Auges auch nicht eiumal sekundär verengt wird. Für die verschiedene Wirkung der Ather- und Chloroformnarkose ist dies Verbalten von grundlegender Bedeutung und soll später noch genauer untersucht werden.

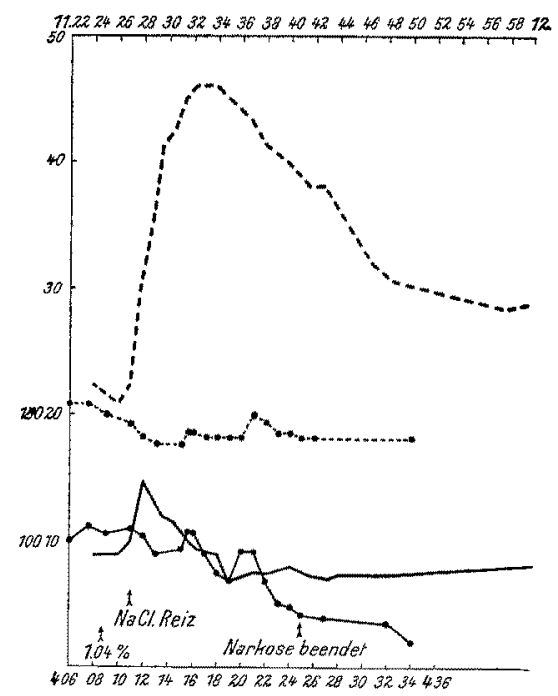

Fig. 32. Die ... und L Linien zeigen den Versuch mit Äthernarkose, die .... und -...- den mit Chloroformnarkose in ihrer Wirkung auf den $\mathrm{Ab}$ lauf des $\mathrm{NaCl}$-Reizes. Die gestrichelten Linien sind der Augendruck, die ausgezogenen der Carotidendruck. Der Ätherversuch ist in den Protokollauszügen nicht aufgeführt. $1 / 2$ natürliche Grösse.

An einer früheren Stelle dieser Arbeit ist darauf aufmerksam gemacht worden, dass der Druckanstieg bei chloroformierten und chloralisierten Tieren ausbleibt, obwohl das Kochsalz in das Innere des Auges eindringt. Durch eine Reihe von Analysen konnte nun nachgewiesen werden, dass auch der Eiweissgehalt des Kammerwassers in diesen Fällen nur unwesentlich vermehrt ist:

Der Schädigung der Gefässe durch die Salzlösung steht also ein anderer Vorgang "antagonistisch" gegenüber, der den Durchtritt des Eiweisses in das Kammerwasser zum grössten Teil verhindert. Dieser Vorgang dürfte in einer "Abdichtung“ der Gefässe zu suchen sein, die dann zustande kommen muss, wenn ihre Lichtung sich verkleinert, 
oder, mit andern Worten, ihre Wandung weniger gedehnt wird und an Dicke zunimmt.

Bestimmung des Stickstoffs im Kammerwasser bei Kaninchen, bei denen durch die Wirkung der Chloroformnarkose der Druckanstieg im Auge nach subconjunctivalem Kochsalzreiz verhindert ist.

\begin{tabular}{|c|c|c|c|c|c|c|c|c|c|c|}
\hline \multicolumn{2}{|c|}{$\begin{array}{c}\text { Kanin- } \\
\text { chen }\end{array}$} & \multirow{2}{*}{$\begin{array}{c}\text { Ent- } \\
\text { nahme } \\
\text { desKam- } \\
\text { mer- } \\
\text { wassers } \\
\text { nach } \\
\text { Minuten }\end{array}$} & \multicolumn{2}{|c|}{$\begin{array}{c}\text { Mengo } \\
\text { des Kammer- } \\
\text { wassers in } g\end{array}$} & \multicolumn{2}{|c|}{$N$-Gehalt in $\mathrm{mg}$} & \multicolumn{2}{|c|}{$\begin{array}{l}\text { In } 100 \mathrm{~g} \\
\text { Kammer- } \\
\text { wasser } \\
N \text {-Gehalt }\end{array}$} & \multicolumn{2}{|c|}{$\begin{array}{c}\text { Differenz } \\
\text { zwischen dem } \\
\text { N-Gehaltbeider } \\
\text { Augen }\end{array}$} \\
\hline Nr. & $\begin{array}{l}\mathrm{Ge}- \\
\text { wicht } \\
\text { in } \mathrm{g}\end{array}$ & & $\begin{array}{l}\text { Kon- } \\
\text { troll- } \\
\text { auge }\end{array}$ & $\begin{array}{l}\text { Ge- } \\
\text { reiztes } \\
\text { Auge }\end{array}$ & $\begin{array}{l}\text { Kon- } \\
\text { troll- } \\
\text { auge }\end{array}$ & $\begin{array}{l}\text { Ge- } \\
\text { reiztes } \\
\text { Auge }\end{array}$ & $\begin{array}{l}\text { Kon- } \\
\text { troll- } \\
\text { auge }\end{array}$ & $\begin{array}{c}\text { Ge- } \\
\text { reiz- } \\
\text { tes } \\
\text { Auge }\end{array}$ & $\begin{array}{c}N \\
\text { in mg }\end{array}$ & $\begin{array}{c}\text { auf } \\
\text { Eiweiss } \\
\text { berechnet }\end{array}$ \\
\hline 1 & & $10^{\prime}$ & 0,2699 & 0,2443 & & & & & & \\
\hline 0 & & $20^{\prime}$ & 0,2634 & 0,2990 & 0 & & & & & \\
\hline
\end{tabular}

Das wichtigste Brgebnis dieser Versuche besteht in der Tatsache, dass es gelingt, die intraokulare Drucksteigerung und damit den Flüssigkeitswechsel des Auges vom allgemeinen Kreislauf durch medikamentöse Massnahmen zu beeinflussen, ohne dass im allgemeinen Blutdruck wesentliche Änderungen wahrgenommen werden müssten.

Dass sich damit eine neue Perspektive in der Behandlung des Glaukoms eröffnet, brauchen wir wohl kaum besonders zu betonen; denn selbst, wenn es allgemein richtig wäre, dass bei dem primären Glaukom die Verlegung der Abflussbahn das Primäre des Krankheitsprozesses sei, wäre noch immer eineVerminderung der Sekretion möglich.

Es wird die Aufgabe der Zukunft sein, der Augenheilkunde diejenigen Mittel zu geben und zu schaffen, welche auf diesem Wege den Flüssigkeitswechsel des Auges zu beeinflussen imstande sind. Denn dann wird es zum erstenmal möglich sein, dem Glaukom nicht nur wie bisher rom Auge aus allein, sondern auch rom Gesamtorganismus aus entgegen $\mathrm{zu}$ treten.

\section{Schlussätze.}

In kurzen Leitsätzen zusammengefasst, sind die Ergebnisse der vorliegenden Untersuchungen:

1. Das Serum von an Coma diabeticum erkrankten Personen ist imstande, bei intravenöser Darreichung den intraokularen Druck des Kaninchenauges herabzusetzen, ohne dass der Blutdruck sich wesentlich ändert. 
Experim. Beiträge zum pathologischen Flüssigkeitswechsel des Auges. 597

2. Auch der Druckanstieg, der beim Kaninchen durch subconjunctivale Injektion von hypertonischer Kochsalzlösung bedingt ist, lässt sich durch dieses Serum unterdrücken.

3. Die Frage, ob in dem Comaserum eine spezifische Substanz erscheint, der diese Wirkung auf das Auge zugesprochen werden muss, ist noch unentschieden. Jedenfalls kann die Wirkung des Comaserums auf das Auge am einfachsten durch Veränderungen der Blutverteilung erklärt werden.

4. Die allgemeine Annahme, dass der intraokulare Druck mit dem Blutdruck in der Aorta parallel geht, besteht nicht zu Recht. Es wurde experimentell nachgewiesen, dass bei steigendem Blutdruck der Augendruck sinken, z. B. nach Bariumchlorid, und bei sinkendem Aortendruck (Amylnitrit) steigen kann.

5. Die Abhängigkeit der Schwankungen des intraokularen Druckes vom Kreislauf muss vielmehr dahin formuliert werden: der intraokulare Druck ist abhängig von dem Füllungszusand der Augengefässe und dieser von der Blutverteilung im Gefässystem, bei der die Angengefässe aktiv oder passiv eine Rolle spielen können.

6. Durch zweckmässige Anderung der Blutverteilung ist es möglich, den intraokularen Druckanstieg nach subconjunctivalem Kochsalzreiz therapentisch zu beeinflussen. So lässt sich durch Chloralhydrat und Chloroformdarreichung die intraokulare Drucksteigerung nach subconjunctivalem Kochsalzreiz sogar ganz aufheben, ohne dass immer eine Anderung des allgemeinen Blutdrucks zu beobachten ist.

7. Der Druckanstieg nach subconjunctivalem Kochsalzreiz beruht nicht auf einem Reflex, ausgelöst durch Erregung sensibler Apparate in der Bindehaut, sondern auf einem osmotischen oder chemischen Reiz, den die in den Bulbus übertretende hypertonische Salzlösung auf die Produktion des Kammerwassers im Sinne einer Vermehrung ausübt.

8. Es lässt sich durch die Mikromethode von J. Bang der Übertritt von Kochsalz in den Bulbus nachweisen; auch andere Substanzen können nach subconjunctivaler Injektion im Innern des Bulbus festgestellt werden.

9. Für den direkten Übertritt der subconjunctival injizierten Substanzen spricht auch die Schädigung der Gefässe, die in der Vermehrung des Eiweissgehaltes ihren Ausdruck findet. Der Gang dieser Eiweissvermehrung lässt sich in seinem zeitlichen Ablaufe mit Hilfe einer Mikromethode der Bestimmung des Stickstoffes im Kammerwasser feststellen, die bisher hierfür noch keine Anwendung gefunden hat. 
598 M. Kochmann und P. Römer, Experimentelle Beiträge usw.

10. Auch wenn der Druckanstieg nach subconjunctivaler Injektion von Kochsalz durch experimentell-therapeutische Eingriffe ausbleibt, lässt sich der Übertritt der Chlorionen ins Kammerwasser nachweisen. Der Eiweissgehalt ist alsdann aber nur in geringem Grade erhöht, da wahrscheinlich die Gefässe durch Vasokonstriktion "abgedichtet" werden.

11. Trotz der Verschiedenheit des Druckanstieges beim Glaukom und nach subconjunetivalem Kochsalzreiz können diese Versuche dazu beitragen, das Problem der medikamentösen Beeinflussung des glaukomatösen Druckanstieges vom Kreislauf aus als nicht aussichtslos erscheinen zu lassen.

12. In praktischer Hinsicht dürfte die Bestimmung des Augendruckes eine einfache Methode zur phármakologischen Untersuchung der Hirncirkulation sein, da die Augengefässe einen Teil der Hirngefässe darstellen.

13. Man könnte daran denken, durch die quantitative Stickstoffbestimmung im Kammerwasser Aufschluss über den quantitativen Anteil des nicht an Eiweiss gebundenen Stickstoffes des Blutes zu erhalten. 